\title{
WestVirginiaUniversity
}

THE RESEARCH REPOSITORY @ WVU

Graduate Theses, Dissertations, and Problem Reports

1998

\section{Computational modeling of brittle impact erosion mechanisms}

Shanmuga Sundaram Balasubramaniyam

West Virginia University

Follow this and additional works at: https://researchrepository.wvu.edu/etd

\section{Recommended Citation}

Balasubramaniyam, Shanmuga Sundaram, "Computational modeling of brittle impact erosion mechanisms" (1998). Graduate Theses, Dissertations, and Problem Reports. 906.

https://researchrepository.wvu.edu/etd/906

This Thesis is protected by copyright and/or related rights. It has been brought to you by the The Research Repository @ WVU with permission from the rights-holder(s). You are free to use this Thesis in any way that is permitted by the copyright and related rights legislation that applies to your use. For other uses you must obtain permission from the rights-holder(s) directly, unless additional rights are indicated by a Creative Commons license in the record and/ or on the work itself. This Thesis has been accepted for inclusion in WVU Graduate Theses, Dissertations, and Problem Reports collection by an authorized administrator of The Research Repository @ WVU. For more information, please contact researchrepository@mail.wvu.edu. 


\section{COMPUTATIONAL MODELING OF BRITTLE IMPACT EROSION MECHANISMS}

Thesis

Submitted to the College of Engineering and Mineral Resources

of

West Virginia University

in Partial Fulfillment of the Requirements for

The Degree of Master of Science in Mechanical Engineering

By

Shanmuga S. Balasubramaniyam

Morgantown

West Virginia

December 1998 


\begin{abstract}
Materials are subjected to an erosion-corrosion environment in a wide range of applications today. Elevated temperatures promote the formation of oxide layers in jet engines. In fluidized bed boilers, the bed materials and piping of slurries and caustic materials cause erosion and corrosion. The process of erosion-corrosion may result in material loss and damage. Proper analytical modeling of the erosion-corrosion processes validated by experiments is needed to estimate the extent of damage in the material.

Empirical relations are available in the literature for predicting the amount of material loss due to erosion. These are obtained by conducting large number of experiments. But many restrictions apply in implementing these empirical relations. If the erosion process can be modeled analytically, in a very generic way, then they can be used to make a parametric study. The current work is focussed on developing a computational model for a metal-oxide system. A 3-D finite element model is developed using a commercial package and a transient dynamic analysis performed in order to predict the effects of erosion. Using suitable failure criteria, the amount of oxide lost in the metal-oxide system is predicted for various parameters like velocity, angle of attack, size of erodent, etc. The result of this study shows that volume loss for various angles of attack is that of typical brittle erosion. The volume loss has three different ranges with increase in velocity. And also two simultaneous adjacent impact results in volume loss as that of two isolated impacts.
\end{abstract}




\section{ACKNOWLEDGEMENTS}

I would like to take this opportunity to thank my research advisors Dr. Kenneth Means and Dr. Nithi Sivaneri, for their support, ideas and motivation. They have provided me with a great deal of inspiration throughout the research. Their guidance and encouragement has helped me overcome the hardships in both academic and nonacademic situations. I would also like to extend special appreciation to Dr. Victor Mucino for being a member of the advisory committee.

I would like to extend my appreciation to Selvam Veluswamy for his support and help that he has provided me. I would like to appreciate my family for their motivation, support and encouragement during this work. 


\section{TABLE OF CONTENTS}

ABSTRACT

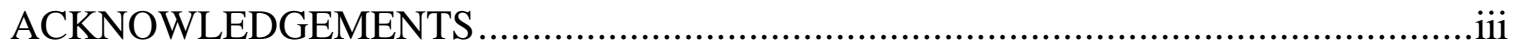

TABLE OF CONTENTS .............................................................................

LIST OF FIGURES AND TABLES .............................................................. vii

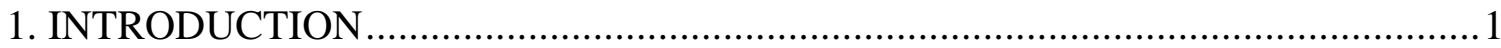

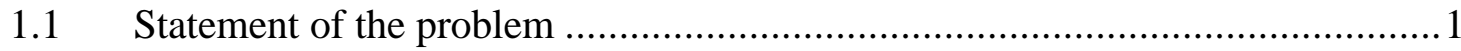

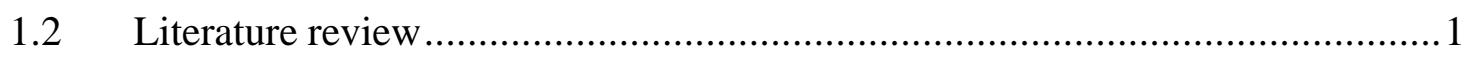

$1.3 \quad$ Need for the present problem ............................................................... 3

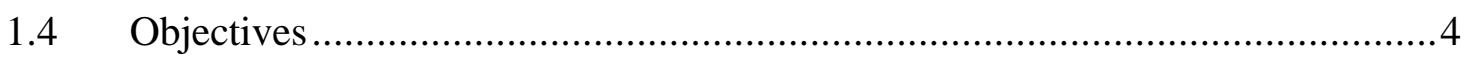

1.5 Summary of present work ................................................................ 4

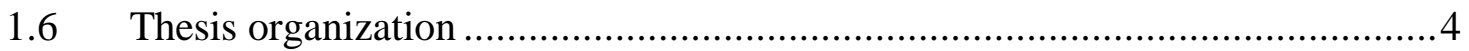

2. EROSION AND CORROSION PHENOMENA AND MODELS ..........................5

$2.1 \quad$ EROSION AND CORROSION PHENOMENA ….................................

$2.2 \quad$ EROSION MODELS .....................................................................

2.2.1 Brittle Erosion Models ............................................................... 9

2.2.2 Ductile Erosion Models ......................................................................... 11

2.3 PARAMETERS AFFECTING EROSION ............................................ 13

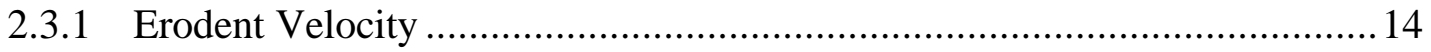




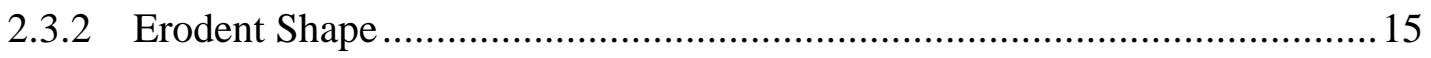

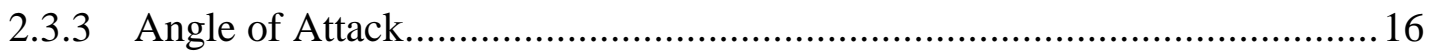

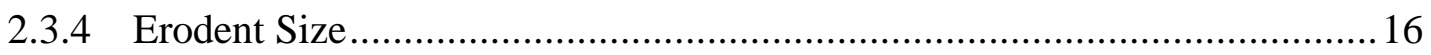

2.3.5 Material Properties of Erodent and Target ................................................ 18

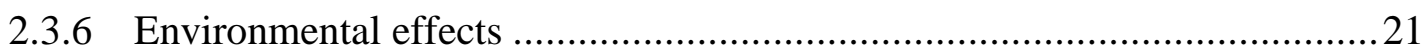

2.3.7 Temperature

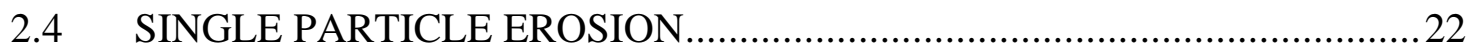

2.5 MULTIPLE PARTICLE EROSION MODELS............................................ 31

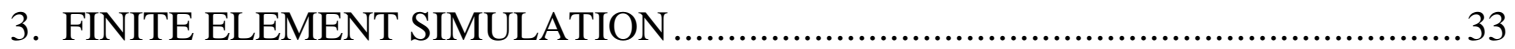

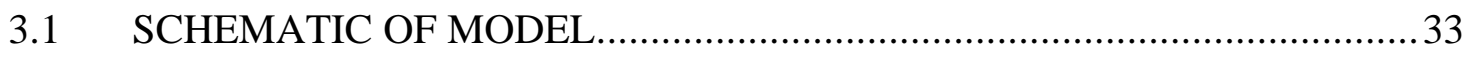

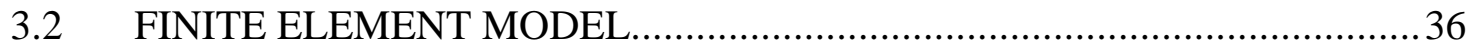

3.3 BOUNDARY AND INITIAL CONDITIONS ............................................

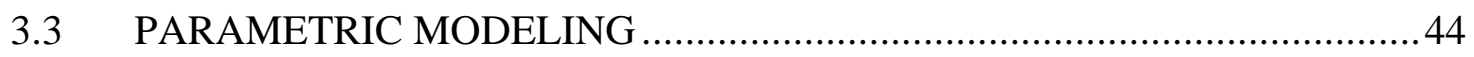

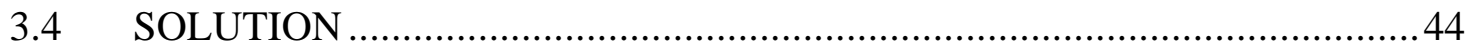

3.5 FAILURE CRITERIA AND MATERIAL LOSS ESTIMATION ..................44

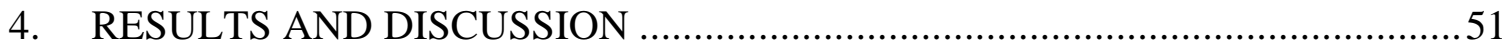

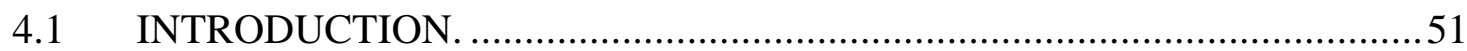

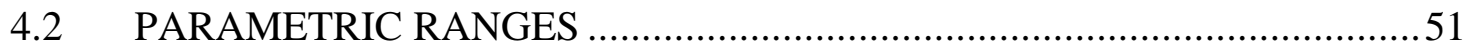

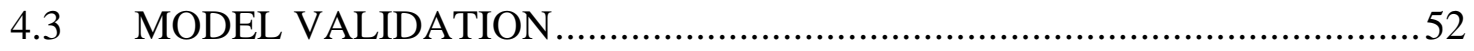

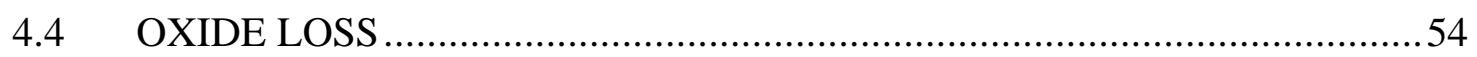

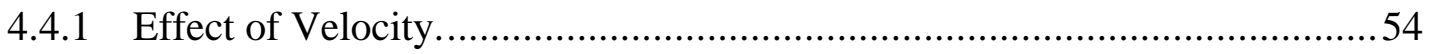

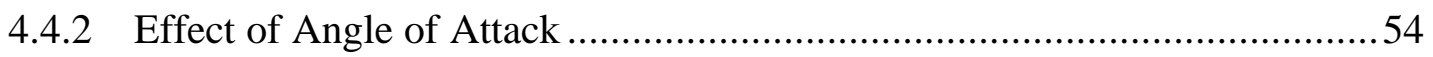

4.4.3 Effect of Size of Erodent ....................................................................5 
4.4.4 Effect of impact near a previously impacted zone

4.4.5 Effect of two simultaneous normal impacts . .56

5. CONCLUSIONS AND RECOMMENDATIONS ............................................ 70

5.1 CONCLUSIONS ....................................................................... 70

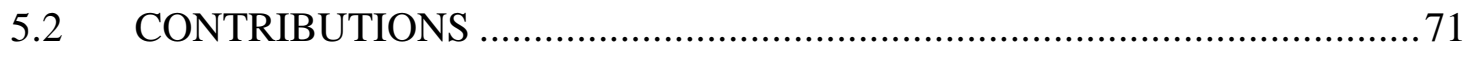

5.3 RECOMMENDATIONS FOR FUTURE WORK ................................... 71

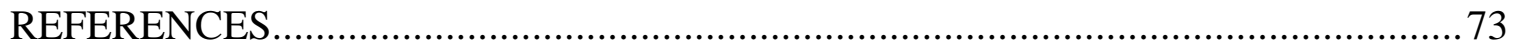

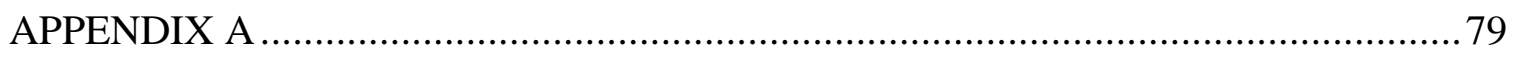

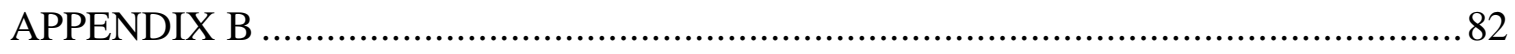

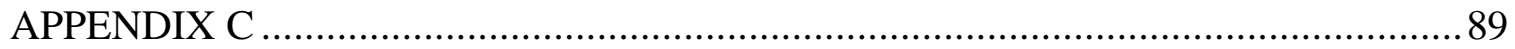

APPROVAL OF EXAMINING COMMITTEE ................................................... 92 


\section{LIST OF FIGURES AND TABLES}

Fig. 2.1 Erosion Behavior of Brittle and Ductile Materials. ..................................... 7

Fig. 2.2 Erosion-Corrosion Regimes ..............................................................

Fig. 2.3 Effect of Size of Erodent on Erosion [Veluswamy] ................................. 18

Fig.2.4 The energy balance before and after the normal impact of a spherical erosive

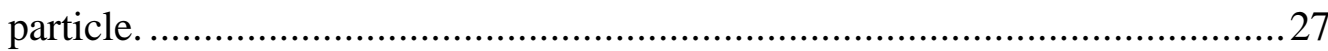

Fig.2.5 The plastic strain associated with one impact is assumed to be directed radially outwards in the plane of the surface [Hutchings, 1981] .............................28

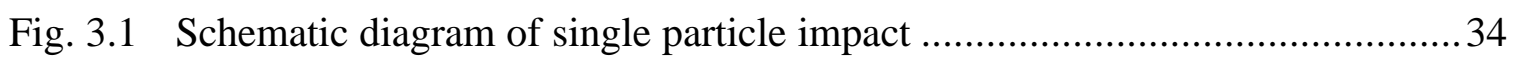

Table. 3.1 Material Properties of Iron and Iron -Oxide at various temperatures.............35

Table 3.2 Material Properties of Silicon Carbide Particle ........................................ 35

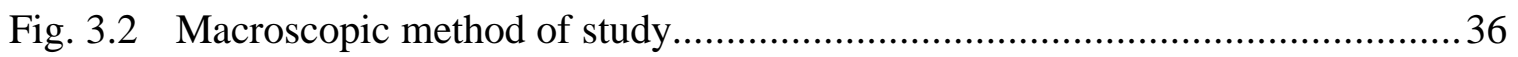

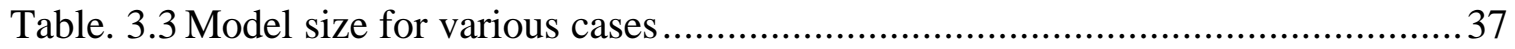

Fig. 3.3 Stress-Strain curve for Iron-Oxide for Elastic-Plastic material.......................38

Fig. 3.4 Finite Element Model for Normal Impact............................................ 39

Fig. 3.5 Finite Element Model for Angular Impact ......................................... 40

Fig. 3.6 Finite Element Model for impact near a previous impact site......................41

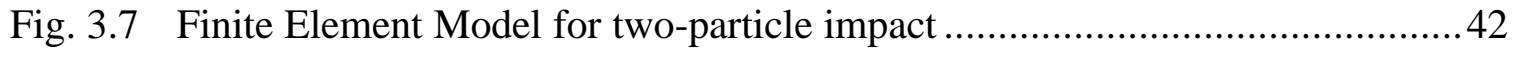

Fig. 3.8 Boundary conditions for the half symmetry model. .................................43

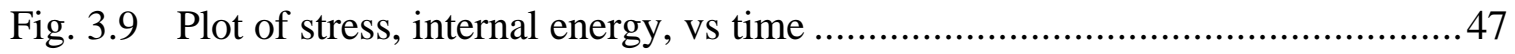

Fig. 3.10 Plot of strain, internal energy, volume fraction of critical elements vs time. ...48

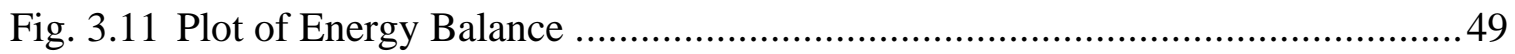


Fig. 3.12 Plot of volume fraction of critical elements for $90 \mathrm{deg}$ impact at various strain

levels. .50

Fig. 4.1 Comparison of FEM and Experimental Results (Sheldon) of Erosion of Aluminum oxide [Yelamanchali, 1997] .................................................53

Fig. 4.2 Volume loss per impact for velocity range of $0-100 \mathrm{~m} / \mathrm{sec}$........................57

Fig. 4.3 Erodent velocity for few normal impact cases. ....................................58

Fig. 4.4 Contour of Von-Mises stress for a $10 \mathrm{deg}$ angular impact..........................59

Fig. 4.5 Contour of Von-Mises stress for a $40 \mathrm{deg}$ angular impact............................60

Fig. 4.6 Volume loss per impact for angle of attack from $0-90$ deg.........................61

Fig. 4.7 Volume loss per impact at $25 \mathrm{~m} / \mathrm{sec}$ against various sizes of erodent.............62

Fig. 4.8 Contour of Von-Mises stress for an impact at a distance of $44 \mu \mathrm{m}$ from previous impact site.

Fig. 4.9 Contour of Von-Mises stress for an impact at a distance of $96 \mu \mathrm{m}$ from previous impact site. 64

Fig. 4.10 Volume loss per impact against distance from previous impact site 65

Fig. 4.11 Contour of Von-Mises stress for two particle impact at zero distance apart. ..66 Fig. 4.12 Contour of Von-Mises stress for two particle impact at 24 micrometers apart.67 Fig. 4.13 Contour of Von-Mises stress for two particle impact at 52 micrometers apart.68 Fig. 4.14 Volume loss due to two particle impact against distance between particles.....69 


\section{INTRODUCTION}

\subsection{Statement of the problem}

Erosion and Corrosion result in potential material loss. Erosion is a physical phenomenon and corrosion a chemical one. Materials can fail due to constant exposure to erosive environment. Determination of this material loss is very important to predict failure. A clear understanding of the effect of single particle impact with various parameters is needed to understand this erosion phenomenon.

\subsection{Literature review}

Solid particle erosion is the loss or removal of materials by the action of impinging solid or liquid particles. Erosion could be a useful phenomenon in applications like sand blasting and high-speed water-jet cutting. But in the case of jet engines (turbines), fluidized bed combustion systems, pipelines carrying slurries and caustic materials, erosion could be a serious problem as it results in material loss. The combined erosioncorrosion phenomenon is not a simple one to be modeled in a deterministic way.

Helicopters and VTOL aircrafts, designed for operation over unprepared air-strips, suffer significant damage due to dust erosion. The helicopter rotor blades have a total life of approximately 10 hours under severely erosive conditions such as dust clouds when particle concentrations of $10 \mathrm{mg}$ per cubicmeter are encountered. The aerodynamic action induced by helicopter tends to result in erosive thinning of the rotor blades from 
the ingestion of dust into the engine which result in erosion of compressor blading [Hibbert, 1965]. Erosion has also been reported in rocket nozzles [Neilson and Gilchrist, 1968b]. In this study, the nozzle wall damage obtained during actual firings it is reported that while some tail nozzles had failed due to thermal shock, most of the damaged nozzles appeared either to have suffered an even erosion around the throat section or deep axial grooves had been gouged out of the nozzle wall at one angular position. They felt that the abrasive action of solid particles was the cause of the damage, especially in motors containing a high percentage of aluminum in the fuel.

In coal gasification process environments, erosion is encountered mainly in gasification area equipment exposed to high pressures and temperatures [Sorell, 1986]. The erosive solids are particles of unconverted coal and ash-rich char. The components most vulnerable to attack are the gasifier vessel itself and its overhead train containing heat extraction and solids separation equipment. Cyclones in coal gasification plants generally remove most of the large particles that cause major erosion, leaving particles smaller than $20 \mu \mathrm{m}$. These particles also cause considerable damage and erosion to the turbine stator and rotor blades, valves, bends, pipelines, etc.

Alloys designed for structural uses at elevated temperatures have microstructures and chemistries optimized to provide strength and resistance to oxidation. The ability of commercial high-temperature alloys, intended for use at temperatures below $850^{\circ} \mathrm{C}$, to resist oxidation rely on the formation of continuous surface layer of essentially $\mathrm{Cr}_{2} \mathrm{O}_{3}$ [Wright, et al., 1986]. The oxide is slow growing and reasonably adherent to the alloy. The ability of the alloys to resist degradation as a result of spallation, thermal cycling and mechanical damage, depends upon the capacity to form a continuous protective external 
oxide layer. The addition of erosion to a high temperature oxidizing environment brings a further mechanism for the possible damage or removal of protective oxide scales.

Interest in erosion-corrosion has increased considerably and studies are in progress to ascertain synergistic effects between erosion and corrosion. Alloy design has progressed to the extent that one can specify the alloy chemistry and microstructure to meet a wide range of applications. In particular, alloys can be designed to form oxide layers which are slow growing and resistant to spallation.

\subsection{Need for the present problem}

Many empirical relations are available in the literature for predicting the amount of degradation by erosion, but most of them have been obtained by conducting experiments and have restrictions in implementation. Veluswamy's [1994] work on the study of single particle erosion using a 2-D finite element model dealt with only normal impacts. To study the effect of angle of attack, impact near the neighborhood of previous impact and multi-particle impact requires a 3-D model. The current work is focussed on arriving at a computational model for predicting the effects of erosion in a metal-oxide system involving as many parameters as possible. A 3-D finite element model with brick elements is developed to simulate single and multi particle erosion by performing a transient dynamic analysis. 


\subsection{Objectives}

The objective of this work is to understand single particle erosion. An attempt is made to understand the effect of angle of attack, size of the erodent, velocity of the erodent, impact in the neighborhood of previous impact and two simultaneous impacts.

\subsection{Summary of present work}

A 3-D finite element model is built and analyzed using a commercial package. A transient dynamic analysis is performed by imparting initial velocity to the erodent. The analysis is run till the rebound of the erodent. Using appropriate failure criteria, the damage or failure zone is estimated in terms of volume loss. Results are presented in term of volume loss against various parameters considered.

\subsection{Thesis organization}

In Chapter 2, the information available in the literature about the erosion-corrosion process is discussed in detail.

In Chapter 3, the methodology used to develop the computational model for erosion process is described. The model generation, finite element aspects and the assumptions involved are discussed in detail.

The results and discussion are presented in Chapter 4. Conclusions and recommendations for future work are discussed in chapter 5 . 


\section{EROSION AND CORROSION PHENOMENA AND MODELS}

\subsection{EROSION AND CORROSION PHENOMENA}

When metals and alloys are exposed to combined erosion and corrosion conditions, a variety of different processes can be important in determining the rates and the characteristics of the resulting degradation. For example, Hogmark, et al., [1983] have identified 6 different regimes of material removal. Each regime corresponds to a specific mode of material removal.

(1) Pure Corrosion

(2) Erosion affected Corrosion

(3) Erosion of corrosive film without flaking

(4) Flaking of the corrosion product at individual impacts

(5) Simultaneous erosion of the corrosion product and metallic substrate, and

(6) Pure Erosion

\section{Regime 1: Pure corrosion}

It is well known that the growth of continuous non-porous film is desirable because it gradually shields the substrate from the ambient reactions thereby drastically reducing the initial high growth of the film. Alloying of steels with chromium will improve the resistance to corrosion. Material degradation in high temperature corrosion is mainly 
because of flaking of the corrosive layer. This is because of poor adhesion between layer and substrate together with high internal stresses.

Regime 2: Erosion affected corrosion

Material is lost by corrosion product flaking at an enhanced rate due to the influence of mild erosion component.

Regime 3: Erosion of corrosive film without flaking

Material removal occurs by erosion of corrosion layer either in a ductile or brittle manner.

Regime 4: Local flaking of the corrosive film at individual impacts

In this regime the erosion-corrosion process is balanced in such a way that the dimension of individual craters is of the same order of magnitude as the instantaneous layer thickness. Adhesion and brittleness of the layer greatly affects the material removal rate and can be considerable as compared to pure corrosion or pure erosion of base material.

Regime 5: Simultaneous erosion of corrosive layer and metallic substrate

In this regime erosion dominates corrosion and degradation of both corrosive layer and substrate occurs with each impinging particle. The mechanism of layer removal could be either brittle type with flaking or in a ductile manner.

Regime 6: Pure Erosion

Two different modes of erosion response of a material are defined: ductile and brittle. The main difference between these two modes is the manner in which the erosion rate varies with the angle of impact. For brittle layers maximum erosion occurs at normal impact but for ductile materials maximum erosion occurs at glancing angles. The failure 
is mainly due to extensive plastic deformation of surface material. The erosion rate vs angle of impingement for ductile and brittle materials is shown in Fig. 2.1 [Finnie, 1958]. Classification of erosion-corrosion regimes is shown in Fig. 2.2 [Hogmark, et al., 1983]. The current work is restricted to this regime i.e., pure erosion.

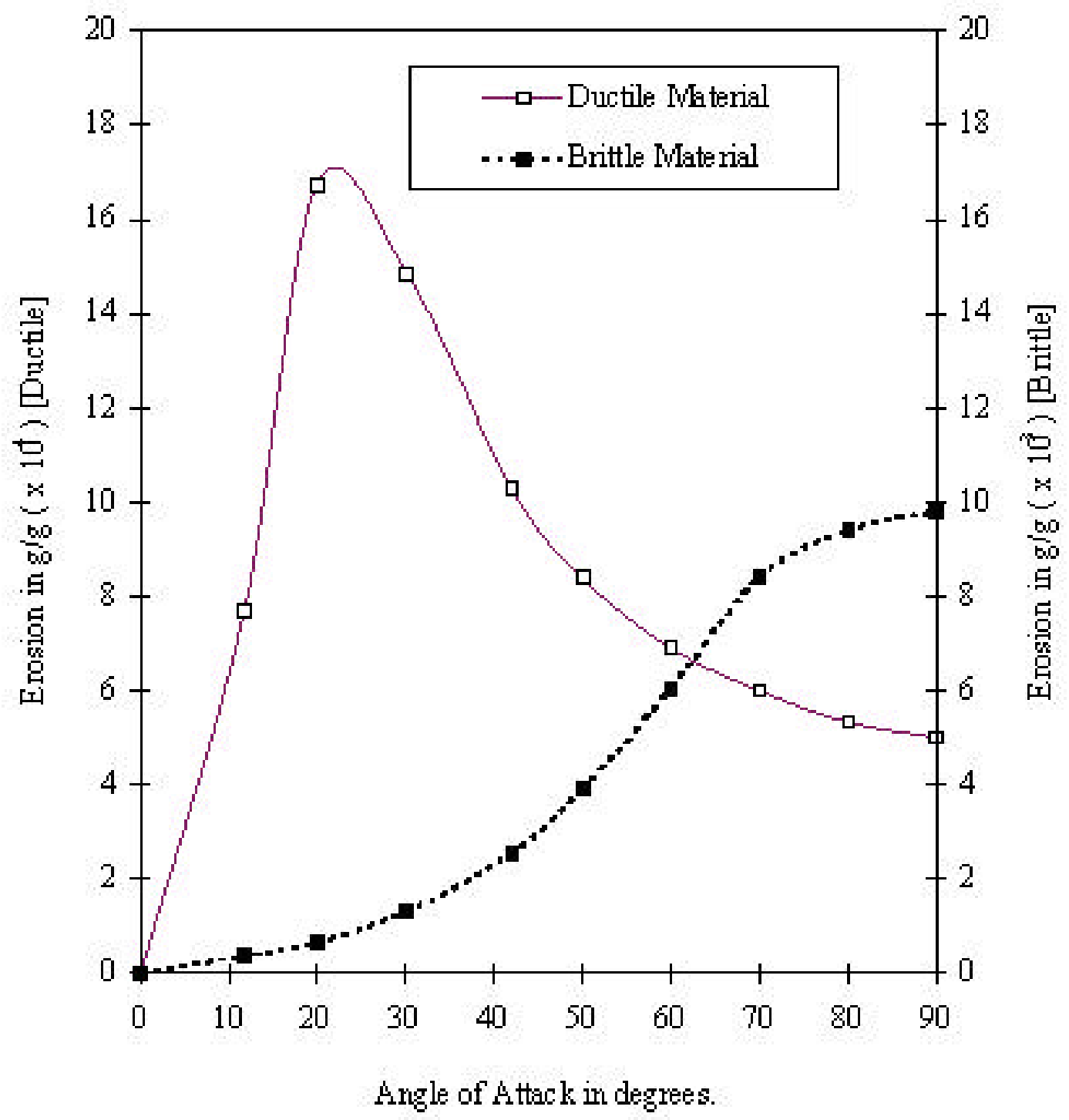

Fig. 2.1 Erosion Behavior of Brittle and Ductile Materials. 


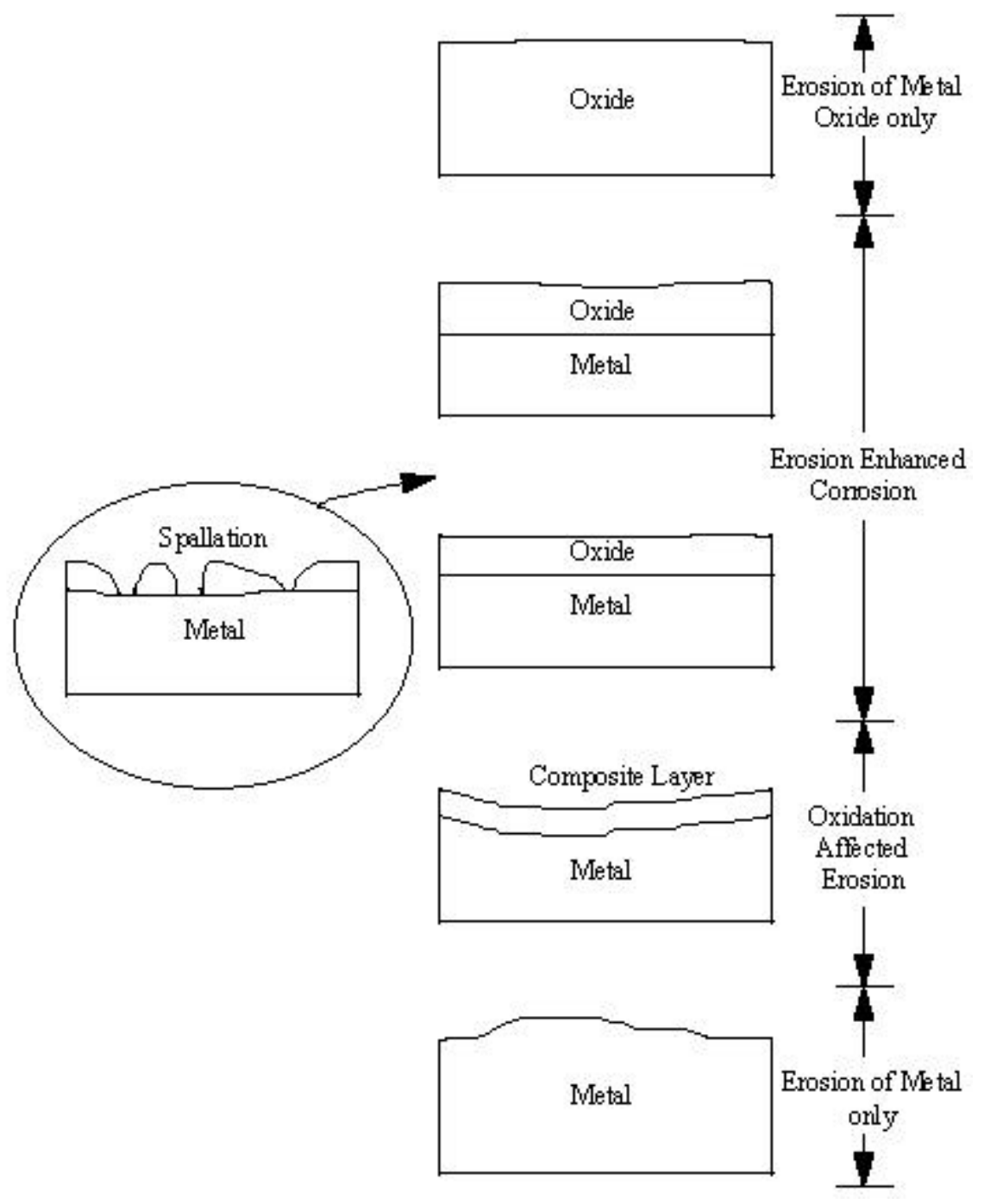

Fig. 2.2 Erosion-Corrosion Regimes 


\subsection{EROSION MODELS}

\subsubsection{Brittle Erosion Models}

Ruff and Wiederhorn [1979] developed two models for erosion of brittle materials: one is based on the assumption that erosion occurs entirely by crack propagation and chipping [Sheldon and Finnie, 1966] and the other is based on the assumption that plastic deformation contributes to the process of crack formation and surface chipping [Evans, et al., 1978]. Erosion rates are predicted in terms of both target (fracture toughness, hardness, flaw density, etc.) and particle (velocity, density, size, etc.) properties. The models assume that particle impact is normal to the target surface, and that erosion is the result of cumulative damage of noninteracting, single particle impacts.

The model proposed by sheldon and Finnie [1966] assumes that erosion occurs as the result of Hertzian contact stresses during impact. These stresses cause cracks to grow from preexisting flaws in the target surface. The load at which crack propagation occurs is related to the distribution of surface flaws through the Weibull distribution. The approximate area $A$ of cracked material is calculated for a particle penetration depth of $h$, and the volume removed per impact is set proportional to $A h$. In the final equation, the erosion rate (Sheldon and Finnie expressed their results in terms of grams lost per gram of impacting particle), $W$ is expressed in terms of the particle size $r$, the particle velocity $v_{o}$, and Weibull constants $m$ and $\sigma_{o}$ :

$$
W=k_{1} r^{a} v_{o}^{b}
$$


Where the exponents $a$ and $b$ are given by:

$$
\begin{array}{ll}
a=3(m-0.67) /(m-2) & \text { for round particles } \\
a=3.6(m-0.67) /(m-2) & \text { for angular particles } \\
b=2.4(m-0.67) /(m-2) & \text { for either shape }
\end{array}
$$

For particles much stiffer than the target, the constant $k_{1}$ is given by

$$
k_{1}=E^{0.8(m+1) /(m-2)} \rho^{1.2(m-0.67) /(m-2)} \sigma_{o}^{-2 /(m-2)}
$$

where $E$ is the modulus of elasticity of the target and $\rho$ the density of the particle.

Sheldon and Finnie [1966] compared the theoretically predicted exponents with the experimentally determined exponents $a$ and $b$ and found satisfactory agreement for several brittle materials ( glass, $\mathrm{MgO}, \mathrm{Al}_{2} \mathrm{O}_{3}$, graphite ). In a later paper, Sheldon [1970] compared experimental and theoretical values of $k_{1}$ and again found reasonable agreement between theory and experiment; however, the agreement was not as good as that for the exponents $a$ and $b$. Ruff and Weiderhorn believed that lateral crack formation was the main cause of material removal during erosion and although the theory by Sheldon and Finnie provided a reasonable description of erosion in brittle materials, they questioned the physical basis since they assumed Hertzian crack formation.

The theory by Evans, et al., [1978] explains erosion in terms of experimental crack behavior during single particle impact events, and thus takes into account lateral crack formation during erosion. The erosion model assumes that the erosion rate is proportional to the amount of material removed by each impact event. The volume $V$ lost per impact is calculated from the depth $h$ of penetration and the maximum size of the 
lateral cracks formed during impact. Since the lateral size is proportional to the radial crack size $c_{\mathrm{r}}, V$ is given by the following equation

$$
V \approx \pi c_{\mathrm{r}}^{2} h
$$

\subsubsection{Ductile Erosion Models}

A model for the erosion of ductile material was first developed by Finnie [1960]. He treated the problem by assigning a plastic response character to the material through a flow stress $\sigma_{f}$. The trajectory of a particle cutting and removing material was calculated, and eroded volume $V$ was determined to be given by the expression:

$$
V=\left(m v_{\mathrm{o}}^{2} / \sigma_{\mathrm{f}} K d\right) g(\alpha)
$$

Where $\quad m$ is the particle mass,

$v_{o}$ is the impact velocity,

$K$ is the ratio of vertical force to horizontal force on the particle,

$d$ the depth of cut, and

$g(\alpha)$ is a function describing the effect of attack angle $\alpha$.

But this model could not be used for attack angle $\alpha=90^{\circ}$ and also quantitative discrepancies arose concerning the effect of flow stress and the velocity exponent. Refinements of the original analysis by Finnie and McFadden [1978], in which the interaction force between the particle and the target surface is modified, have led to 
velocity exponents of about 2.5 , which match closely to those found by experiment. Bitter [1963] developed a model to account for erosion at all attack angles. He considered erosion to consist of two simultaneous processes, indentation deformation wear for high angle of attack and cutting wear for low angles. This theory, as well as that of Nielson and Gilchrist [1968], requires experimentally determined parameters for complete applications. Tilly [1973] proposed a two-stage mechanism of erosion recognizing explicitly that particles impacting at near-normal incidence may fragment and the fragments may subsequently erode exposed surface features. He was able to account for a reported decrease of erosion with decreasing particle size and introduced the concept of a minimum particle size for effective erosion.

Sheldon and Kanhere [1972] examined the mechanism of single particle erosion of ductile materials. They developed a model to describe the deformation and machining actions observed using indentation theory and an energy balance equation. Their results differ from previous calculations, giving the erosion volume as

$$
V=K\left(d^{3} v_{0}^{3} \rho_{p}^{3 / 2} / H^{3 / 2}\right)
$$

Where $\quad d$ is the spherical particle diameter,

$\rho_{p}$ is the particle density,

$H$ is the Vickers hardness value of the material.

This theory leads to a greater velocity dependence than expected from energy arguments (proportional to $v^{2}$ ). 
Studies by Winter and Hutchings [1975] and Hutchings [1977, 1978] into the mechanisms of single particle erosion have led to suggestions of several significant impact processes and materials parameters. Titanium in particular appears sensitive to local thermal effects due to particle energy release. As a result, detachment of small metal chips took place more frequently from the ploughed metal at the impact crater in titanium than in steel specimens similarly impacted.

\subsection{PARAMETERS AFFECTING EROSION}

The knowledge of various factors affecting the process of erosion is highly essential when developing any type of model for erosion. Obviously, variations in the physical, mechanical, chemical, thermal and dynamic behavior of both the eroding and eroded materials need to be considered. The main parameters that affect erosion are listed below.

1. Erodent velocity

2. Erodent shape

3. Angle of impact

4. Erodent size

5. Material properties of erodent and target

6. Temperature

In the following sections, each of the above mentioned parameters are discussed in detail. 


\subsubsection{Erodent Velocity}

Finnnie [1960] based on his work on SAE 1020 Steel, reported that the erosion was proportional to a simple power of velocity. That is

$$
\varepsilon=b V^{n}
$$

where $V$ is the velocity of erodent and $n$ was 2.0 , however he subsequently reported work on other materials giving a range of values for $n$ between 2.05 and 2.44. Goodwin et. al. [1969, 1970] studied the influence of impact velocity for different materials. They investigated the influence of velocity for the range of 200 to $1800 \mathrm{ft} / \mathrm{sec}$ using different sizes of quartz from $25-210 \mu \mathrm{m}$ to erode steel containing $11 \%$ chromium at $90^{\circ}$ impact. They concluded from the results that erosion $(\varepsilon)$ is dependent upon a simple power of velocity $(V)$, i.e.,

$$
\varepsilon=c V^{\alpha}
$$

where the exponent $\alpha$ varies from 2.0 for $25 \mu \mathrm{m}$ to 2.3 for the saturation erosion occurring for $125 \mu \mathrm{m}$ and above. By further investigation using $125-150 \mu \mathrm{m}$ quartz at normal impact, they showed that the exponent for saturation erosion was close to 2.3 for all the materials tested. However, values as high as 6.5 have been reported for tests involving $90 \mu \mathrm{m}$ steel spheres against glass [Finnie, 1960]. And also testing of the 11 percent chromium steel using 0 to $150 \mu \mathrm{m}$ dust for both $20^{\circ}$ and $90^{\circ}$ impact angles confirmed the simple velocity dependence and indicated that it was unaffected by angle 
of impact. Bitter [1963] reported that there is a threshold velocity below which no erosion occurs but calculated values are very low (less than $10 \mathrm{ft} / \mathrm{sec}$ ) so that it can usually be neglected. This is in marked contrast with rain erosion for which much higher values have been estimated [Fyall and Strain, 1962].

\subsubsection{Erodent Shape}

For both ductile and brittle materials, more effective erosion is generally found to be associated with angular particles [Finnie, 1960]. Some basic understanding of rake angle effects is emerging for ductile materials [Hutchings, 1977, 1978]. Steady-state erosion by spherical particles apparently generally develops a "hill and valley" surface topography, with the "mogul" spacing being significantly greater than single-impact dimensions. This is significantly different from the surface topography produced by angular particles.

Brown, et al., [1981] found that material removal occurred both by plowing deformation on the sides of the hills and by removal of flakes of material from the valleys. Considerable embedding of glass was observed to play a role in the material removal in the valleys, with the glass/metal composite layer being formed, and recrystallization also played a role.

As might be expected, angular particles give higher erosion rates than spheres. For example, Maji and Sheldon [1979] observed increases of $70^{\circ}, 20 \mathrm{~m} / \mathrm{s}$ erosion of 6061-T6 aluminum by about a factor of 5 for $270 \mu \mathrm{m}$ angular hardened steel grit compared with spherical shot of the same size, and also showed that fragmentation of the spherical shot caused a significant increase of $E$. The degree of angularity of angular particle is also 
important. Methods of quantifying angularity by means of image analysis, and its effects on $E$ have been discussed by Bahadur and Badruddin [1989], who found that $E$ increased by a factor of 2 to 3 with angularity, which is found to vary with grit size.

\subsubsection{Angle of Attack}

Angle of incidence or the angle of attack of the particle onto the surface of the target greatly influences erosion. The influence of impact angle is dependent upon the type of material. For ductile materials the peak erosion loss occurs at around $20^{\circ}$. For brittle materials the peak erosion loss occurs at $90^{\circ}$ (normal incidence). Many researchers have reported this general behavior [Fig. 2.1].

\subsubsection{Erodent Size}

For ductile materials, relative erosion is essentially independent of particle size for sizes greater than a critical value. Smaller sizes are less effective and a lower threshold size $(\cong 5 \mu \mathrm{m})$ for any erosion has been suggested. For brittle materials, a strong dependence of erosion rate and strength degradation on particle size is predicted and some confirmation of these predictions has been obtained. Further work is required to fully characterize the effect of particle size on the erosion of brittle materials.

Kosel found that the size of erodent particles has little or no effect on the erosion rate of ductile materials as long as the particle size is above about $100 \mu \mathrm{m}$, but the erosion rate decreases rapidly with decreasing particle size below $100 \mu \mathrm{m}$. This fact, known as the size effects is also found in abrasive wear. 
Misra and Finnie [1981] discussed the many theories that had been suggested to explain this effect and concluded that it is probably due to an actual increase in the flow stress with decreasing indentation size. Evidence for this has been presented by Gane and Cox [1970], who performed microhardness indentation tests. Some other studies have found that $E$ is not always constant for particle sizes above approximately $100 \mu \mathrm{m}$. For instance, Liebhard and Levy [1991] have found that $E$ became constant for SiC sizes above $200 \mu \mathrm{m}$ at $20 \mathrm{~m} / \mathrm{s}$ on 1018 steel, but continued to rise even up to $850 \mu \mathrm{m}$ particle sizes for $60 \mathrm{~m} / \mathrm{s}$ erosion of the same material.

Goodwin, et al., [1969] in their studies on erosion in helicopter engines, found that there is an erodent size below which resulting erosion may be considered negligible. Montgomery and Clark [1962] suggested that particles as small as $5 \mu \mathrm{m}$ can cause significant damage. On the other hand, data for erosion testing on a rover $1 \mathrm{~S} / 60$ engine [Duke, 1968] indicted that no significant damage was caused by particle smaller than 5-7 $\mu \mathrm{m}$. In the series of laboratory tests by Goodwin, et al., [1969-70] no erosion was noted for quartz particles below $5 \mu \mathrm{m}$ and little damage for 5-20 $\mu \mathrm{m}$ dust at velocities up to $1000 \mathrm{ft} / \mathrm{sec}$ in either $20^{\circ}$ or $90^{\circ}$ impact.

Veluswamy [1994] developed a computational model of oxide layer erosion by single particle impact. He performed a transient dynamic analysis on a two-dimensional axisymmetric finite element model using ANSYS. He studied the effect of size on erosion. He produced the results in the form of volume loss versus erodent size. A plot of erosion with erodent size under normal impact at $10 \mathrm{~m} / \mathrm{s}$ is shown in Fig. 2.3. 


\subsubsection{Material Properties of Erodent and Target}

(a) Erodent hardness

For ductile solids, so long as the target surface hardness is much less than the particle hardness, little effect is expected except indirectly through particle fragmentation or other changes. Theories of brittle erosion assume the particle to be harder than the target; however, for many ceramics materials, this assumption is not valid. Experimental data by Gulden [1978] suggests that particle hardness may be an important variable that must be considered when characterizing the wear of brittle materials. Wellinger and Uetz [1957-58] found that the erosion rate drops dramatically when particle hardness decreases below that of the material being eroded. This and other similarities between erosive and abrasive wear have been discussed by Misra and Finnie [1981]. Finnie [1979] showed it is quite possible that heat treatment of steel could have almost no effect on their erosion resistance which might be due to the use of hard particles such as $\mathrm{SiC}$ and $\mathrm{Al}_{2} \mathrm{O}_{3}$.

\section{(b) Erodent frangibility}

For ductile materials, the effect of particle fragmentation to provide additional erosion loss has been described by Tilly [1973] and recently studied by Maji and Sheldon [1978]. The increased erosion potential of abrasives due to water or impurity content may derive from an altered tendency to fragment [Uuemois and Kleis, 1975]. Particle frangibility has not been considered as variable in the erosion of brittle materials, although it is known to occur in these materials [Evans and, 1977].

Fig. 2.3 Effect of Size of Erodent on Erosion [Veluswamy] 


\section{Volume Loss Vs Erodent Size}

\section{Temperature $743^{\circ} \mathrm{C}$ \\ Velocity $10 \mathrm{~m} / \mathrm{s}$}

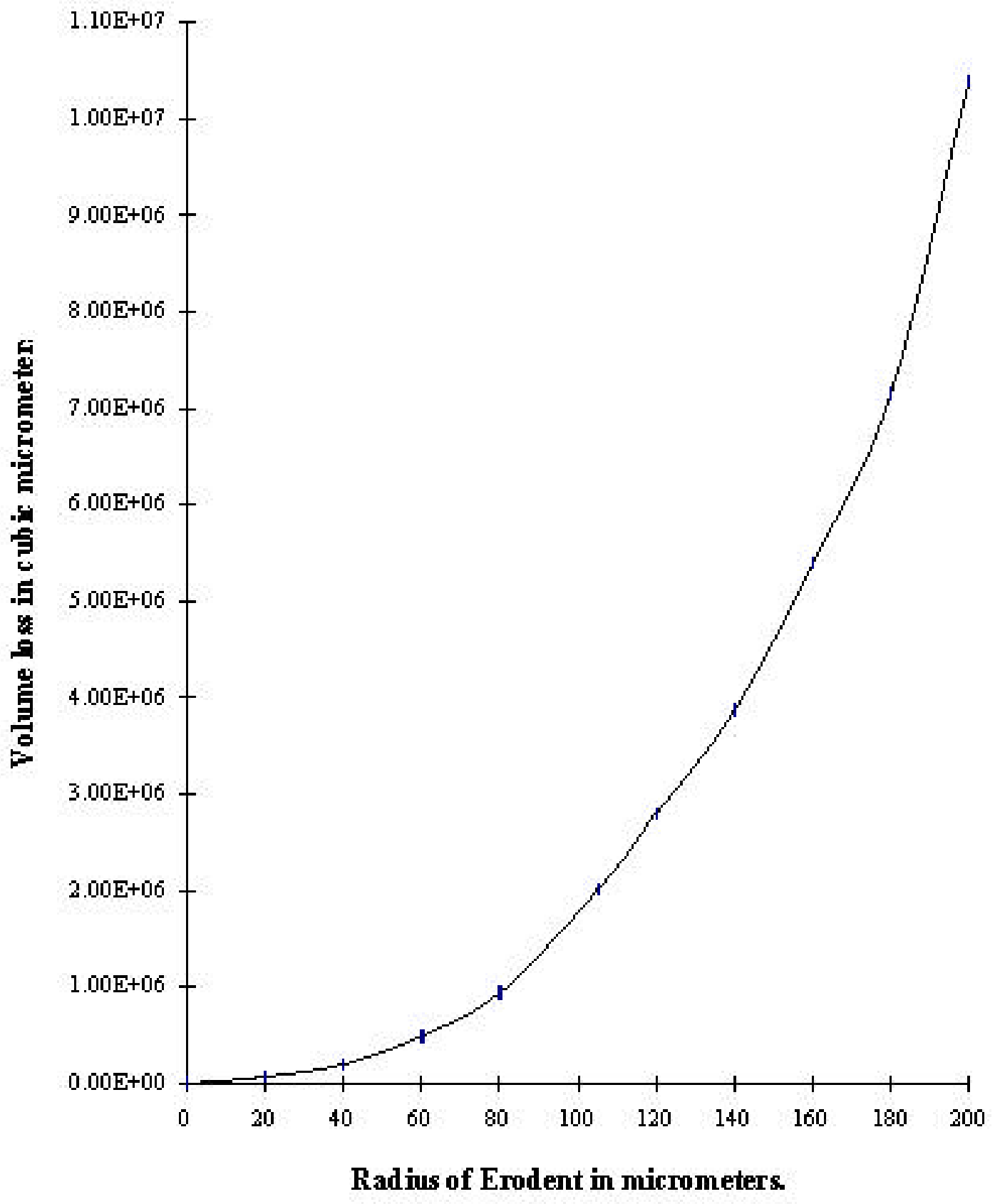


(c) Surface hardness

Surface hardness is the single parameter most often chosen to describe ductile material erosion rate variation. Within one alloy system, indentation hardness is frequently not a valid parameter to describe erosion differences. However, Sheldon [1977] has suggested that fully abraded surface hardness may be a more suitable quantity. As noted in this review, dynamic hardness is probably the more appropriate variable for characterizing the erosion of either ductile or brittle materials.

(c) Strain rate sensitivity

Single particle studies on metals by Winter and Hutchings [1975] and Hutchings [1977] indicate that the high strain rates associated with particle erosion may lead to different deformation modes in different materials. This material characteristic has not been examined thoroughly for either ductile or brittle materials.

(d) Grain orientation and grain size effects

No systematic studies of the details of these characteristics are available for solid particle erosion processes. However, Preece, et al., [1978] studied such microstructural effects on cavitation erosion.

(e) Surface thermal parameters

Correlations between erosion rates on the one hand, and thermal conductivities and specific heats on the other hand, have been noted, but detailed explanations are not available.

(f) Target Toughness

Because brittle materials erode by elastic plastic processes, the dynamic toughness (dynamic $K c$ ) plays an important role in the wear of brittle materials. Measurements of 
dynamic $K c$ are needed, both to rank brittle materials and to develop a better understanding of the process of brittle erosion.

\subsubsection{Environmental effects}

Some remaining significant considerations are

(a) Impact energy release, surface heating, and possible local melting. Temperature effects on deformation may be important in many cases. Otherwise thermal effects may only be significant for high temperature erosion.

(b) Abrasive bonding to the eroded surface. The possibility of chemical reaction and bonding to the eroded surface has been noted in the literature for high temperature erosion processes. This effect can significantly effect the erosion rate, offering protection from mechanical damage at the possible expense of chemical attack on the exposed surface.

(c) Atmospheric reaction. The formation of substantial films on exposed surfaces due to chemical reaction would be expected in actual elevated temperature exposures. It has been reported that such films can alter erosion rates, particularly for smaller particle sizes that are of the same order as the film thickness.

\subsubsection{Temperature}

Young, et al., [1977] reported various effects of temperature on erosion. They showed that there is a large increase in erosion of type 310 Stainless Steel when the temperature is raised from $25^{\circ} \mathrm{c}$ to $975^{\circ} \mathrm{c}$. In a study of effect of temperature on erosion, Hockey et al., [1978] demonstrated that plastic flow processes occur during the erosion of 
brittle materials. The erosion rate of glass, silicon nitrate and aluminum oxide was measured as a function of temperature and impingement angle using silicon carbide particles as the erosion agent. Kosel found that the influence of temperature on erosion, in the absence of complications caused by corrosion, is not as simple as might be expected on the basis of decreasing yield strength with increase in temperature. Sundarajan [1990] reviewed that in some cases the erosion rate $E$ increases with temperature, while in others it decreases.

\subsection{SINGLE PARTICLE EROSION}

Various models are available in literature to model the erosion of ductile and brittle materials. Most of them are empirical models based on experimental results. A few analytical models are also available, which have highly restricted applications.

Finnie [1958] proposed and erosion model derived from an analysis of the equations of motion of a single particle during its impact with a ductile surface. The particle trajectory through the material was used to estimate the volume of surface material displaced by the particle. This estimate was subjected to the following assumptions.

- $\quad$ Cutting of the surface is produced by plastic deformation of the surface material, which is true only for ductile materials.

- $\quad$ No cracks develop in the eroded surface ahead of the cutting particle.

- $\quad$ The displacement of surface material created by the impacting particle is the only contribution to erosion.

The Finnie single-particle impact erosion model has the form 


$$
w_{i}=\frac{\Gamma g^{2} F(\alpha)}{\psi}
$$

Where

$$
G=\frac{r_{w} m_{p}}{p}
$$

and

$$
F(\alpha)=\left\{\begin{array}{ll}
\frac{1}{k} \sin 2 \alpha-\frac{6}{k^{2}} \sin ^{2} \alpha & \text { for } \tan \alpha<\frac{k}{6} \\
\frac{1}{6} \cos ^{2} \alpha & \text { for tan } \alpha>\frac{k}{6}
\end{array}\right\}
$$

Here $w_{i}$ represents the mass of material removed from the surface during a single-particle impact, $\rho_{w}$ is the density of the surface material and $m_{p}$ is the mass of the impacting particle. The parameter $p$ is the horizontal component of the contact stress, termed the "plastic flow stress". The parameter $k$ is the ratio of vertical-to-horizontal forces on the particle caused by the surface. It is assumed to be constant over the duration of the cut. the parameter $\Psi$ is the ratio of length-to-depth of cut made by the particle and was also assumed to be constant during the cut. Scratch-test experiments have shown a variation in the value of the force ratio $\mathrm{k}$ from 1.6 to 2.4 for ductile materials, to values as high as 6. Values of $\Psi$ ranging from 2 to 10 have been observed in metal cutting experiments, a impact angle of the particle, $\alpha$, is measured from the eroding surface. Finnie's model 
inadequately described the erosion process because no erosion was predicted at zero degree (tangential) and $90^{\circ}$ (normal) impact angles.

Finnie, et al., [1967] proposed that $p$ is approximately equivalent to the Vicker's Hardness Number (VHN) of the material being eroded. Deffenbaugh, et al., [1988] compiled the parameters used in Finnie's Erosion Model, showing various studies where the flow stress parameter was specified as different surface properties.

Bitter [1963] assumed that both types of erosion mechanisms - cutting and deformation - occur simultaneously. The model uses particle and surface material properties as well as empirically determined deformation wear and cutting wear factors. The Bitter model has the form

$$
w_{i}=\left(w_{i}\right)_{d}+\left(w_{i}\right)_{c}
$$

Where the deformation wear contribution is given by

$$
\left(w_{i}\right)_{d}=\frac{\rho_{w} m_{p}\left(g \sin \alpha-k_{1}\right)^{2}}{2 \varepsilon_{d}}
$$

The parameter $\varepsilon_{d}$ is the deformation wear factor representing the amount of energy needed to remove a unit volume of surface material through deformation. The cutting wear contribution is specified according to 


$$
\left(w_{i}\right)_{c}=\left\{\begin{array}{ll}
\frac{2 m_{p} K_{3} \rho_{w}\left(g \sin \alpha-K_{1}\right)^{2}\left[g \cos \alpha-\frac{K_{3}\left(g \sin \alpha-K_{1}\right)^{2} \varepsilon_{c}}{\sqrt{g \sin \alpha}}\right]}{\left.\rho_{w} m_{p} g^{2} \cos ^{2} \alpha-K_{2}\left(g \sin \alpha-K_{1}\right)^{\frac{3}{2}}\right]} & \text { for } \alpha \leq \alpha_{0} \\
2 \varepsilon_{c} & \text { for } \alpha \geq \alpha_{0}
\end{array}\right\}
$$

The parameter $\varepsilon_{C}$ is a cutting wear factor representing the amount of energy needed to remove a unit volume of surface material by cutting action. The parameter $\alpha O$ is the angle of impingement when the horizontal component of $g$ becomes zero and is given by

$$
\frac{0.576 \rho_{s}^{\frac{1}{4}} g^{\frac{1}{2}} \varepsilon_{c}}{y_{e l}^{\frac{5}{4}}}=\frac{\cos \alpha_{0}}{\sin ^{\frac{3}{2}} \alpha_{0}}
$$

where $y_{e l}$ is the elastic load limit. The material constants $K_{1}, K_{2}$ and $K_{3}$ are given by

$$
\begin{aligned}
& K_{1}=\frac{\pi^{2} y_{e l}^{\frac{5}{2}}}{2 \sqrt{10}} \sqrt{\frac{1}{\rho_{s}}}\left[\frac{1-q_{1}^{2}}{E_{1}}+\frac{1-q_{2}^{2}}{E_{2}}\right]^{2} \\
& K_{2}=0.82 y_{e l}^{2}\left(\frac{y_{e l}}{\rho_{s}}\right)^{\frac{1}{4}}\left[\frac{1-q_{1}^{2}}{E_{1}}+\frac{1-q_{2}^{2}}{E_{2}}\right]^{2}
\end{aligned}
$$

and

$$
K_{3}=\frac{0.288}{y_{e l}}\left(\frac{\rho_{s}}{y_{e l}}\right)^{\frac{1}{4}}
$$

where $q_{1}$ and $q_{2}$ are Poisson's ratios for the particle and surface, respectively. $E_{1}$ and $E_{2}$ are Young's moduli for the particle and surface respectively. Good correlation with 
experiment was obtained and the variation of wear with impact angle was well-described. Neilson and Gilchrist [1968a] simplified the Bitter expression to produce a model in which the deformation wear component is given as before and the cutting wear component is given by

$$
\left(w_{i}\right)_{c}=\left\{\begin{array}{ll}
\frac{\rho_{w} m_{p} g^{2} \cos ^{2} \alpha \sin \eta \alpha}{2 \varepsilon_{c}} & \text { for } \alpha \leq \alpha_{0} \\
\frac{\rho_{w} m_{p} g^{2} \cos ^{2} \alpha}{2 \varepsilon_{c}} & \text { for } \alpha \geq \alpha_{0}
\end{array} \mid\right.
$$

where

$$
\alpha_{0}=\frac{\pi}{2 \eta}
$$

The parameter $\eta$ is an empirical constant.

As mentioned earlier, Bitter assumed "deformation wear" to be the dominant wear mechanism at normal incidence and "cutting wear" at shallow angles. But Bitter presented little justification for his assumptions. Hutchings [1981] presented a simple analytical model for erosion at normal incidence by platelet formation. He considered spherical particles for two reasons: first, because it was clear that, with spherical projectiles at normal incidence, platelet formation is the dominant mechanism of erosion [Rickerby and Macmillan, 1980] [Bellman and Levy, 1980] [Brown, et al., 1980]; second, because a firmer foundation existed for the theoretical analysis of sphere impact that for the impact of angular particles.

Hutchings proposed "critical strain" as a suitable criterion to determine failure, i.e. removal of a fragment occurs when the maximum plastic strain within the fragment 
reaches a critical value $\square_{c}$. The idea of critical strain has previously been proposed by Suh [1980] in connection with abrasive wear. Hutchings illustration of energy balance for a single impact is show in Fig. 2.4.

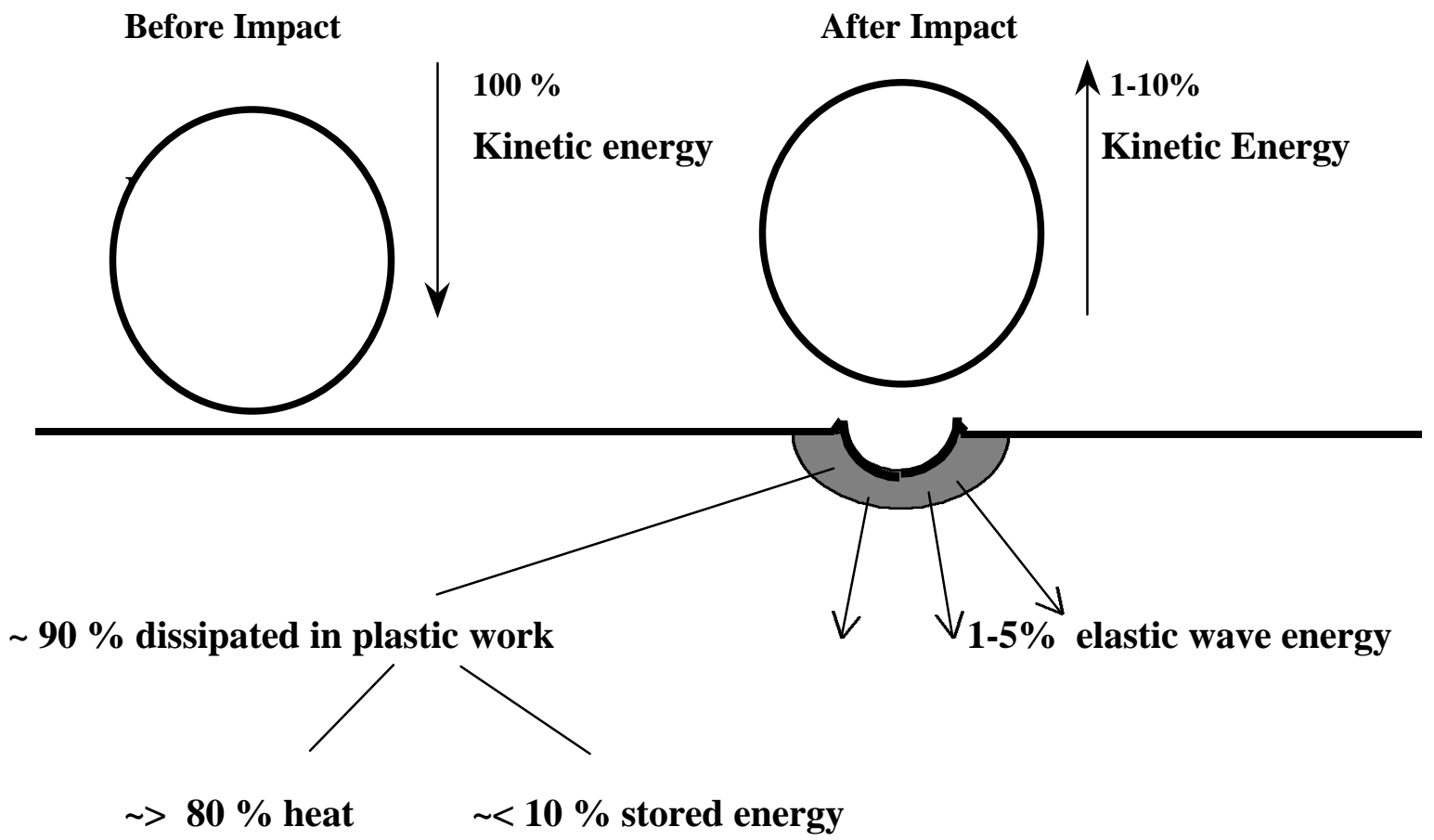

Fig.2.4 The energy balance before and after the normal impact of a spherical erosive particle.

Hutchings's derivation is as follows:

He considered the target to be struck by a large number of spherical projectiles distributed at random over the surface, each travelling at the same velocity and therefore causing the same pattern of plastic deformation in the target on impact. He assumed that the whole volume plastically deformed by each impacting sphere is subjected to a plastic 
strain increment $\Delta \varepsilon_{p}$ of the same magnitude and that the strains are directed with circular symmetry about the line of impact of the sphere (Fig.2.5).

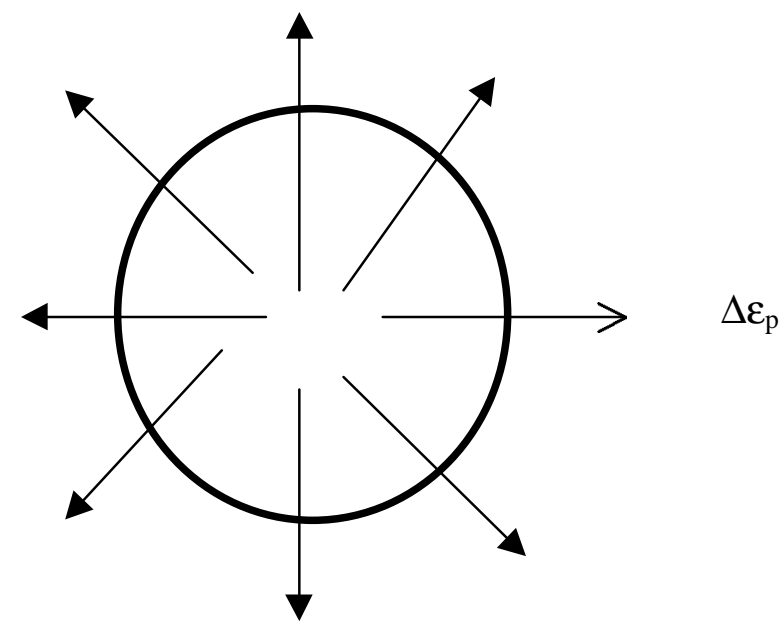

Fig.2.5 The plastic strain associated with one impact is assumed to be directed radially outwards in the plane of the surface [Hutchings, 1981]

Material at any point on the surface will therefore be subjected to successive increments of strain of magnitude $\Delta \varepsilon_{p}$, randomly oriented in the plane of the surface. After $N$ impacts the expectation value of the resultant strain at the point may be shown from random walk theory [Fellar] to be $\Delta \varepsilon_{p} N^{1 / 2}$. If $N_{f}$ is the mean number of impacts (i.e. strain increments) needed to cause detachment of material then application of the failure criterion gives

$$
\Delta \varepsilon_{p} N_{f}^{1 / 2}=\varepsilon_{c}
$$

Hutchings, for simplicity assumed the metal being eroded as rigid perfectly plastic solid with no work hardening. The eroding particles were assumed to be rigid nondeforming spheres of radius $r$ and density $\sigma$. The mass $m$ of one sphere is therefore given by 


$$
m=\frac{4 \pi r^{3} \sigma}{3}
$$

and its kinetic energy at impact velocity $v$ is $m v^{2} / 2$.

The behavior of the metal target was assumed to resist indentation with a constant pressure $P$ (analogous to the quasi-static indentation hardness). Elastic forces were ignored. An examination of the energy balance during the impact indicated that atleast $90 \%$ of the initial kinetic energy of the particle is dissipated in plastic deformation in the target, and this confirmed that it is permissible, for the purpose of this calculation, to ignore elastic effects. Fig. 2.4. illustrates how the kinetic energy of an erosive particle is partitioned after normal impact: Assuming that all the initial kinetic energy of the particle is available to form indentation, the volume $V$ of which will therefore be given by

$$
V=\frac{m v^{2}}{2 P}
$$

This relationship was first determined empirically by Martel in 1985 [Tabor, 1951] and will be approximately true for impact on metal by erosive particles of any shape at impact velocities typical of erosion $(\mathrm{v} \cong 10-500 \mathrm{~m} / \mathrm{sec})$, provided that the particle does not deform or fracture and that elastic effects can be neglected.

He assumed that the volume of metal which is plastically deformed around an indentation is some fraction $\alpha$ of the volume of indentation. Therefore the volume of material which is plastically strained by each impact is $\alpha m v^{2} / 2 P$; which is called "elementary volume". After $N_{f}$ impacts the volume loss per impact is therefore $\alpha m v^{2} / 2 P N_{f}$. If the target material has density $\rho$ then the erosion $E$ defined as the mass loss from the target per unit mass of impinging particles is given by 


$$
E=\frac{\alpha \rho v^{2}}{2 P N_{f}}
$$

For a quasi-static indentation by a rigid sphere of radius $r$, Tabor [1951] has shown that the average strain introduce into a metal is given by

$$
\varepsilon \approx \frac{0.2 a}{r}
$$

where $a$ is the final chordal radius of the indentation and $\varepsilon$ is the strain in an equivalent uniaxial compression test.

By equating the initial kinetic energy of the impinging sphere with the work done in forming the indentation, it was shown that

$$
\alpha=2^{1 / 2} r v^{1 / 2}\left(\frac{2 \sigma}{3 P}\right)^{1 / 4}
$$

By combining the above equations, the erosion is given by

$$
E=0.033 \frac{\alpha \rho \sigma^{1 / 2} v^{3}}{\varepsilon_{c}^{2} P^{3 / 2}}
$$

where $\alpha=$ fraction of volume of indentation which is plastically deformed

$r=$ radius of spherical particle

$a=$ final chordal radius of the indentation

$\varepsilon=$ is the strain in an uniaxial compression test

$\sigma=$ density of particle

$v=$ impact velocity

$\rho=$ target material density

$P=$ constant pressure of resistance by the target material for indentation

$\varepsilon_{\mathrm{c}}=$ critical strain 


\subsection{MULTIPLE PARTICLE EROSION MODELS}

Tabakoff et al. advanced an empirical wear model to predict impact wear per unit mass of impacting coal ash particles as a function of impact angles, impact velocity, tangential restitution ratio and three empirical constants. Good correlation was obtained for impact angles ranging from $10^{0}$ to $60^{\circ}$ from the horizontal. They developed semiempirical impact wear rate expressions for several metals. They used experimental data for impact velocities varying from $85 \mathrm{~m} / \mathrm{s}$ to $137 \mathrm{~m} / \mathrm{s}$. The models were accurate for impact angles ranging from $30^{\circ}$ to $60^{\circ}$. The predicted wear rate depended on the ratio of material strengths at ambient and operating temperatures which implicitly accounted for temperature effects, the particle impingement velocity magnitude and angle and the normal and tangential restitution ratios which are measured ratios of particle speeds before and after collisions.

Hutchings [1979] used the one- dimensional elastic wave theory and contact analyses between a non-deforming sphere and a target to analyze impact pressure at normal incident angles. It was found that the duration of the impact pressure is much less than the total duration of the particle-surface impact indicating that the transient impact pressure has little influence on the wear process. An analysis of wear at high impact angles using a load-cycle (high strains) fatigue model was performed to predict mass wear per unit mass of impacting particles. Resultant wear predictions compared favorably with experimental results but necessary parameters, such as the ratio of the volume of deformed metal to the volume of the indentation and the average strain associated with the volume, are difficult to measure. 
Hutchings [1991] formulated a model for erosion of metals by spherical particles impacting at normal incidence predicting mass wear per unit mass of impacting particles. The assumed mechanism of metal removal was the formation and detachment of platelets of material. Detachment was assumed to occur only after the plastic strain in the deformed material reached a maximum or 'critical' strain. This strain was also termed the 'erosion ductility' of the material.

Sundararajan and Shewmon [1983] derived a model for erosion produced by particles impacting at normal angles using the criterion of a critical plastic strain needed for material removal. The model assumed the formation and subsequent removal of an extruded lip of material along the rim of the indentation crator. Compared to the 'fatigue' model of Hutchings, this model showed improved experimental correlation.

Zhu [1998] advanced a simple model for low-velocity impact wear based on empirical observation and the assumptions that surface fatigue is the material loss mechanism, local plastic deformation causing the surface fatigue is directly related to local elastic deformation, material loss is directly proportional to the volume of the surface materials that undergoes elastic deformation, wear rate is proportional to the cube of the maximum elastic deformed depth and all impacting particles striking at a given angle transfer the same fraction of their kinetic energy to the surface 


\section{FINITE ELEMENT SIMULATION}

\subsection{SCHEMATIC OF MODEL}

A schematic diagram of single particle impact is shown in Fig. 3.1. The erodent which is assumed to be a spherical particle, hits the oxide layer at certain velocity and rebounds. This causes material failure in the vicinity of impact. The erodent size is in the range of $20-120 \mu \mathrm{m}$ and is a silicon carbide particle. The target medium is ironoxide which is formed on iron (substrate) at $570^{\circ} \mathrm{C}$. The thickness of iron-oxide at this temperature is $36 \mu \mathrm{m}$ [Bruce and Hancock, 1969]. 


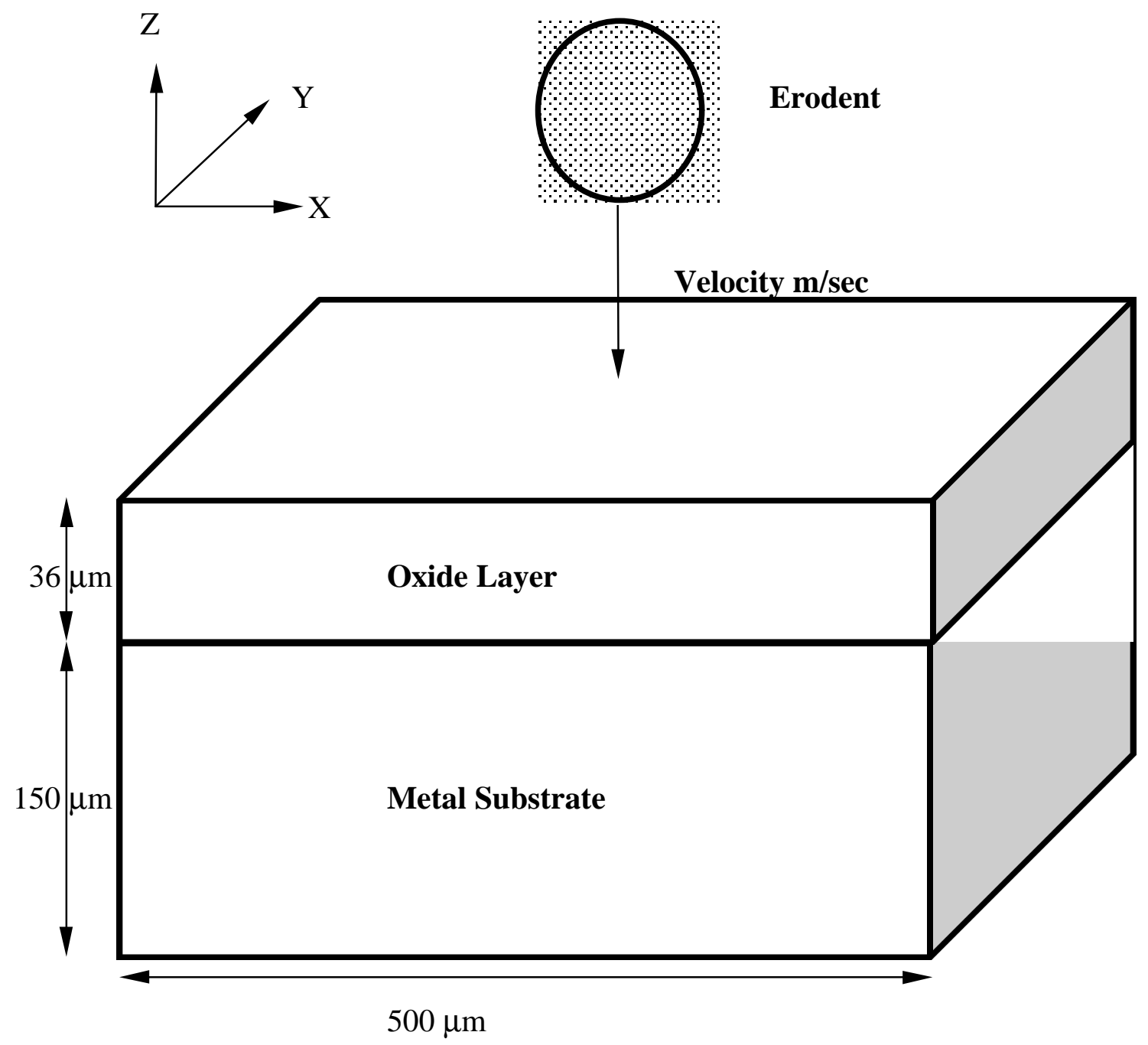

Fig. 3.1 Schematic diagram of single particle impact 
The material properties of Armco iron and iron oxide are taken from the experimental results of Bruce and Hancock [1969] and Hancock and Nicholls [1988].

$\begin{array}{llll}\text { Temperature } \rightarrow \quad 570{ }^{\circ} \mathrm{C} & 674^{\circ} \mathrm{C} & 743^{\circ} \mathrm{C} & 800^{\circ} \mathrm{C}\end{array}$

Properties $\downarrow$

$\begin{array}{lllll}\text { Iron oxide } & & & & \\ \text { Modulus of Elasticity }(\mathrm{GPa}) & 182 & 168 & 158 & 151 \\ \text { Mass Density }\left(\mathrm{kg} / \mathrm{m}^{3}\right) & 5190 & 5188 & 5187 & 5185.5 \\ \text { Poisson Ratio } & 0.345 & 0.345 & 0.345 & 0.345 \\ \text { Scale Thickness }(\mu \mathrm{m}) & 36 & 111 & 206 & 325 \\ \text { Fracture Stress }(\mathrm{MPa}) & 38 & 40 & 31 & 74 \\ \text { Strain (x 104) } & 2.1 & 2.4 & 1.9 & 4.9 \\ \text { Iron } & & & & 125.41 \\ \text { Modulus of Elasticity }(\mathrm{GPa}) & 155 & 149.53 & 135.06 & 7798 \\ \text { Mass Density }\left(\mathrm{kg} / \mathrm{m}^{3}\right) & 7810 & 7802 & 7800 & 0.34 \\ \text { Poisson Ratio } & 0.34 & 0.34 & 0.34 & 25 \\ \text { Scale Thickness }(\mu \mathrm{m}) & 150 & 100 & 50 & \end{array}$

Table. 3.1 Material Properties of Iron and Iron -Oxide at various temperatures.

The properties of silicon carbide particle is taken from ASM handbook, [1990].

The properties are shown in Table. 3.2.

\begin{tabular}{ll}
\hline & Properties of Silicon Carbide Particle \\
\hline Modulus of Elasticity $(\mathrm{GPa})$ & 37.49 \\
Mass Density $\left(\mathrm{kg} / \mathrm{m}^{3}\right)$ & 71.28 \\
Poisson Ratio & 0.192 \\
\hline
\end{tabular}

Table 3.2 Material Properties of Silicon Carbide Particle 


\subsection{FINITE ELEMENT MODEL}

The process of finite element analysis consists of three stages as shown in Fig.3.1.

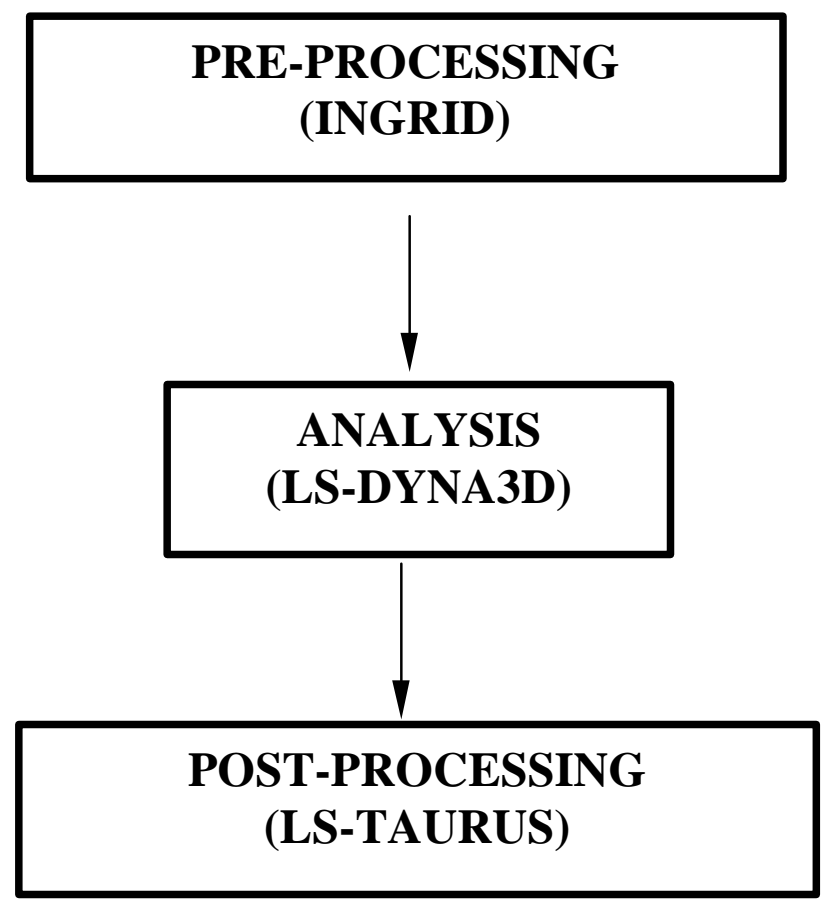

Fig. 3.2 Macroscopic method of study.

Pre-processing involves the preparation of the geometric model of the metal/oxide system and the erodent. The dimensions of the oxide layer, metal substrate and the size of the erodent are required. Since the size of the erodent is very small when compared to the target, the target medium should be considered as an infinite medium for analytical purposes. But, a computational model cannot handle infinite dimensions and hence proper dimensions have to be assumed for the target media. When making such a discretization, care should be to avoid

- Unreasonable reaction forces at the restraints, which might affect stress distribution near the impact region

- An untraceable local region 
The erodent, oxide layer and the substrate is modeled using 8 noded hexahedron (Brick) elements. The dimensions for the oxide layer and the metal are given below for various cases.

\begin{tabular}{|l|c|c|}
\hline & $\begin{array}{c}\text { Dimension of Oxide layer } \\
\mu \mathrm{m} \times \mu \mathrm{m} \times \mu \mathrm{m}\end{array}$ & $\begin{array}{c}\text { Dimension of Iron } \\
\mu \mathrm{m} \times \mu \mathrm{m} \times \mu \mathrm{m}\end{array}$ \\
\hline Normal Impact & $500 \times 250 \times 36$ & $500 \times 250 \times 150$ \\
\hline Angular Impact & $500 \times 250 \times 36$ & $500 \times 250 \times 150$ \\
\hline $\begin{array}{l}\text { Impact in the neighborhood } \\
\text { of previous impact }\end{array}$ & $310 \times 150 \times 36$ & $310 \times 150 \times 150$ \\
\hline Two particle impact & $500 \times 250 \times 36$ & $500 \times 250 \times 150$ \\
\hline
\end{tabular}

Table. 3.3 Model size for various cases

The number of elements for the oxide layer is 8000 to 13000 . The number of elements for the metal substrate is around 3000 to 5000 and that of erodent is around 500 to 2000. Single point integration is used for the elements of the erodent and the substrate. Eight point integration is used for the oxide layer

There are several material models available in LS-DYNA3D. Since we are more interested in the oxide than the erodent, a 'rigid-material' model is used for the analysis. This material model provides an inexpensive method for modeling portions of a structure which experience negligible deformations. Stresses are not calculated for this kind of material. The input data required are

Modulus of Elasticity

Mass density

Poisson's ratio

The modulus of elasticity is required for contact calculations and the density is required for kinetics.

The oxide scales formed at $570^{\circ} \mathrm{C}$ temperature behaved in a brittle manner as discussed in previous chapter. The oxide scales behave linearly elastic until failure. 
They have very little ability to carry plastic strains. For the current work an 'ElasticPlastic' material model is used. Though they were treated as elastic-plastic, the strain at the onset of plasticity was assumed as the failure strain for the calculation of erosion.

The data required for this type of material are

Modulus of Elasticity

Mass density

Poisson's ratio

Yield stress

Tangent Modulus

A plot of stress vs strain for the oxide layer is shown in Fig. 3.3.

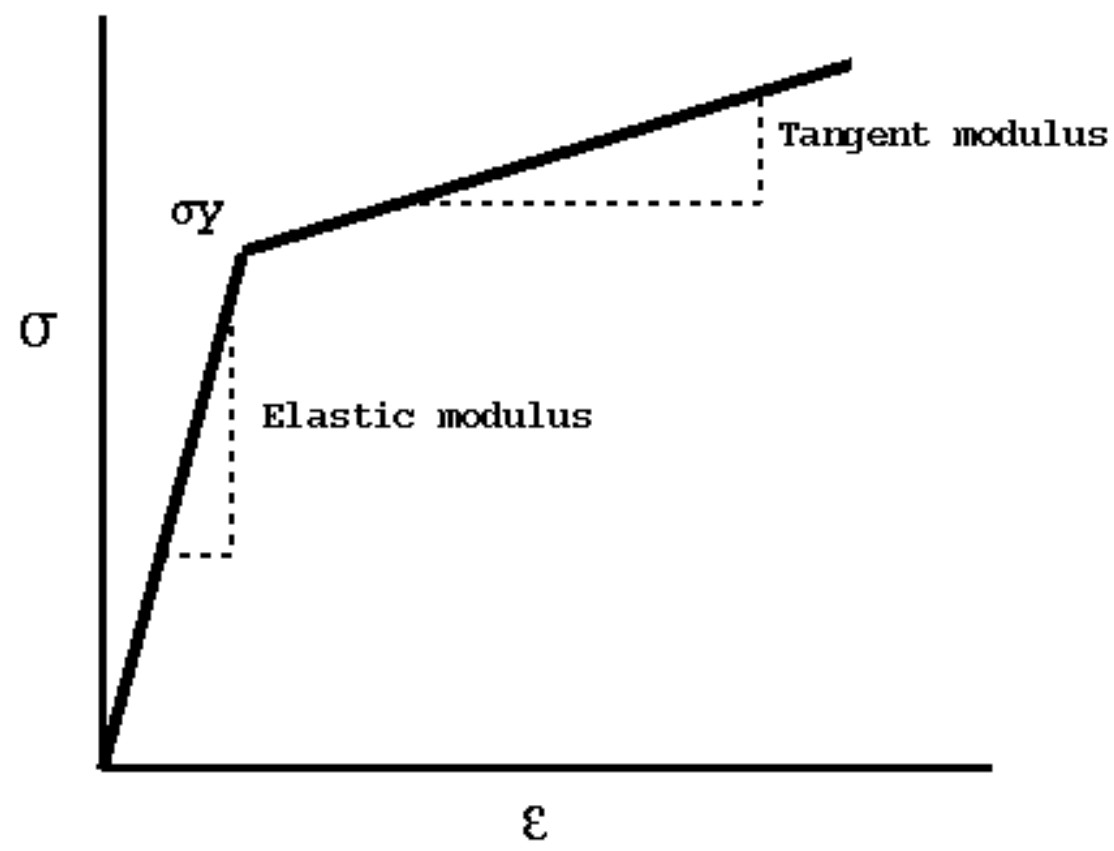

Fig. 3.3 Stress-Strain curve for Iron-Oxide for Elastic-Plastic material.

For the metal substrate, an elastic material model is used which requires the density, poisson's ratio and elastic modulus. 
As can be seen from the schematic diagram, the problem is symmetrical about $\mathrm{XZ}$ plane. Hence the advantage of symmetry is used in the model. Only one half of the schematic diagram is modeled by taking the symmetry plane through the center of the erodent in the $\mathrm{XZ}$ plane. The nodes on this plane are constrained in translation along $\mathrm{Y}$ axis and rotation about $\mathrm{X}$ and $\mathrm{Z}$ axes. The finite element model for normal, angular, erodent size and impact near previous impact site is shown in Fig. 3.4., Fig. 3.5. and Fig. 3.6. The model for two particle impact is shown is Fig 3.7.

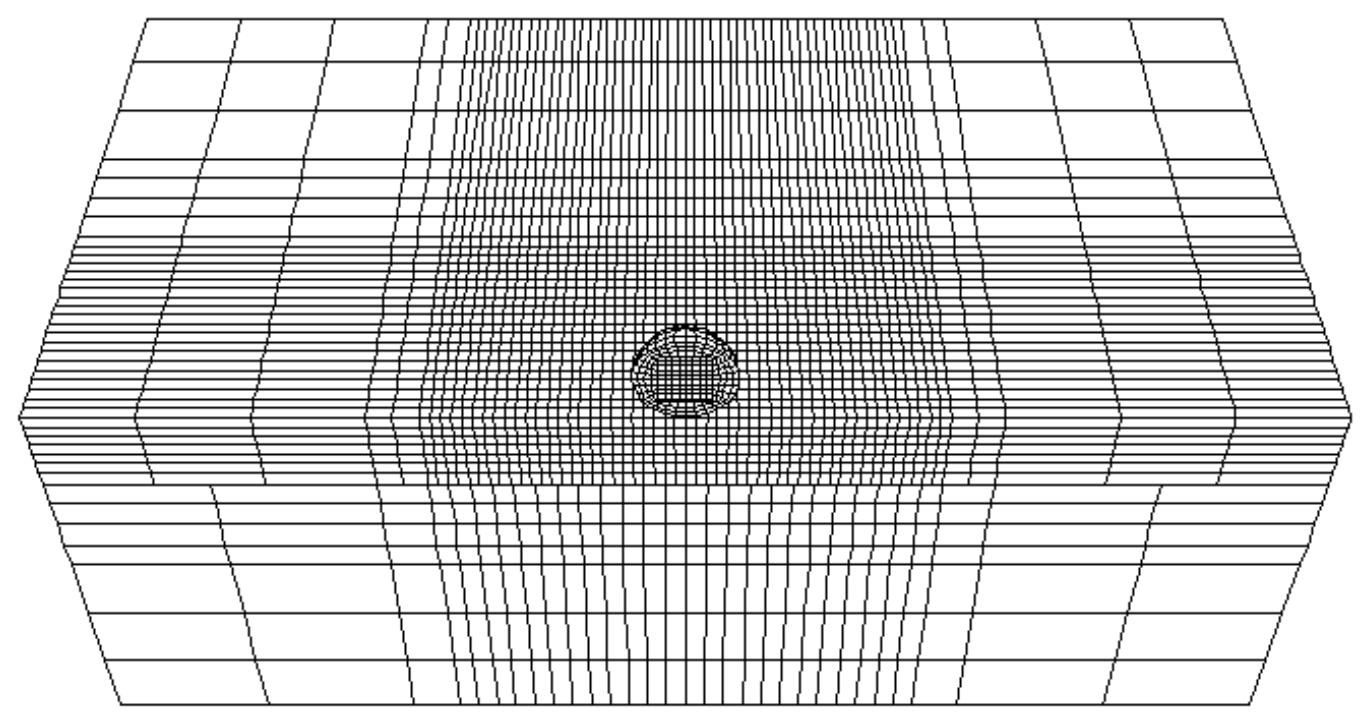

Fig. 3.4 Finite Element Model for Normal Impact. 


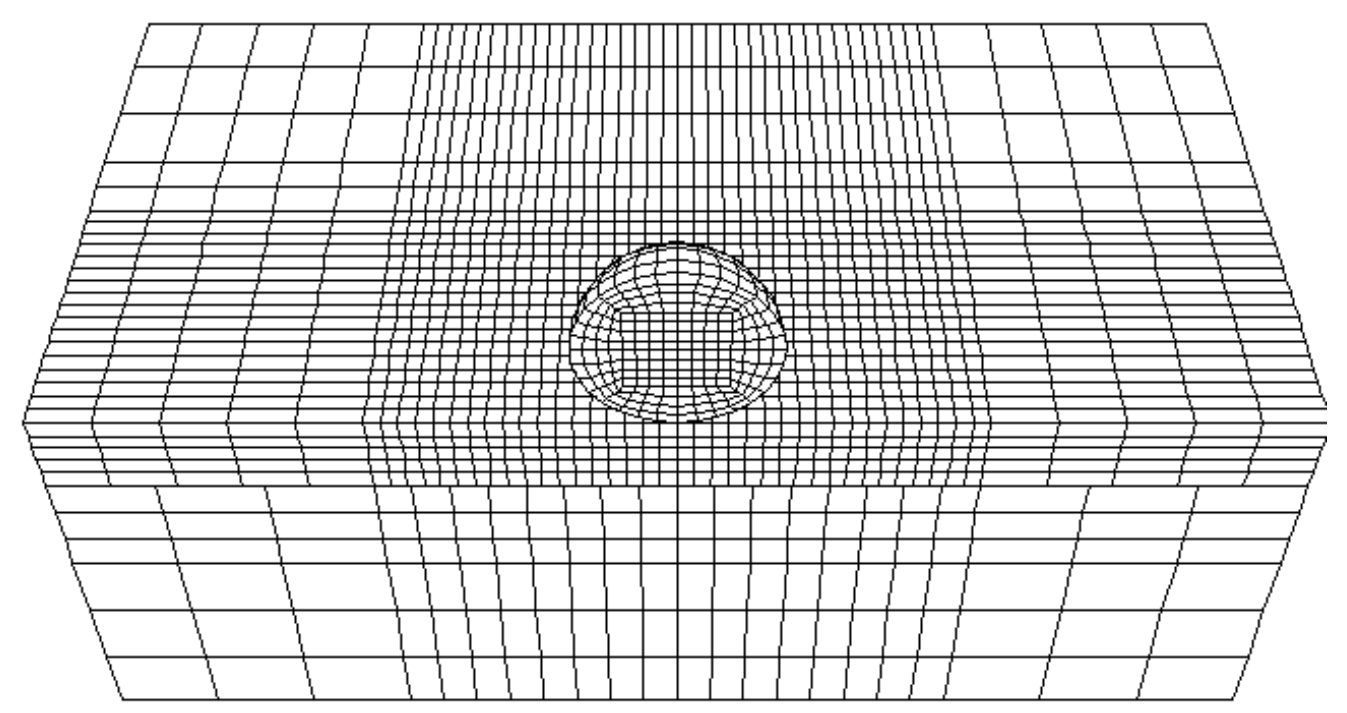

Fig. 3.5 Finite Element Model for Angular Impact 


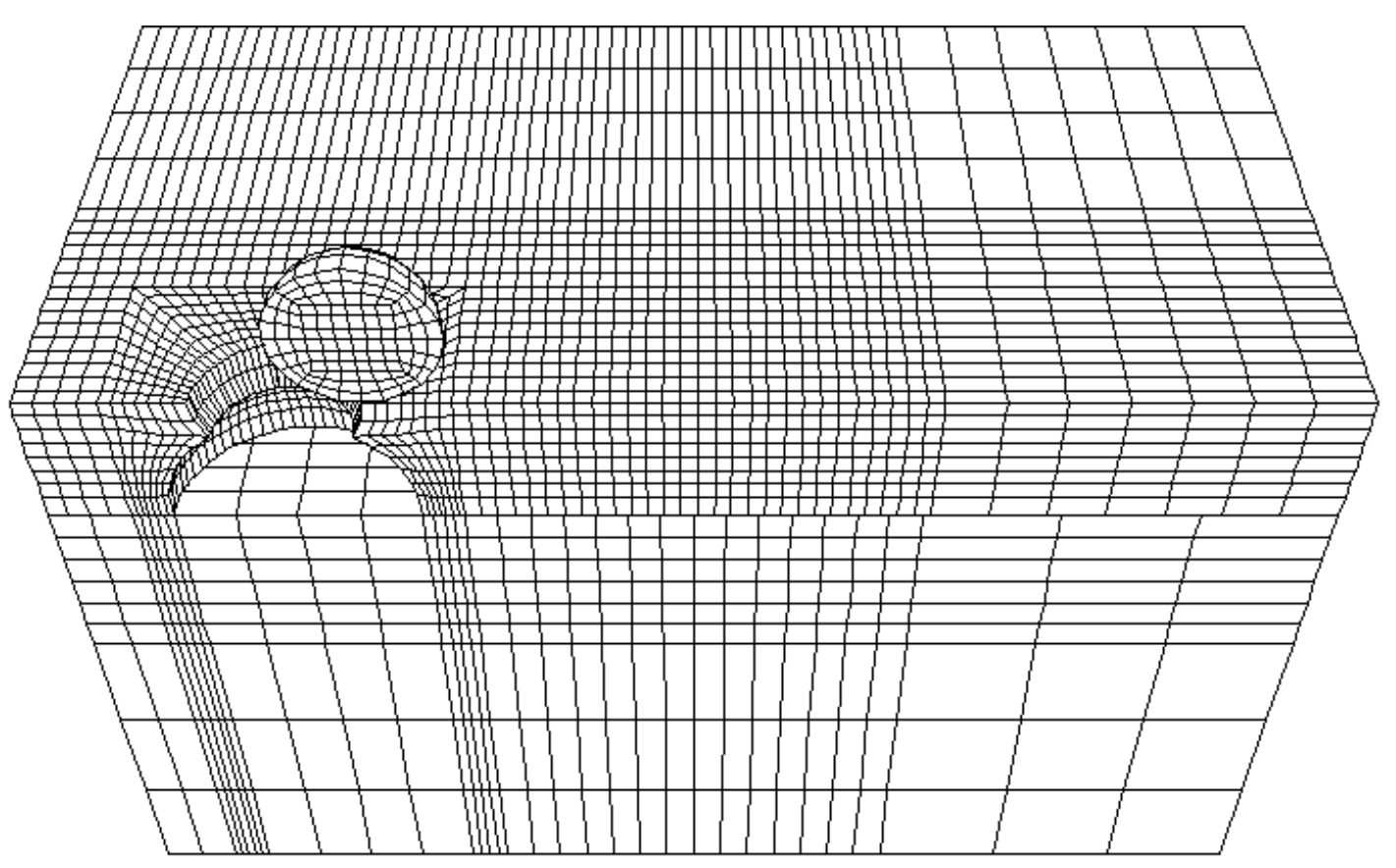

(a) At $20 \mu \mathrm{m}$ from the center of previous impact

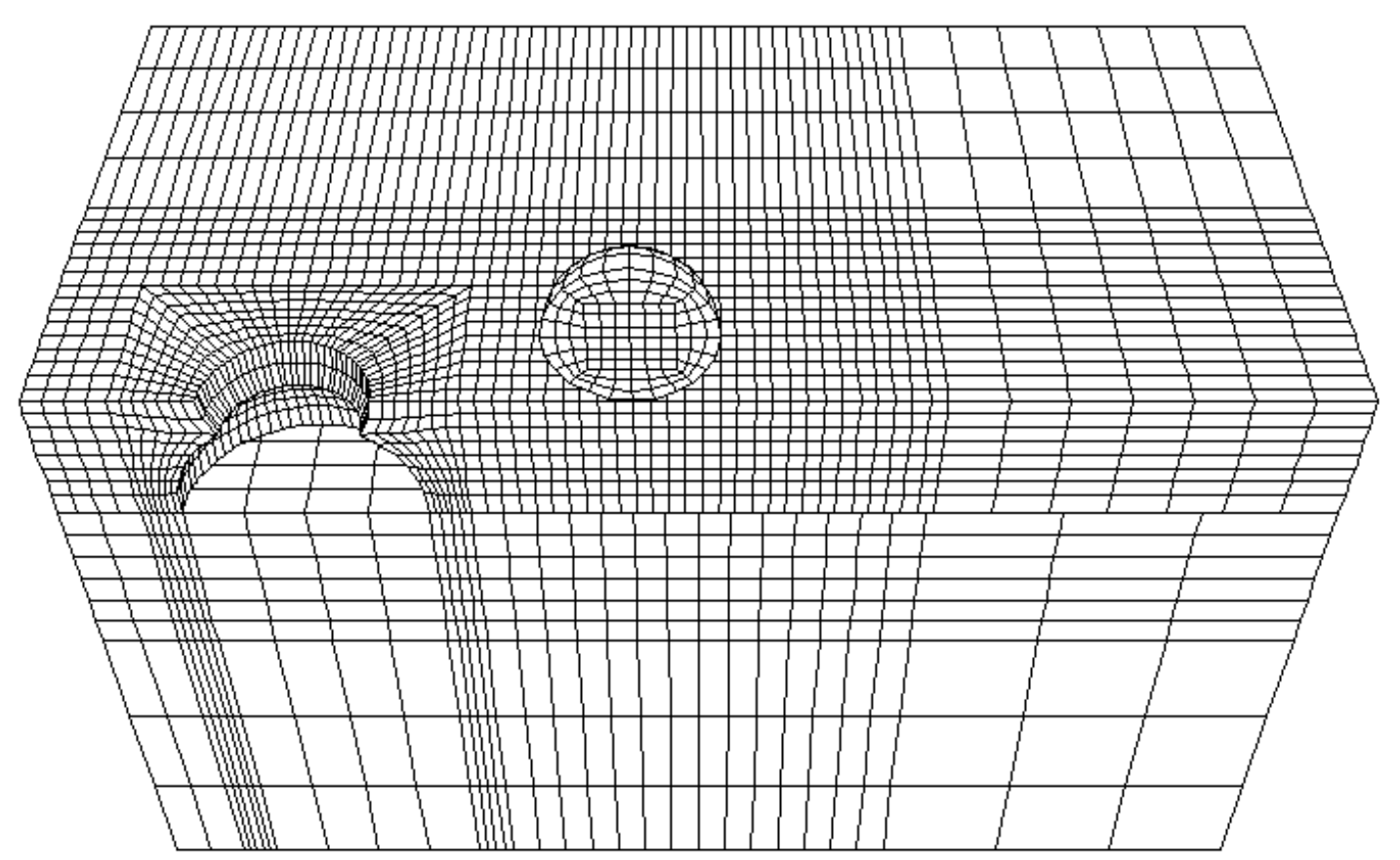

(b) At $64 \mu \mathrm{m}$ from the center of previous impact

Fig. 3.6 Finite Element Model for impact near a previous impact site 

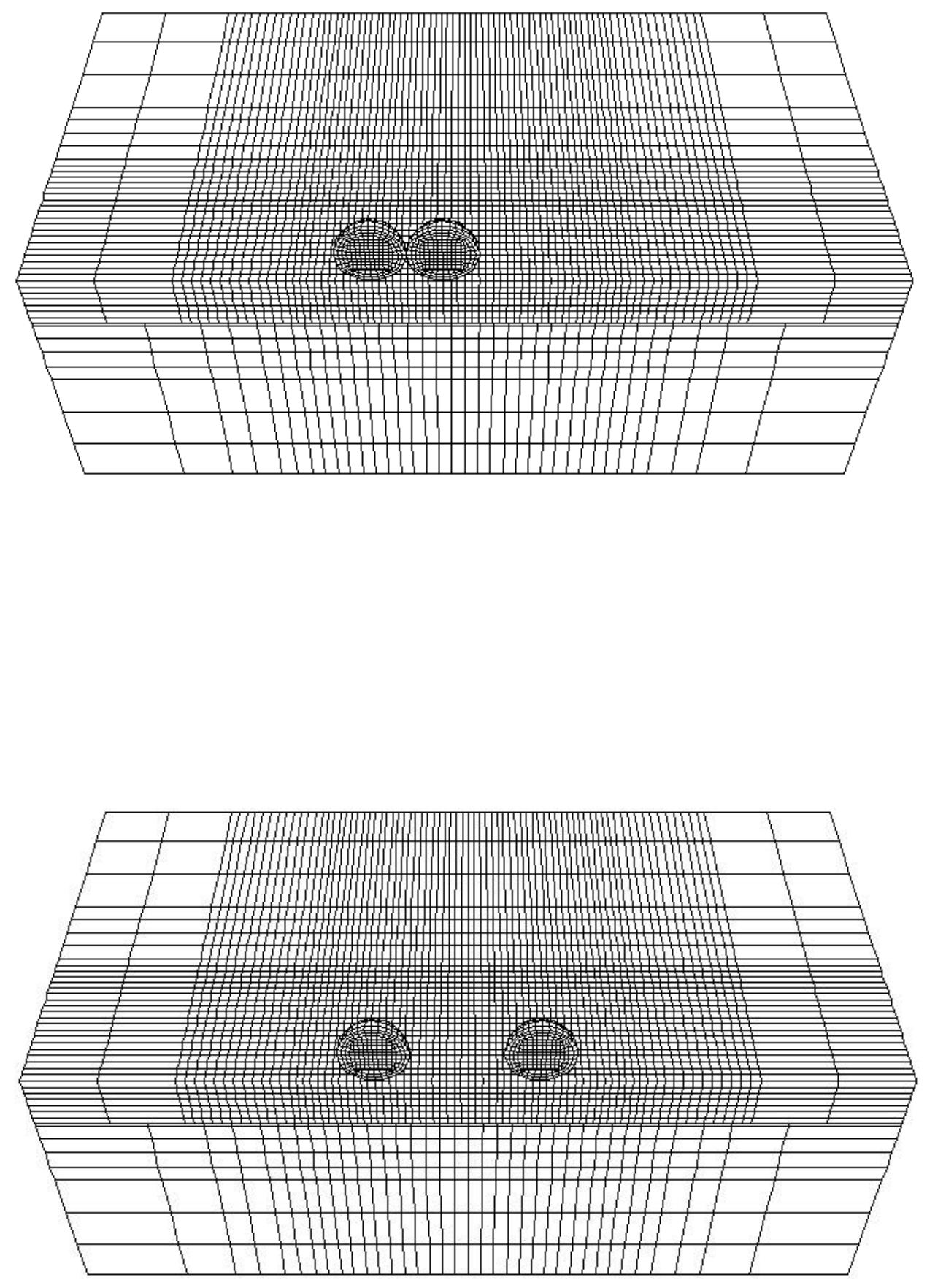

Fig. 3.7 Finite Element Model for two-particle impact 


\subsection{BOUNDARY AND INITIAL CONDITIONS}

The effect of single particle impact is assumed to have only local effects. Therefore in the far field, the target media is expected to have negligible deformation. Therefore all the nodes on the far boundary from the region of impact are totally restrained from undergoing any kind of deformation as shown in Fig.3.8. Three boundary conditions are applied to the model.

1. Zero initial nodal velocities

2. Constraints

3. Symmetry boundary conditions

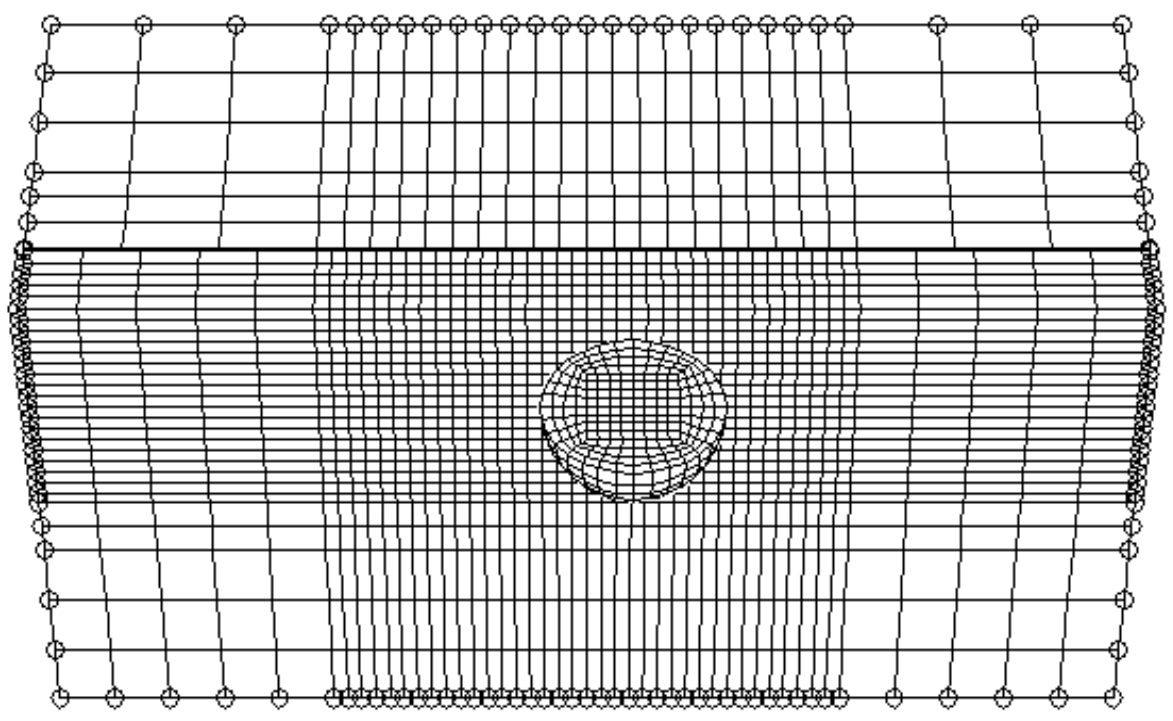

Fig. 3.8 Boundary conditions for the half symmetry model. (The nodes on the boundary are totally restrained) 


\subsection{PARAMETRIC MODELING}

The parameters considers in this study are

- Velocity of erodent

- Angle of attack of erodent

- Size of erodent

\subsection{SOLUTION}

LS-DYNA3D is a fully vectorized, explicit, three dimensional, dynamic analysis code capable of solving problems involving large deflections and high rates of deformation [Hallquist et. al. 1995].

A nonlinear transient dynamic analysis is performed using LS-DYNA3D. The time step for the analysis is based on the smallest element size in the model and it is in the range of $4 \mathrm{e}-4$ microsec. The simulation is run until the erodent rebounds.

\subsection{FAILURE CRITERIA AND MATERIAL LOSS ESTIMATION}

Yelamanchalli [1997], in his work had used Von-Mises stress for the estimation of volume loss. Basically the procedure involved identifying the elements that have exceeded the threshold stress at the time of maximum internal energy. Since the material does not involve progressive failures, it is possible under certain impact conditions, like in a typical angular impacts, some elements in the model which had exceeded the 
threshold stress during the initial contact with the erodent, may not have the same stress level at the point of maximum internal energy since the erodent is making a glancing impact and moving away from these elements. A plot of stress and internal energy vs time in Fig. 3.9. for a 30 deg angular impact substantiates this.

Hence, as discussed in the previous chapters, since the oxide scales are brittle in nature 'critical strain' is used as the criteria for failure. Again as mentioned earlier, progressive failure is not considered in the analysis, meaning elements that exceed the critical strain are not deleted during the analysis. They are allowed to behave as per the stress strain curve, which extends to the plastic region also. After the analysis is done, in the phase I of LS-TAURUS, material loss is calculated. LS-TAURUS has a built in command to identify the elements in a particular part (here the entire oxide layer) that have exceeded a user defined plastic strain and then give the volume fraction of critical elements. This is the ratio of volume of critical elements to the volume of the entire oxide layer. The advantage of this method is we can get a curve of this volume fraction with time for any number of levels of plastic strain. A typical volume fraction curve is shown in Fig. 3.12. In this method, since strain value is used, the elements that exceed the yield stress or the threshold stress enter the plastic region and get picked up as critical elements and are thus accounted for material loss which other wise would not have been seen as a critical element at the time of maximum internal energy based on Von-Mises stress. Figure 3.9. shows the Von-Mises stress for one such case. The stress in element 5586 had reached the yield stress at a much earlier time than the peak of internal energy. 
The stress value at .2796 microsec, the point of maximum internal energy, has come down due to unloading as the erodent is moving away from the element because of glancing impact.

After yielding, strain increment $d \varepsilon$, can be regarded as composed of an elastic contribution $d \varepsilon^{e}$ and a plastic contribution $d \varepsilon^{p}$, so that $d \varepsilon=d \varepsilon^{e}+d \varepsilon^{p}$. In Fig\#3.10, the time history of effective $d \varepsilon^{p}$ for element 5586 is plotted. So, if the strain value were taken as the failure criteria, the elements that have reached the yield stress at any instant would still retain the unrecoverable plastic strain during unloading also. Referring to Fig. 3.10, the effective plastic strain for the same element stays flat after it reaches the yield stress.

A typical energy balance curve for an analysis is shown in Fig.3.11. The impact simulation for the current work is an energy conserved system. So at all times the total energy in the system should remain same, which is equal to the initial kinetic energy of the particle. In Fig. 3.11 as the kinetic energy comes down, the internal energy goes up, and a small portion of the energy is used up for contact. 


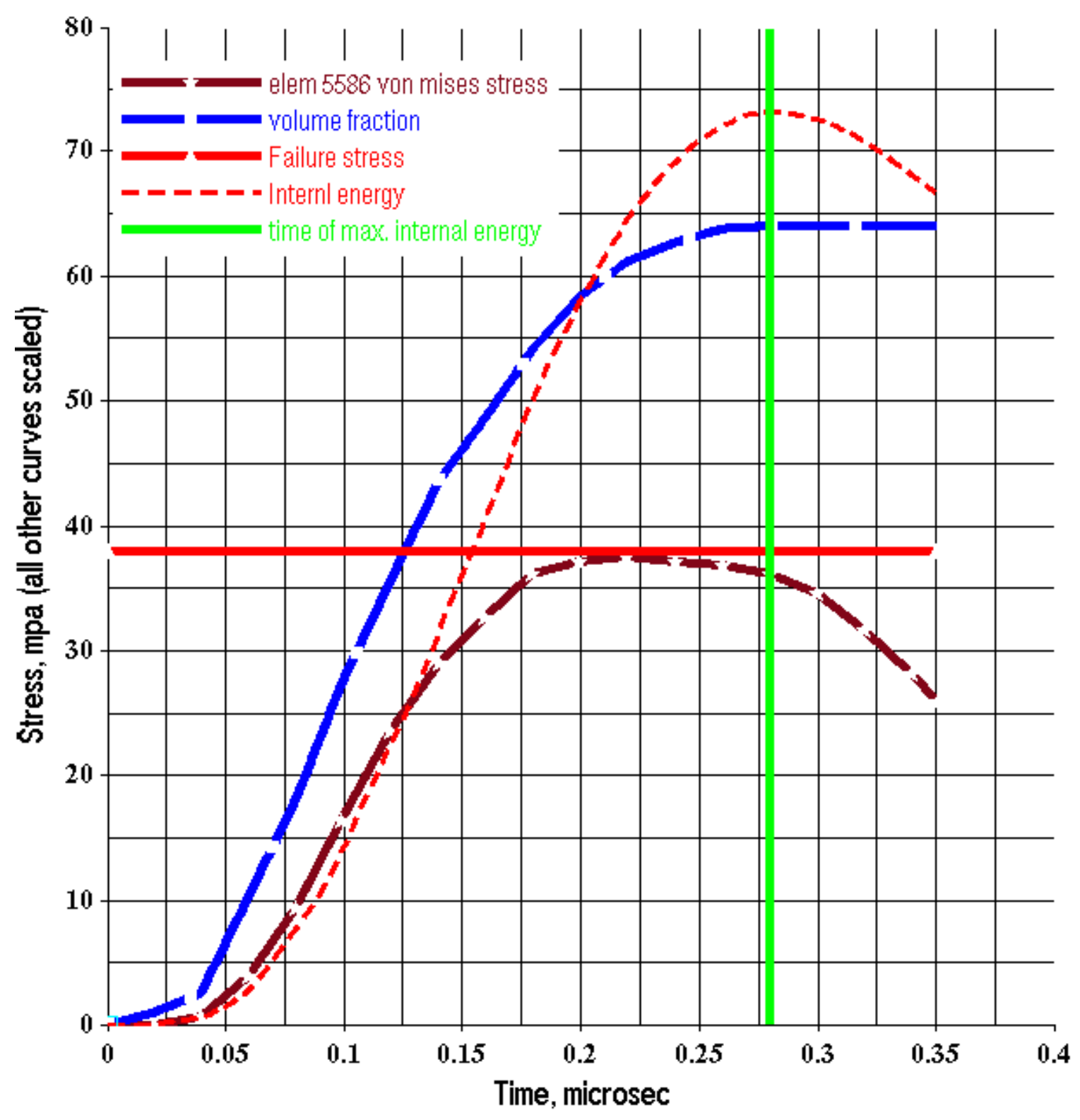

Fig. 3.9 Plot of stress, internal energy, vs time 


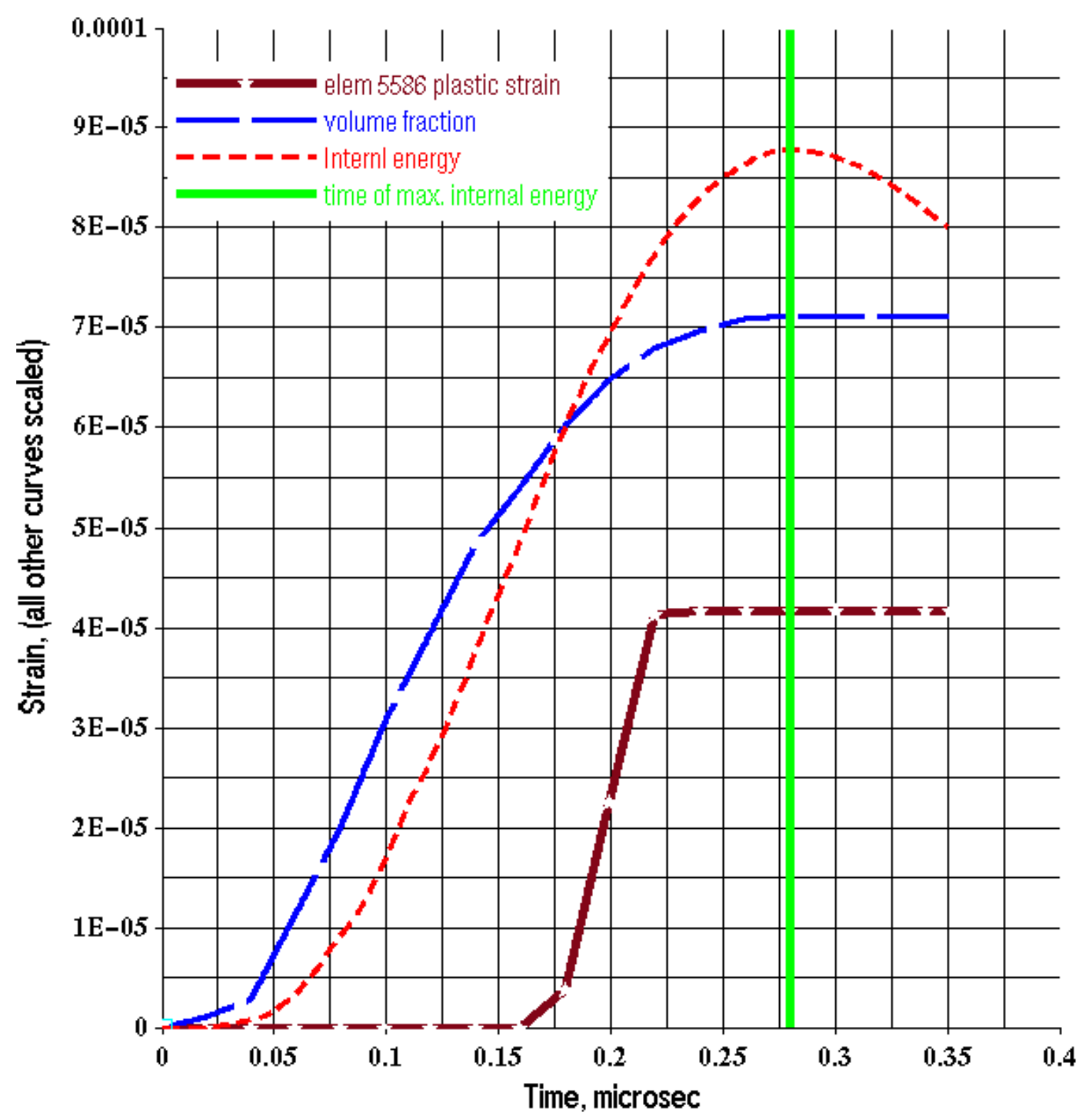

Fig. 3.10 Plot of strain, internal energy, volume fraction of critical elements vs time. 


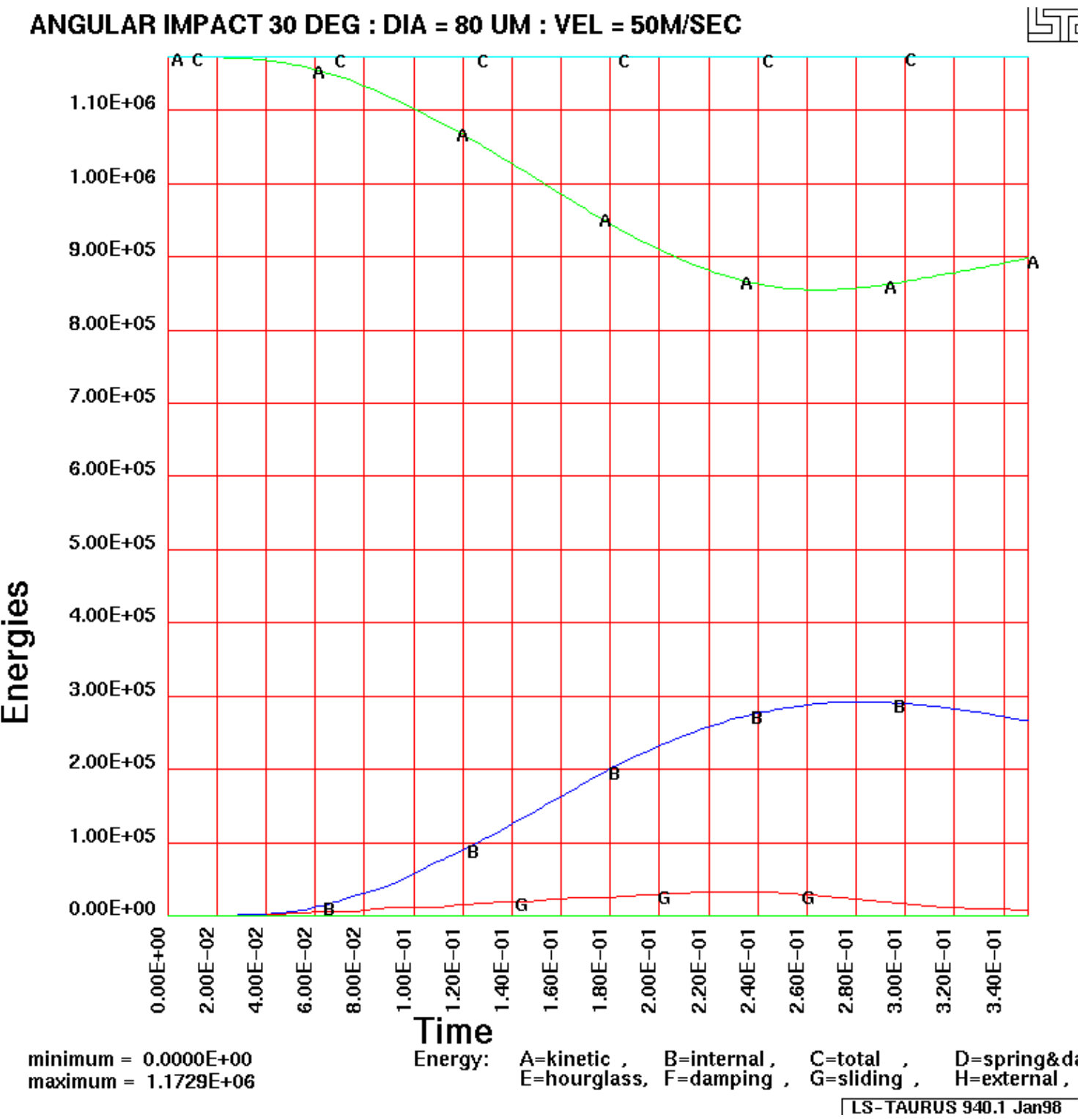

Fig. 3.11 Plot of Energy Balance . 




Fig. 3.12 Plot of volume fraction of critical elements for $90 \mathrm{deg}$ impact at various strain levels. 


\section{RESULTS AND DISCUSSION}

\subsection{INTRODUCTION.}

The results based on the finite element model developed in chapter 3 are preseneted here in terms of the following parameters.

- Velocity of erodent

- Angle of erodent

- Size of erodent

In addition results are presented for the following while varying the distance between impacts.

- Normal impact near a previously impacted site

- Two simultaneous normal impacts

The temperature is $570^{\circ} \mathrm{C}$ for all the cases.

\subsection{PARAMETRIC RANGES}

The following cases were studied.

- Normal Impact with diameter of erodent $40 \mu \mathrm{m}$ in the velocity range of $0-100 \mathrm{~m} / \mathrm{sec}$ in steps of $5 \mathrm{~m} / \mathrm{sec}$.

- Angular Impact with diameter of erodent $80 \mu \mathrm{m}$, velocity $50 \mathrm{~m} / \mathrm{sec}$ from 0-90 deg in steps of 10 degrees. 
- Normal Impact at $25 \mathrm{~m} / \mathrm{sec}$ with diameter of erodent $0-120 \mu \mathrm{m}$ in steps of $10 \mu \mathrm{m}$

- Normal Impact with diameter of erodent $40 \mu \mathrm{m}$, velocity $25 \mathrm{~m} / \mathrm{sec}$ and varying the distance from the previously impacted zone in steps of $4 \mu \mathrm{m}$.

- Normal Impact with diameter of erodent $40 \mu \mathrm{m}$, velocity $20 \mathrm{~m} / \mathrm{sec}$ and varying the distance from the previously impacted zone in steps of $4 \mu \mathrm{m}$.

- Two normal simultaneous impacts with diameter $40 \mu \mathrm{m}$, velocity $15 \mathrm{~m} / \mathrm{sec}$ and varying the distance between the two particles in steps of $4 \mu \mathrm{m}$.

\subsection{MODEL VALIDATION}

Work was done by Yelamanchali [1997] to establish correlation with test data. His work on aluminum oxide using this simulation technique showed a good correlation with the experimental results of Sheldon et. al, [1966]. The present model is similar to that of Yelamanchili's model. The plot showing the correlation is shown in Fig. 4.1.

For the current work there is no quantitative verification but only a qualitative one. The trends of the results are compared to Veluswamy's [1994] work. Also for angle of attack study, the results are qualitatively compared with the experimental results of brittle materials, available in the literature. 


\section{Comparison of Erosion af Aluminium Oxide}

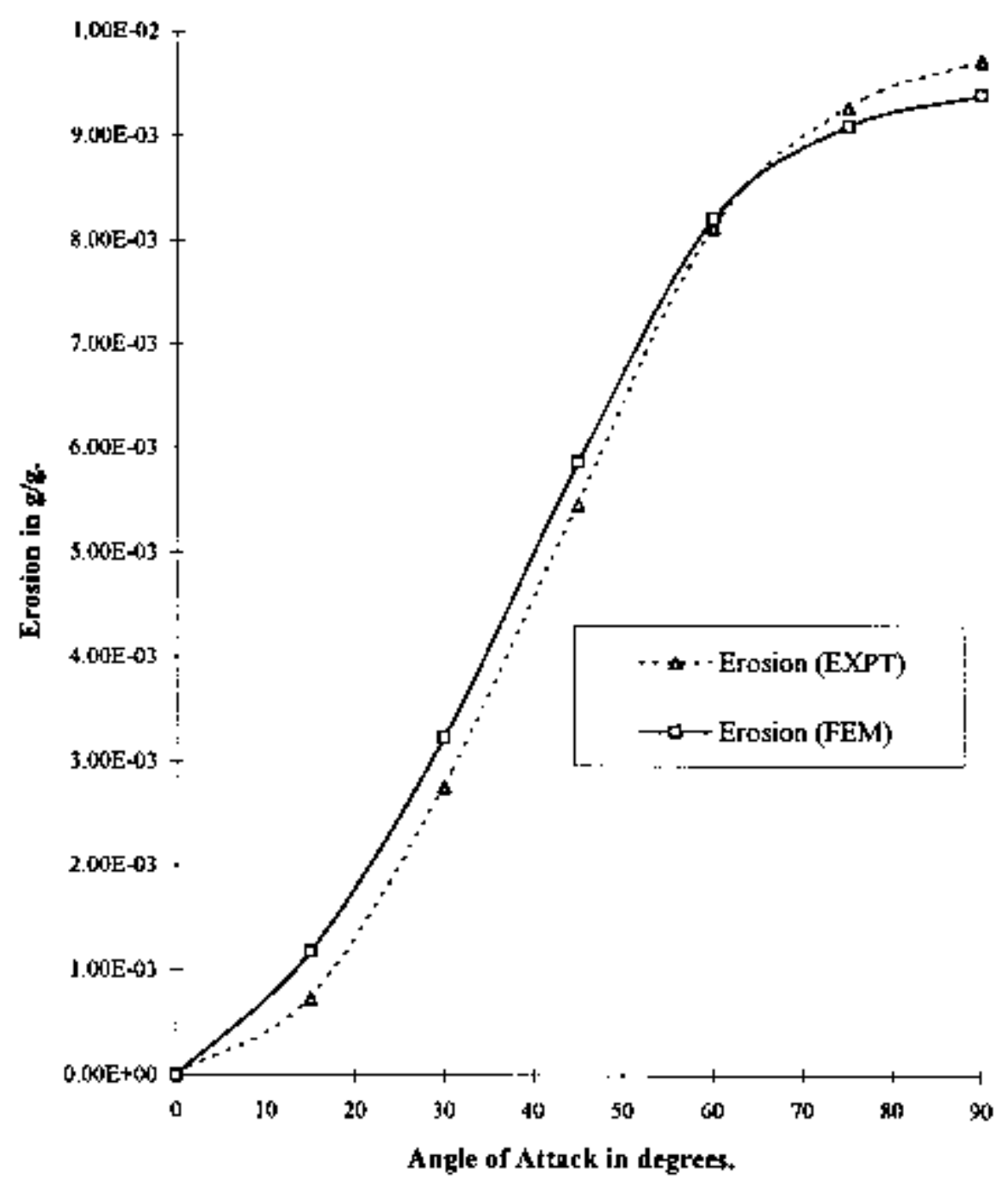

Figure 5.2: Comparison of FEM and Experimental Results (Sheldon) of Erosion of Aluminitum Oxide.

Fig. 4.1 Comparison of FEM and Experimental Results (Sheldon) of Erosion of Aluminum oxide [Yelamanchali, 1997] 


\subsection{OXIDE LOSS}

\subsubsection{Effect of Velocity.}

The velocity range considered is $0-100 \mathrm{~m} / \mathrm{sec}$, typical for Jet engine applications. A plot of volume loss against velocity is shown in Fig. 4.2. The volume loss varies nonlinearly from $0-20 \mathrm{~m} / \mathrm{sec}$. It then increases linearly to about $60-70 \mathrm{~m} / \mathrm{sec}$ and after this was still linear but with a reduced slope. Veluswamy [1994] in his work had also observed a similar trend. It was observed, for a velocity range of $0-100 \mathrm{~m} / \mathrm{sec}$, the rebound energy was between $27-37 \%$. A plot of erodent velocity for some cases is shown in Fig. 4.3. As discussed in the literature review, Hutchings in his energy balance for single particle impact, Fig. 2.4. had estimated that after impact the erodent to have about $10 \%$ of the initial kinetic energy of the erodent The high rebound energy in this study can be explained by the fact that the oxide layer is brittle, and cannot absorb much energy in the plastic range and hence results in more rebound energy.

\subsubsection{Effect of Angle of Attack}

The angle of attack was varied from 0-90 deg. The oxide is brittle in nature at $570^{\circ} \mathrm{C}$ as mentioned earlier. Von-Mises stress contours at various time steps are shown in Fig. 4.4 and 4.5 for $10 \mathrm{deg}$ and $40 \mathrm{deg}$ angles of attack, respectively. The failure zone is shown red in color. The failure region for $40 \mathrm{deg}$ angle of attack is more than at $20 \mathrm{deg}$. A plot of volume loss vs angle of attack is shown Fig. 4.6. The volume loss is maximum 
at 90 deg impact. This is typical of brittle materials as mentioned in the literature review. The volume loss curve is nonlinear from 0-90 deg.

\subsubsection{Effect of Size of Erodent}

Erodent sizes from 20-120 $\mu \mathrm{m}$ were considered. The plot of volume loss vs erodent diameter is shown in Fig. 4.7. The volume loss increased nonlinearly up to $40 \mu \mathrm{m}$ and then it increased linearly up to $120 \mu \mathrm{m}$. Veluswamy [1994] observed a similar trend [Fig.2.3]. The temperature was $743^{\circ} \mathrm{C}$ and velocity was $10 \mathrm{~m} / \mathrm{sec}$. He observed a nonlinear increase up to particle diameter of $240 \mu \mathrm{m}$ and then it varied linearly upto $400 \mu \mathrm{m}$. The oxide thickness at $570^{\circ} \mathrm{C}$ is $36 \mu \mathrm{m}$ and at $743^{\circ} \mathrm{C}$ it is $206 \mu \mathrm{m}$. The volume loss tends to increase non-linearly till the failure region reaches the metal surface in the direction of loading. After that it varies linearly, as the failure region extends radially outwards since there is no oxide available in the direction of loading.

\subsubsection{Effect of impact near a previously impacted zone}

The erodent size considered for this normal impact analysis is $40 \mu \mathrm{m}$. Two different velocities are considered, 20 and $25 \mathrm{~m} / \mathrm{sec}$. Von-Mises stress contour at various time steps are shown in Fig. 4.8 and 4.9 for impact at a distance of $40 \mu \mathrm{m}$ and $96 \mu \mathrm{m}$ respectively from the previous impact site. The volume loss curve is shown in Fig. 4.10. The $\mathrm{x}$-axis on the volume loss plots is the distance from the center of the previous impact. For both the velocities considered, the volume loss increased non-linearly up to certain distance and then increased linearly with a steep slope, until it reached a maximum. Beyond that point the volume loss remained at a constant level. This level is equal to the 
loss due to an isolated impact. For a velocity of $25 \mathrm{~m} / \mathrm{sec}$, the volume loss reached as that of an isolated impact, at a distance $80-90 \mu \mathrm{m}$ from the center of previous impact site. Beyond this distance, previous impact does not effect the volume loss. For the case of 20 $\mathrm{m} / \mathrm{sec}$ velocity, this distance is between 70 and $80 \mu \mathrm{m}$. This is because the zone of influence at a lower velocity is also low. The behavior of the volume loss with distance was very identical except for the magnitude of volume loss. Figure. 4.8 shows that the effect of the previous impact site is not affecting the stress distribution and therefore equivalent to an isolated impact.

\subsubsection{Effect of two simultaneous normal impacts}

The diameter of the erodent is $40 \mu \mathrm{m}$ and the velocity is $15 \mathrm{~m} / \mathrm{sec}$. The two erodents are placed side by side to start with and then the distance between the erodents is increased in steps of $4 \mu \mathrm{m}$. The Von-Mises stress contours are shown in Fig. 4.11 - 4.12 for distance between erodents of zero, 24 and $52 \mu \mathrm{m}$, respectively. The failure region changed from one common zone to two separate zones as the distance is increased. The volume loss curve is shown in Fig. 4.14. The volume loss after about a distance of $30 \mu \mathrm{m}$ resulted in as that of two isolated impacts. But the variation in volume loss is within $10 \%$. 


\section{Volume Loss vs Velocity}

Diameter of Erodent $=\mathbf{4 0}$ micrometer, Normal Impact

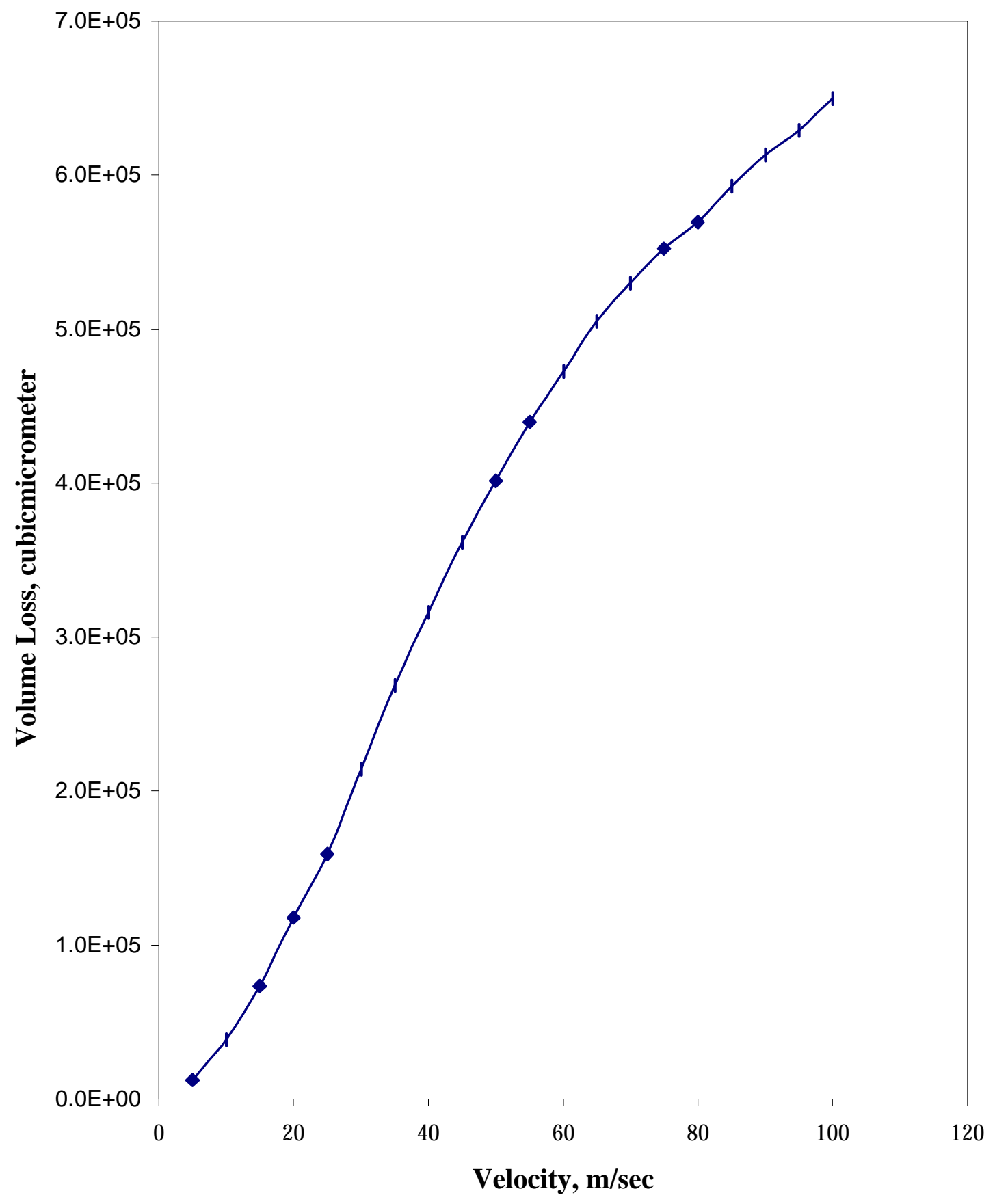

Fig. 4.2 Volume loss per impact for velocity range of $0-100 \mathrm{~m} / \mathrm{sec}$ 
Velocity of Erodent For Normal Impact

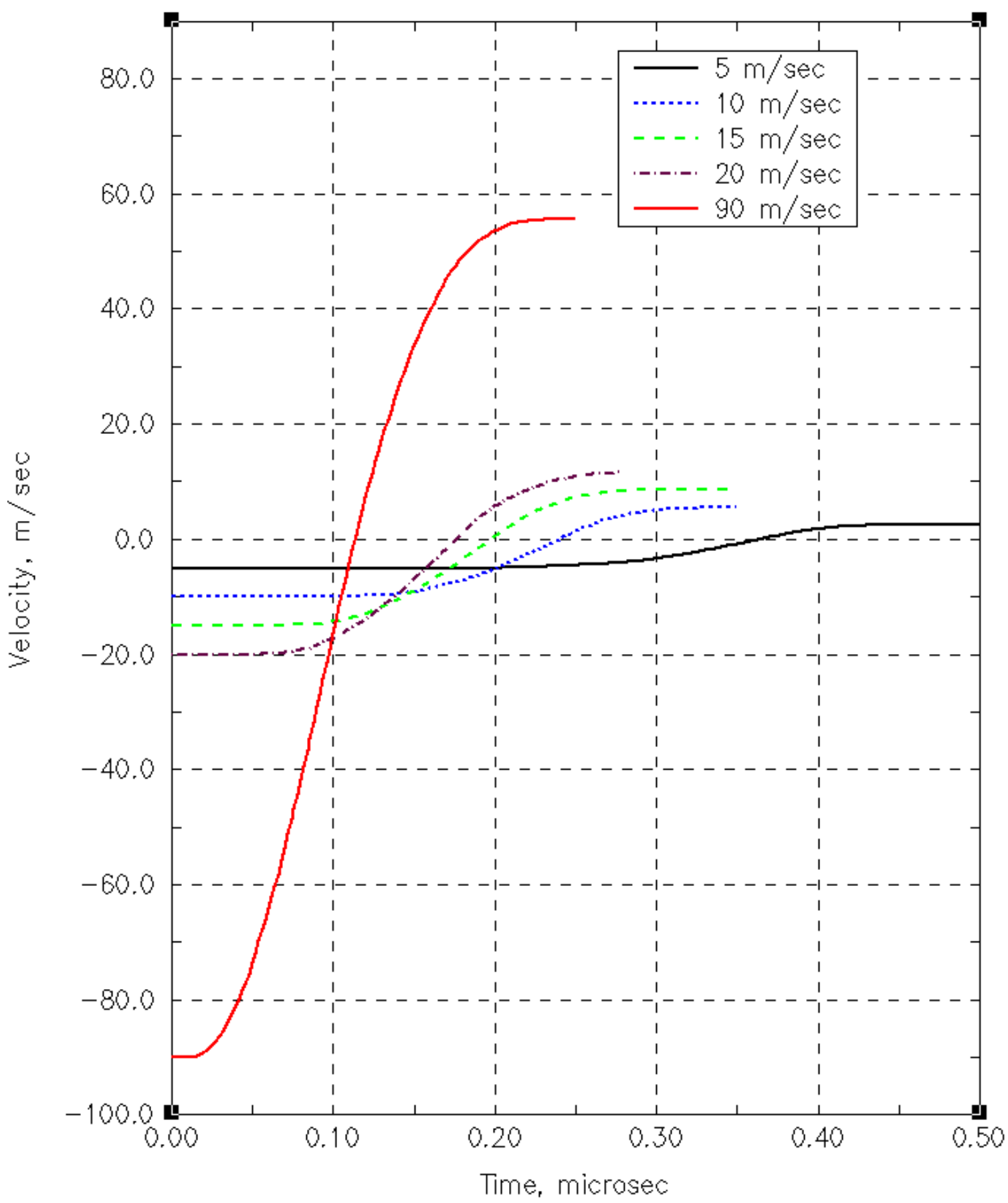

Fig. 4.3 Erodent velocity for few normal impact cases. 


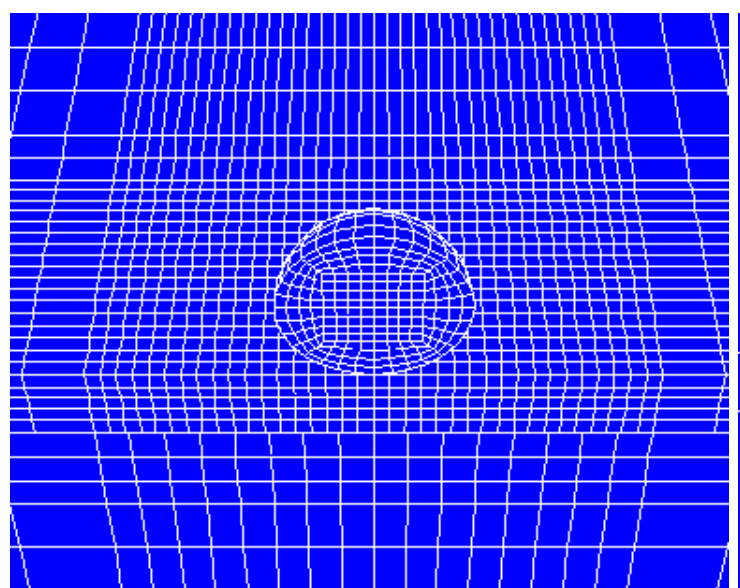

Time $=0.0$ microsec

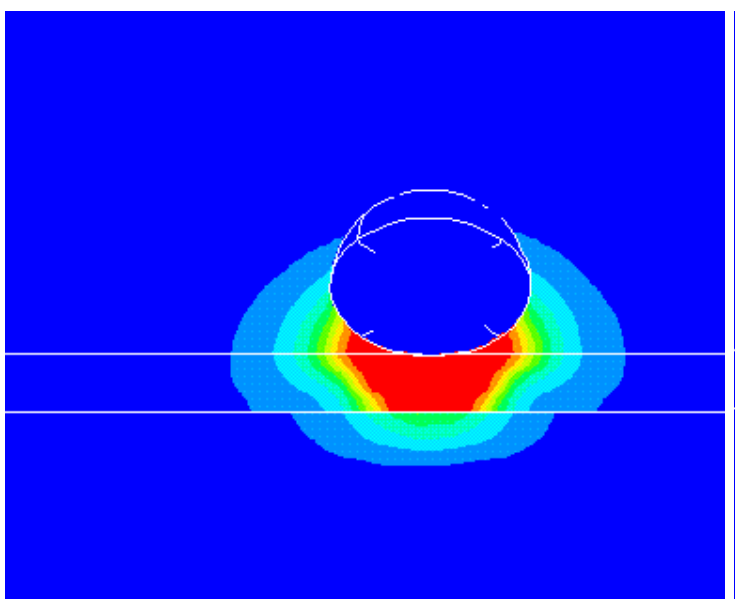

Time $=0.17988$ microsec

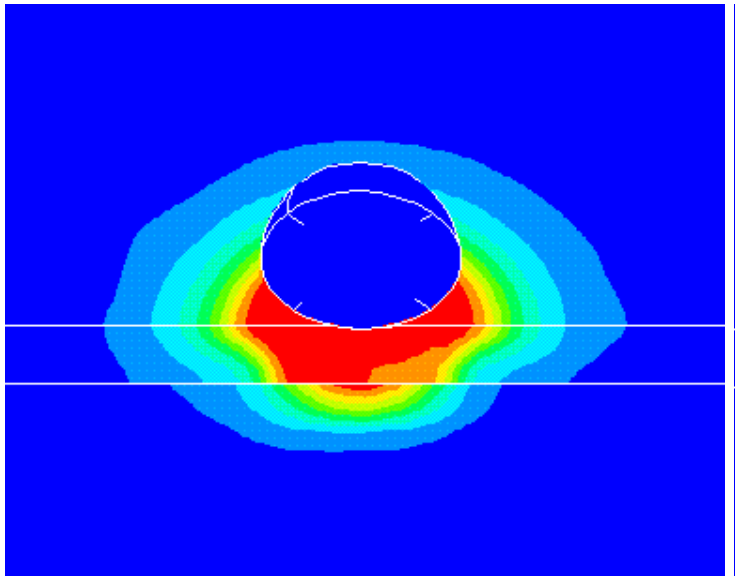

Time $=0.31957$ microsec

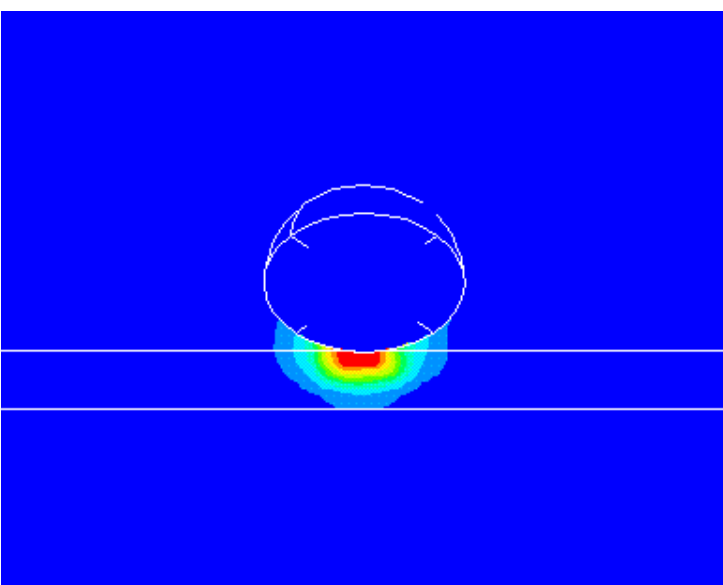

Time $=0.09927$ microsec

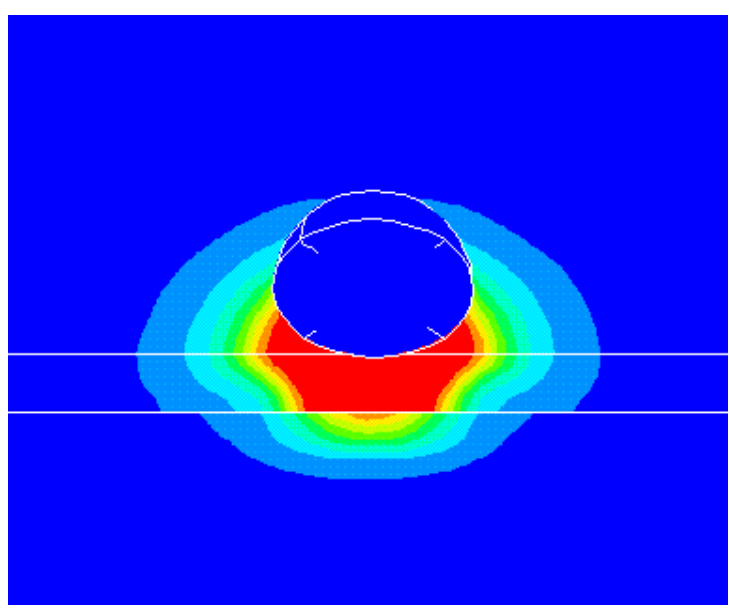

Time $=0.23949$ microsec

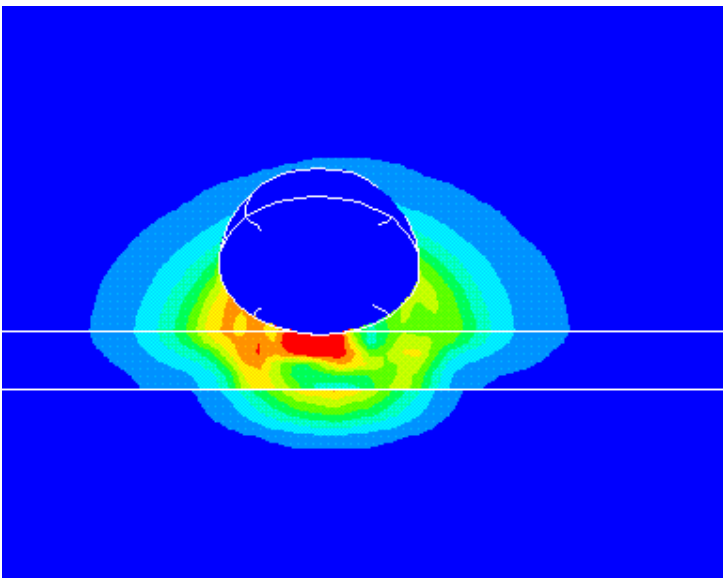

Time $=0.419886$ microsec

Fig. 4.4 Contour of Von-Mises stress for a 10 deg angular impact 


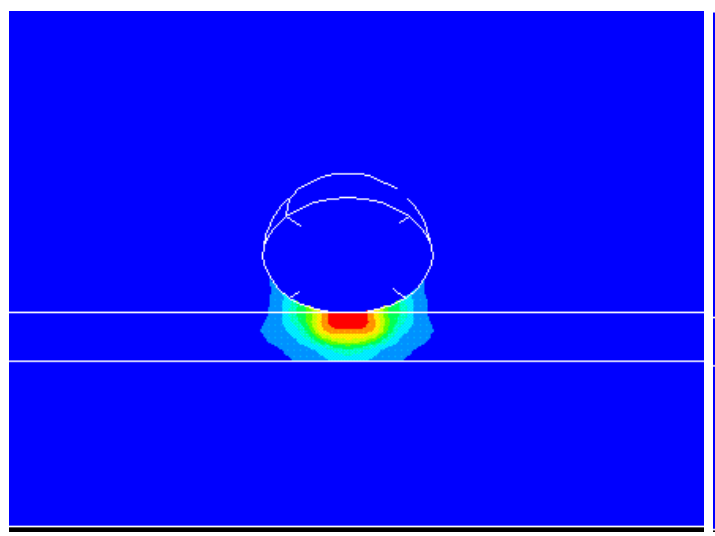

Time $=0.0196$ microsec

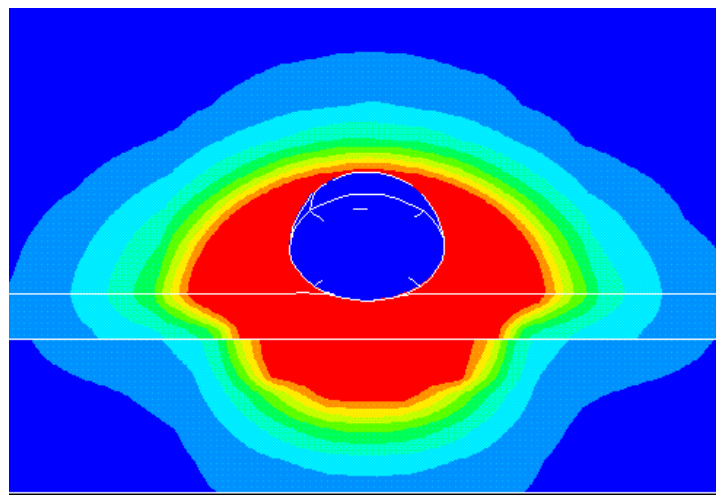

Time $=0.1799$ microsec

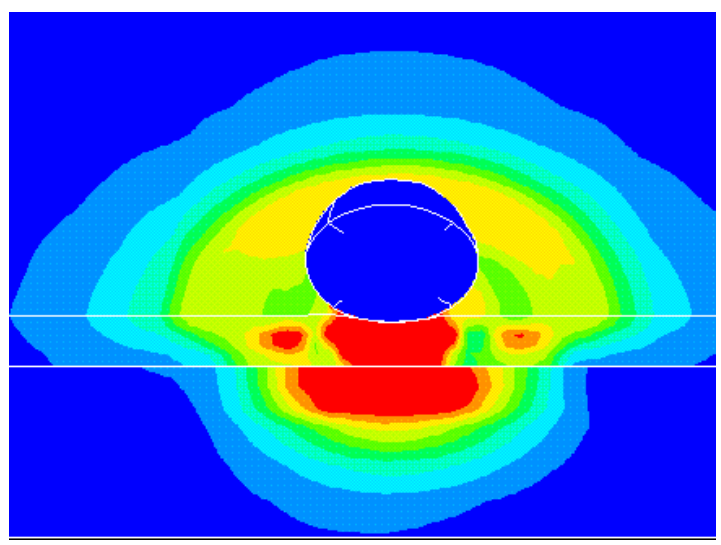

Time $=0.29938$ microsec

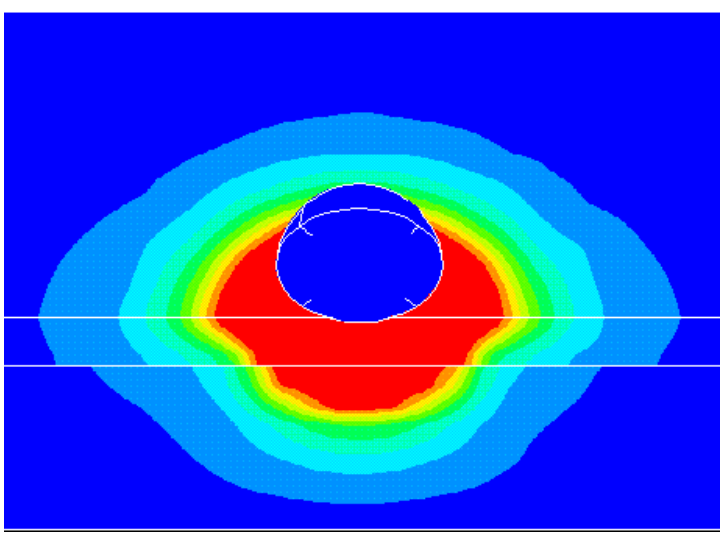

Time $=0.09946$ microsec

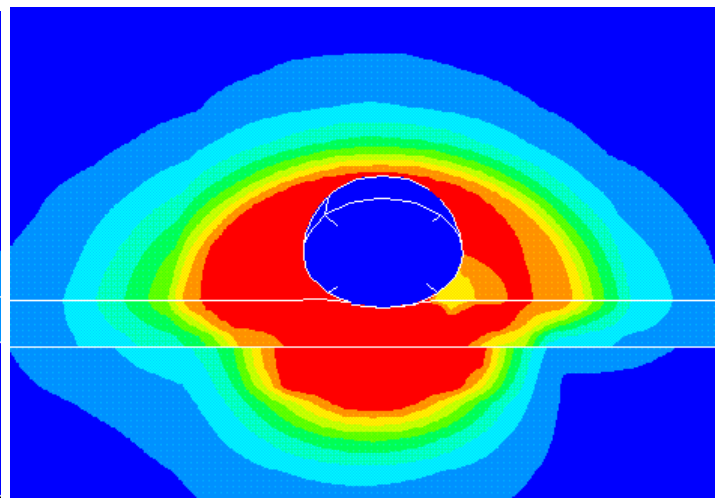

Time $=0.2599$ microsec

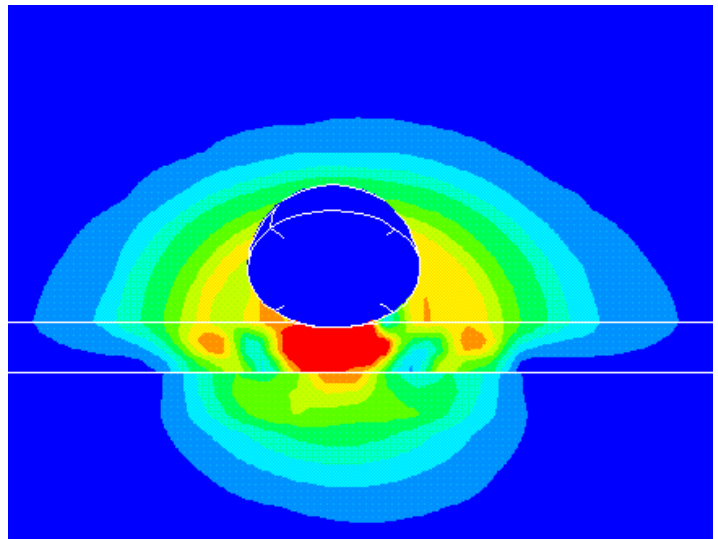

Time $=0.035$ microsec

Fig. 4.5 Contour of Von-Mises stress for a 40 deg angular impact 
Volume Loss vs Angle of Impact

Diameter $=80$ micrometer, Velocity $=50 \mathrm{~m} / \mathrm{sec}$

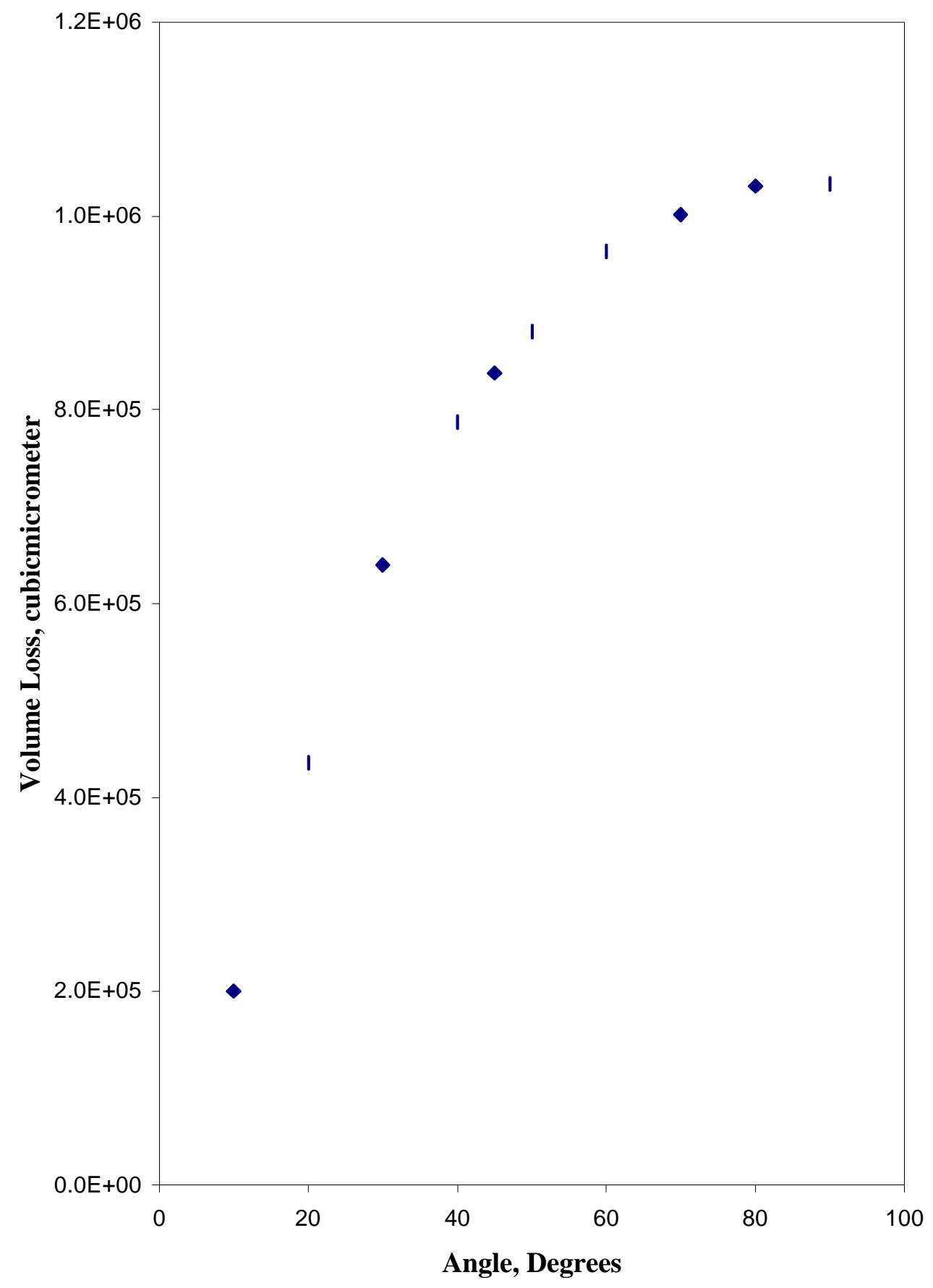

Fig. 4.6 Volume loss per impact for angle of attack from 0-90 deg. 


\section{Volume Loss vs Erodent Size}

Velocity $=25 \mathrm{~m} / \mathrm{sec}$, Normal Impact

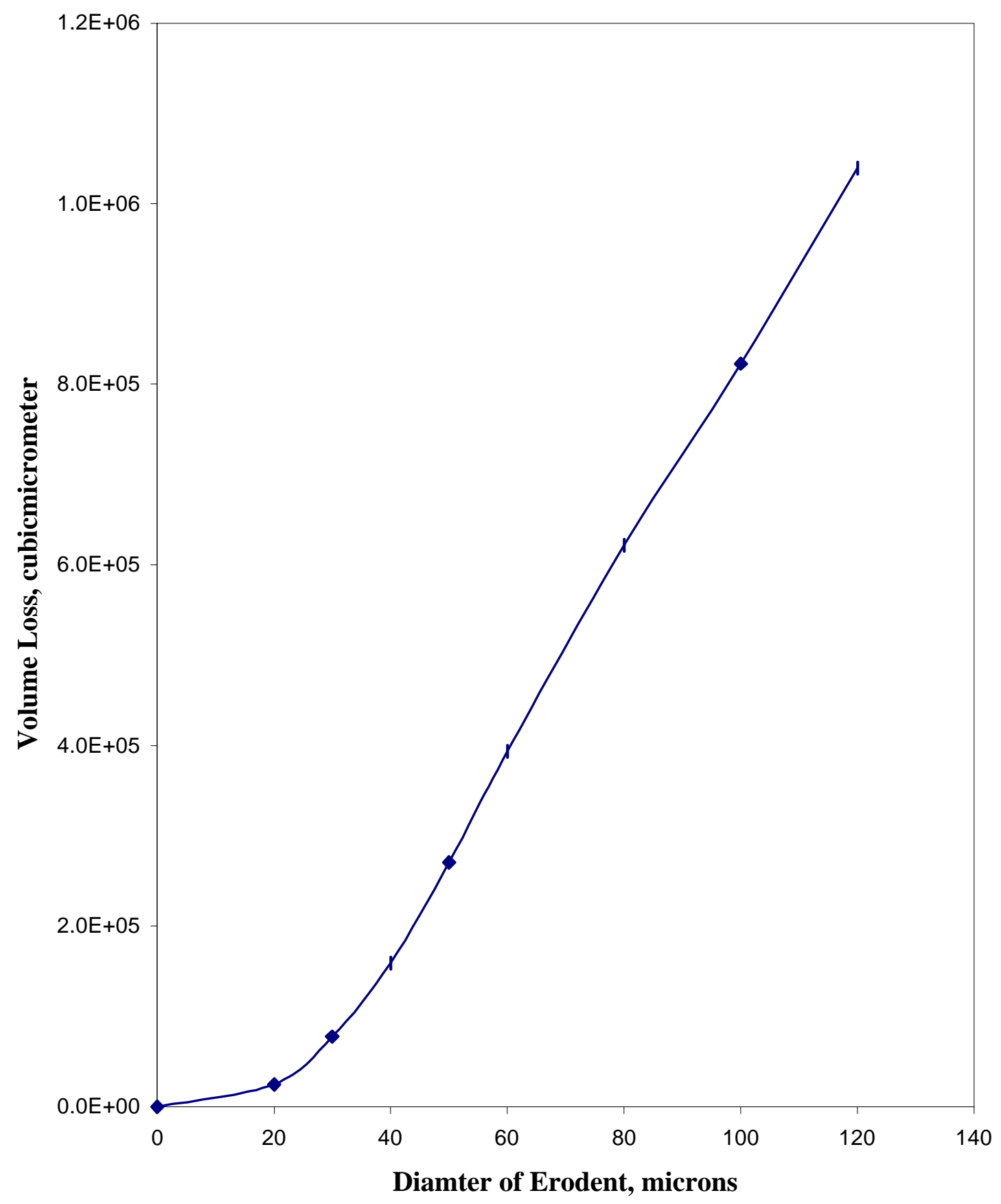

Fig. 4.7 Volume loss per impact at $25 \mathrm{~m} / \mathrm{sec}$ against various sizes of erodent. 


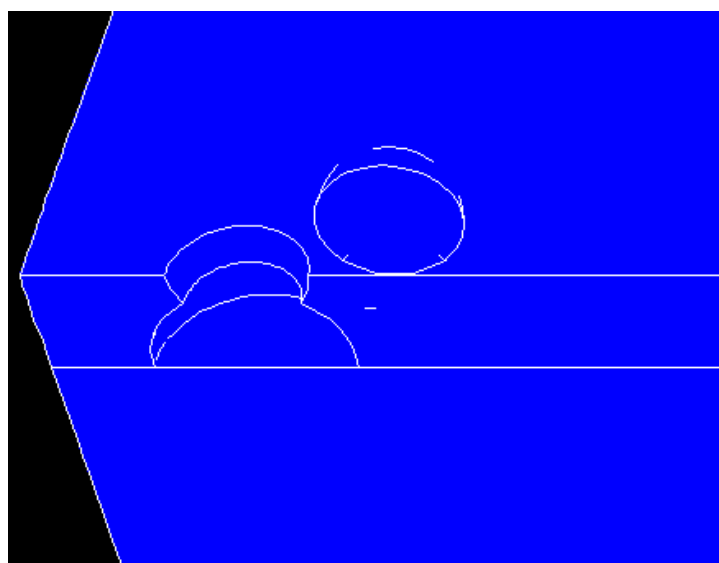

Time $=0.0$ microsec

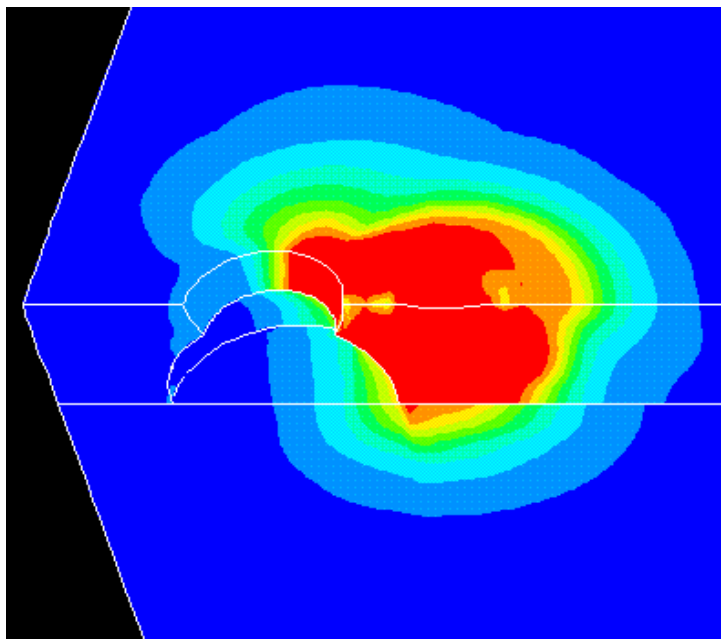

Time $=.0798$ microsec

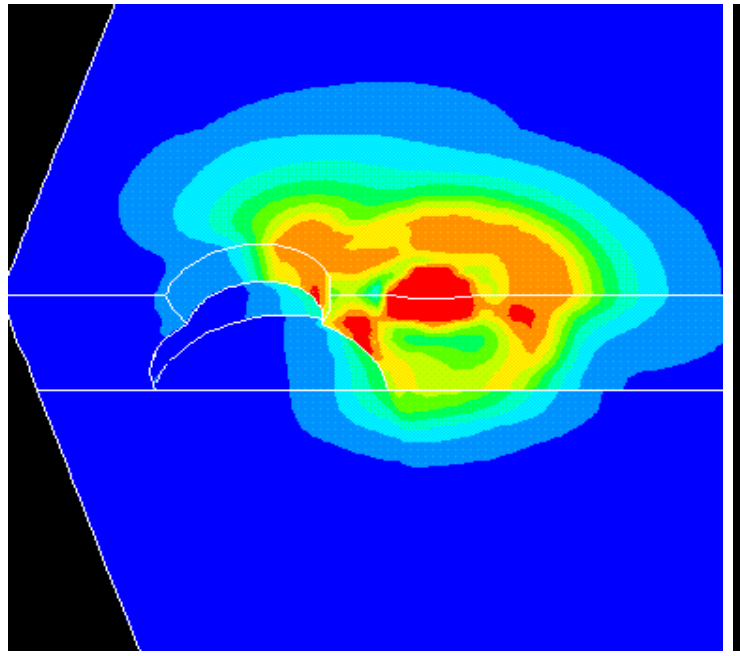

Time $=0.1799$ microsec

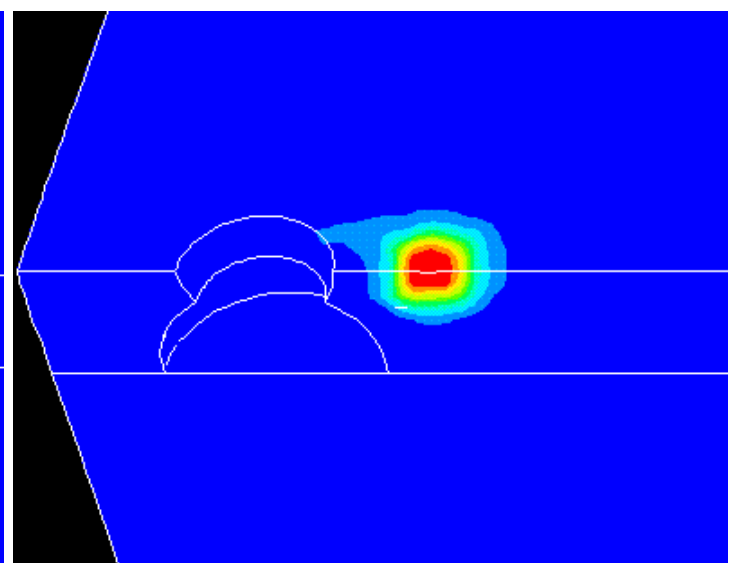

Time $=.0399$ microsec

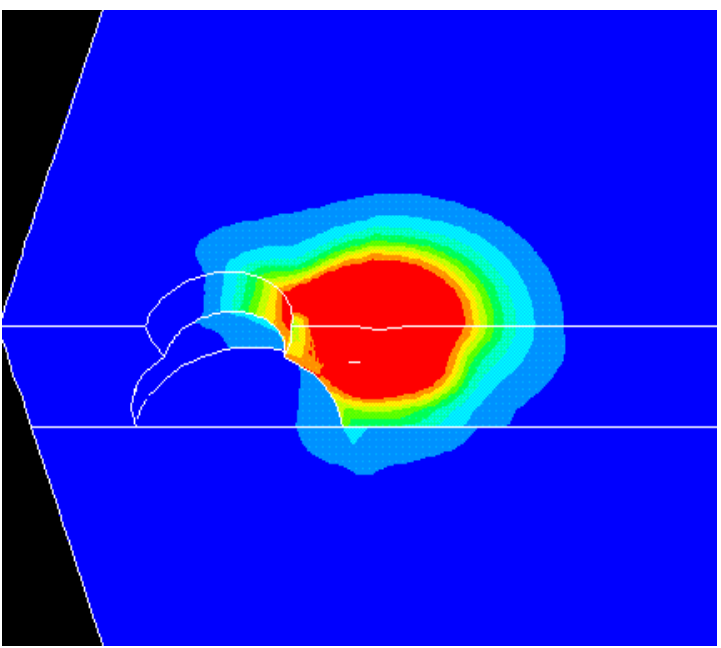

Time $=0.1399$ microsec

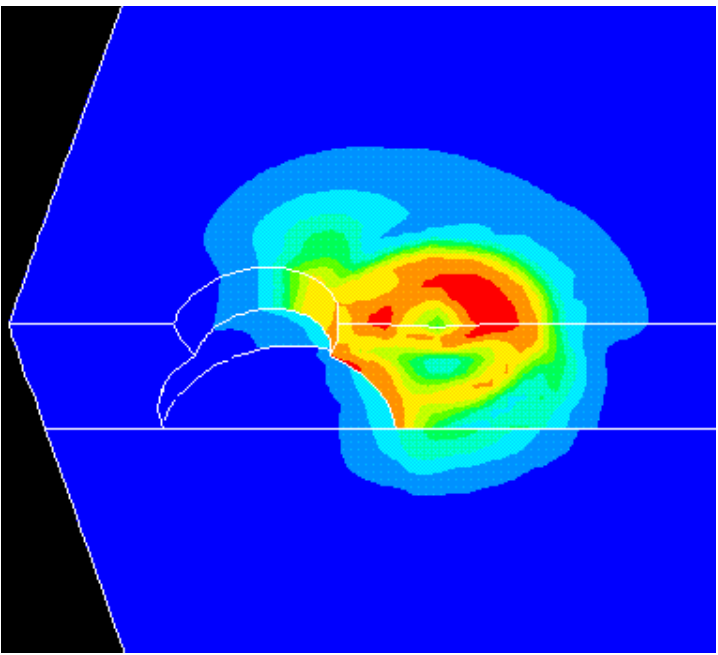

Time $=0.3$ microsec

Fig. 4.8 Contour of Von-Mises stress for an impact at a distance of $44 \mu \mathrm{m}$ from previous impact site 

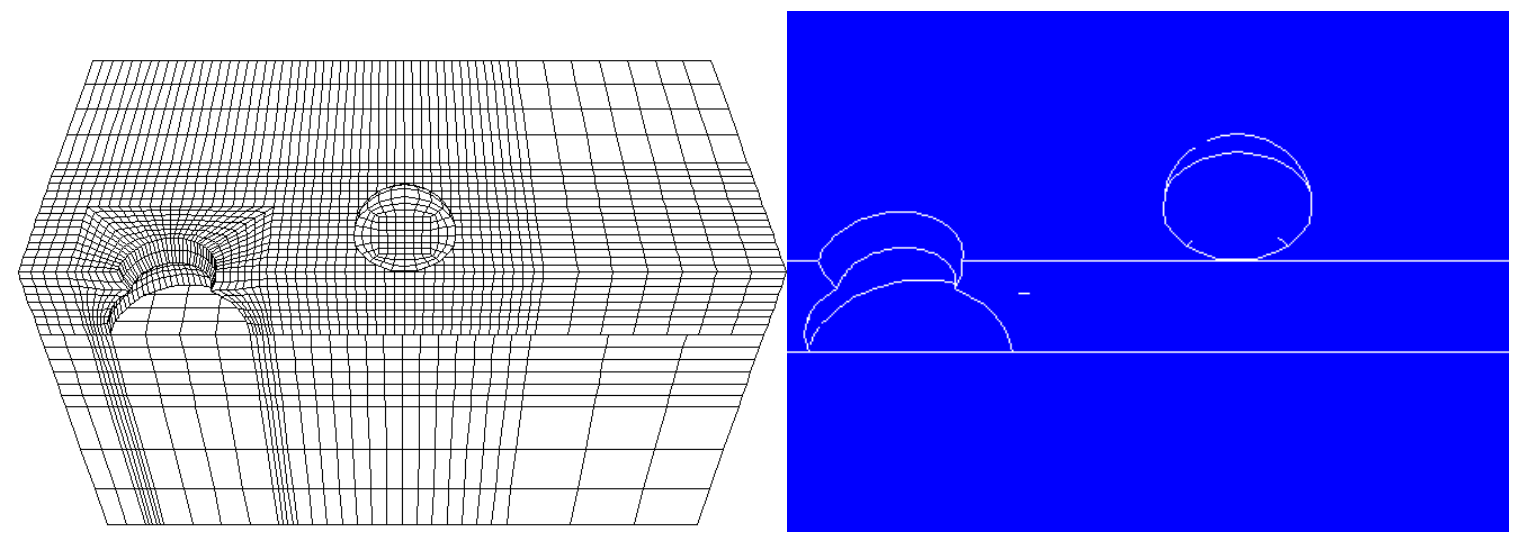

Time $=0.0$ nicrosec
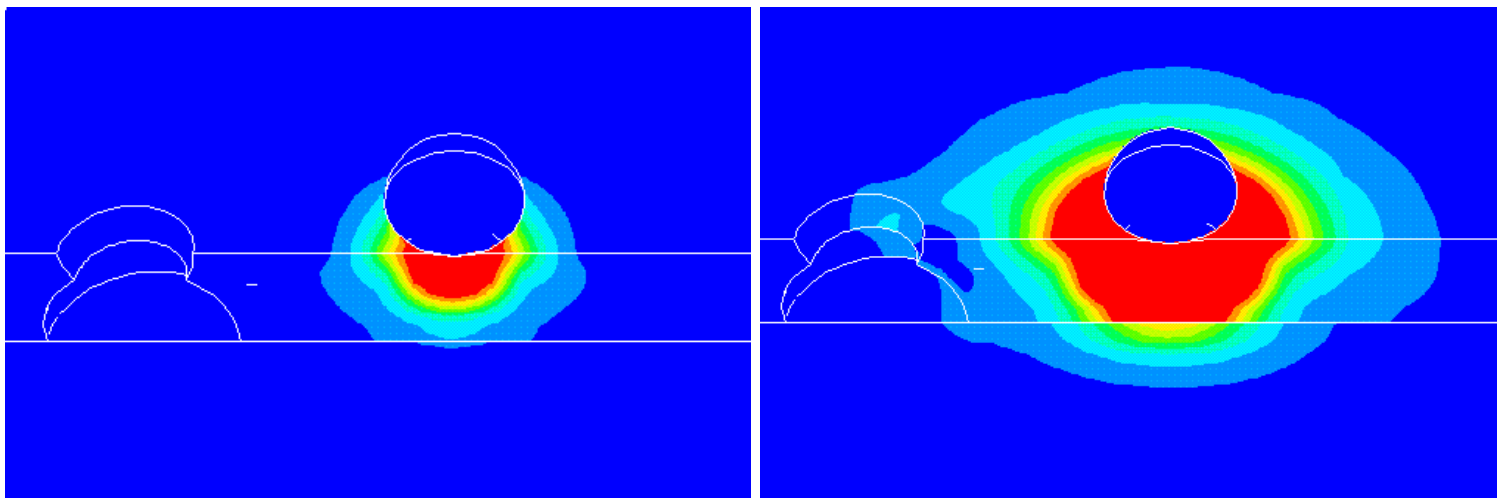

Time $=0.059947$ microsec

Time $=.119848$ microsec
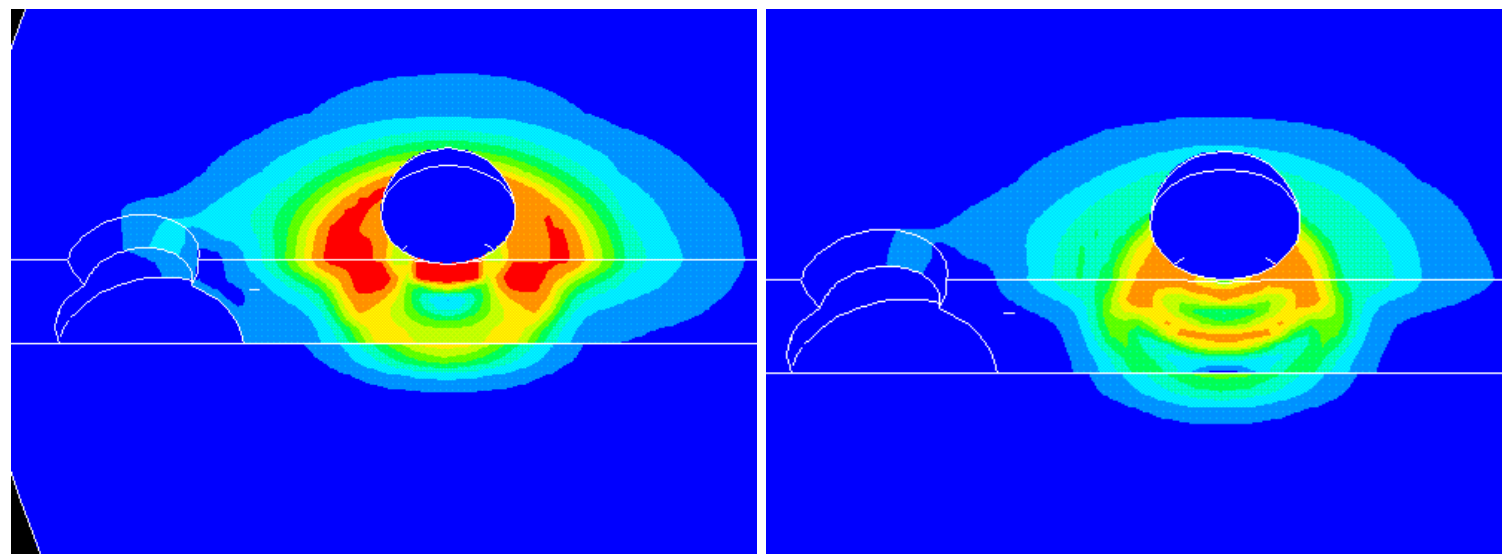

Time $=.1799$ microsec

Time $=.35$ microsec

Fig. 4.9 Contour of Von-Mises stress for an impact at a distance of $96 \mu \mathrm{m}$ from previous impact site 
Volume Loss vs Distance

Angle of Impact $=90$ degrees and Diameter $=40$ micrometer

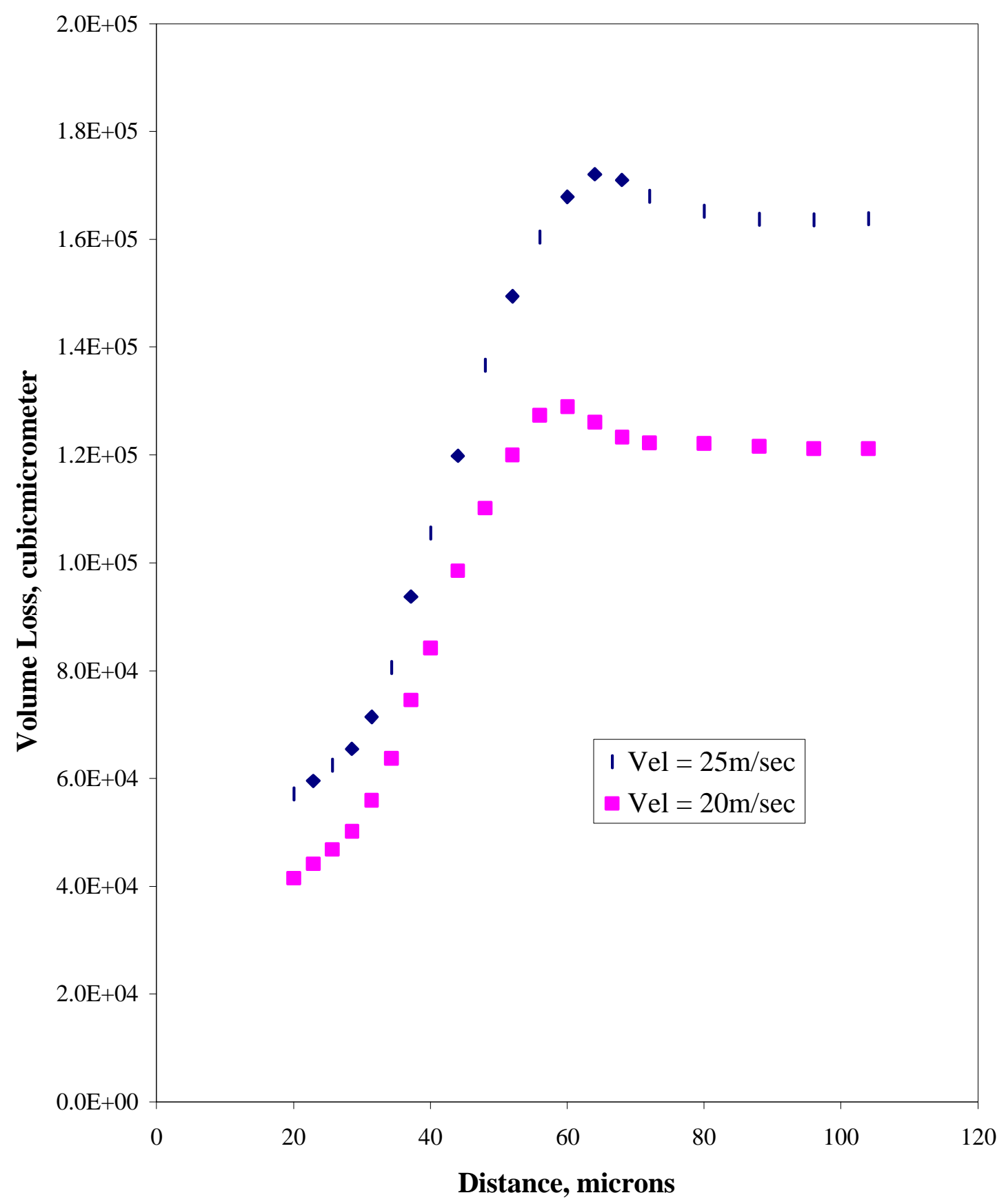

Fig. 4.10 Volume loss per impact against distance from previous impact site. 


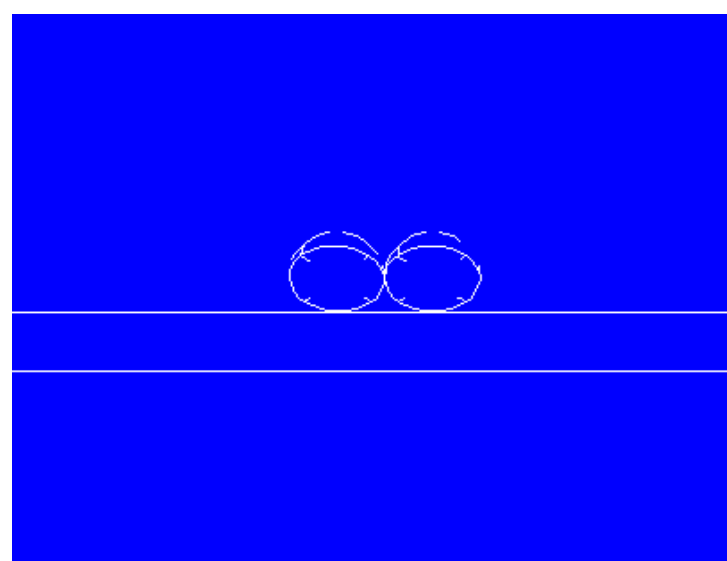

Time $=0.0$ microsec

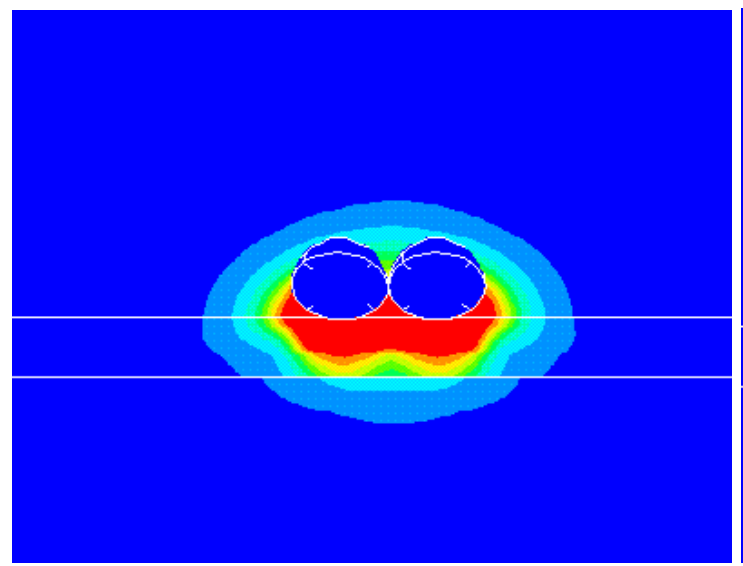

Time $=0.1399$ microsec

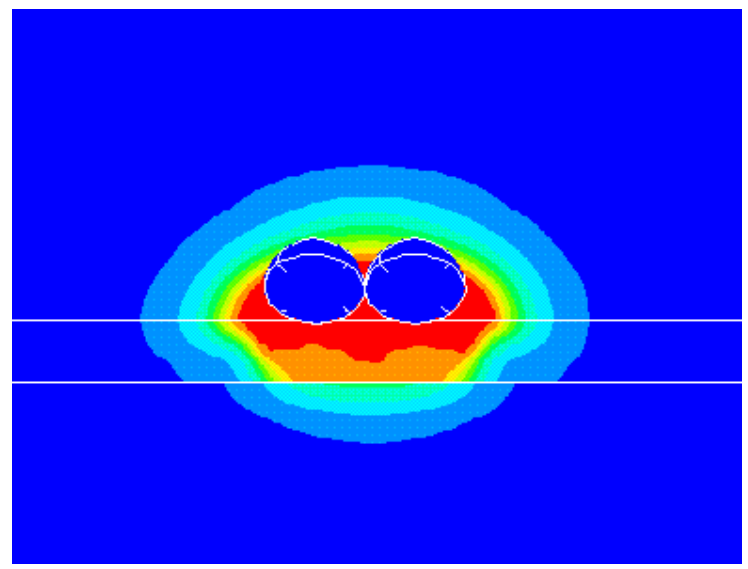

Time $=0.21989$ microsec

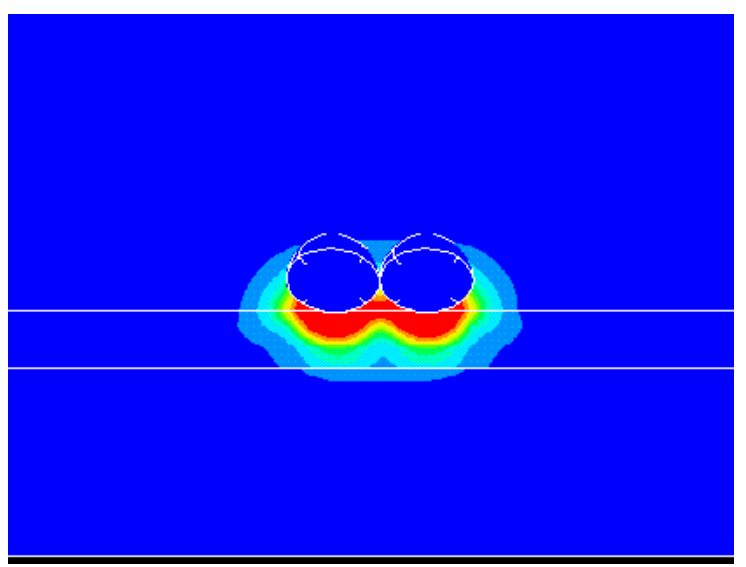

Time $=0.1198$ microsec

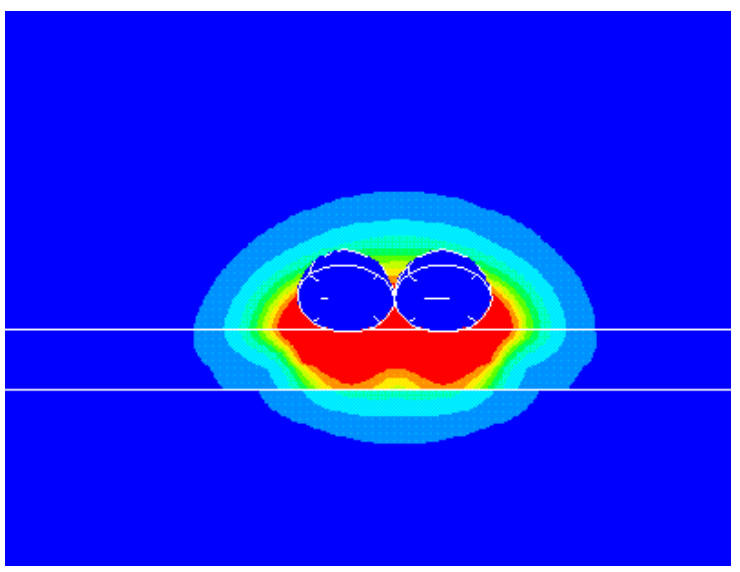

Time $=0.15997$ microsec

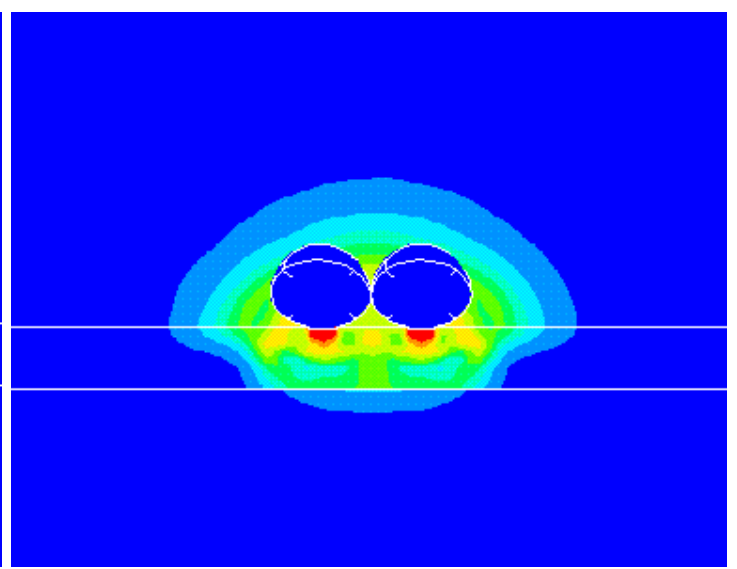

Time $=0.2799$ microsec

Fig. 4.11 Contour of Von-Mises stress for two particle impact at zero distance apart. 


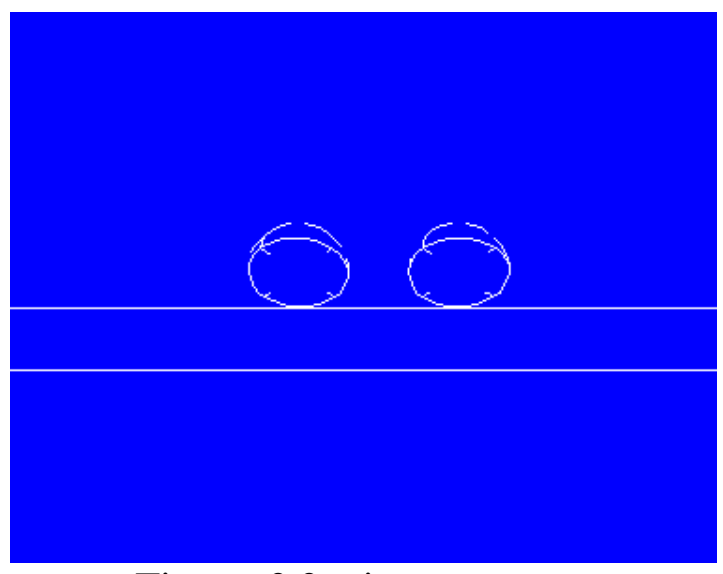

Time $=0.0$ microsec

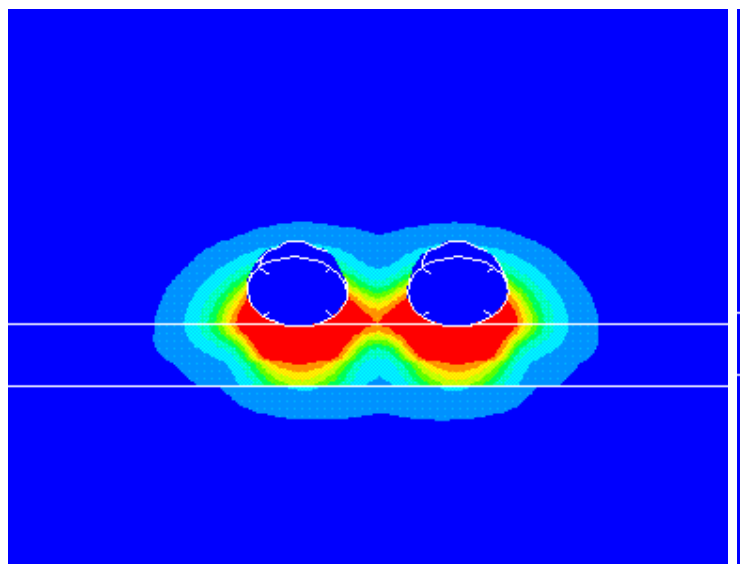

Time $=0.1399$ microsec

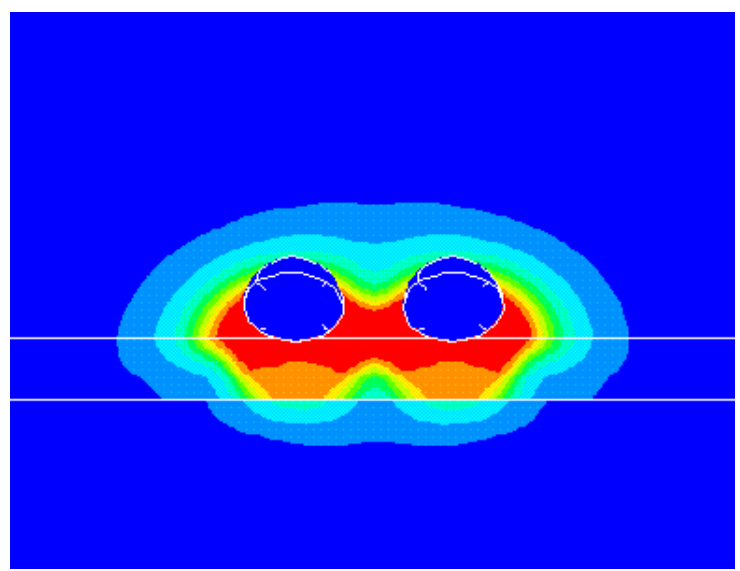

Time $=0.2399$ microsec

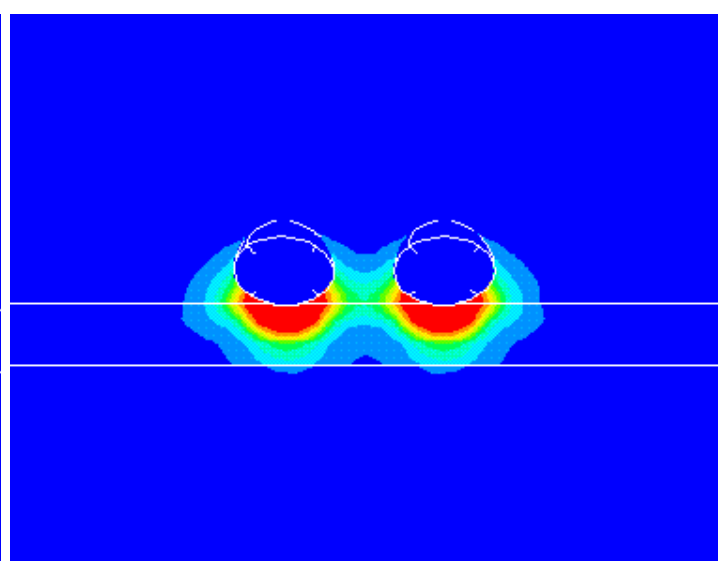

Time $=0.11985$ microsec

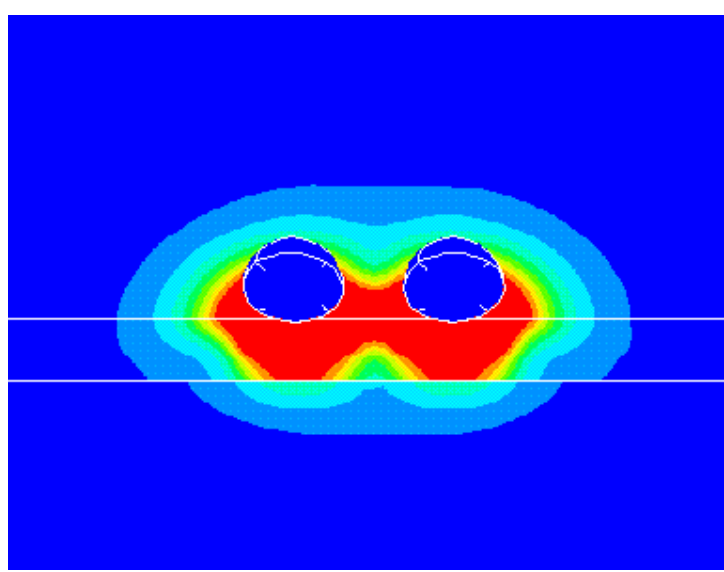

Time $=0.1998$ microsec

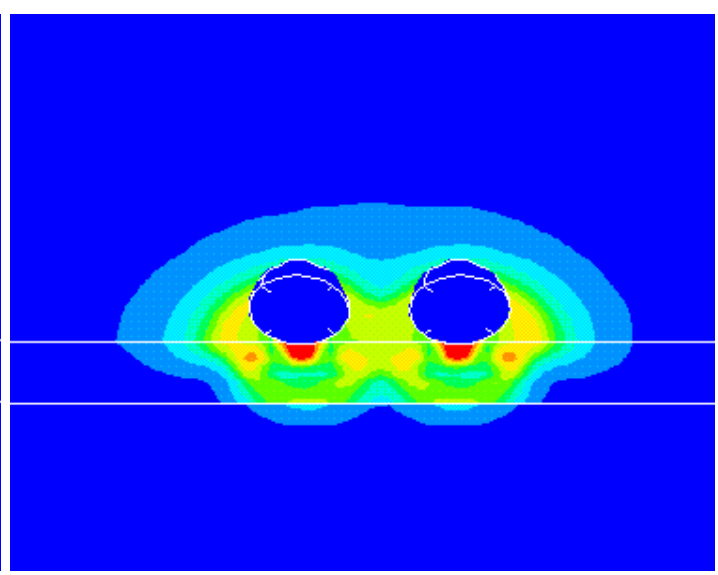

Time $=0.25986$ microsec

Fig. 4.12 Contour of Von-Mises stress for two particle impact at 24 micrometers apart. 


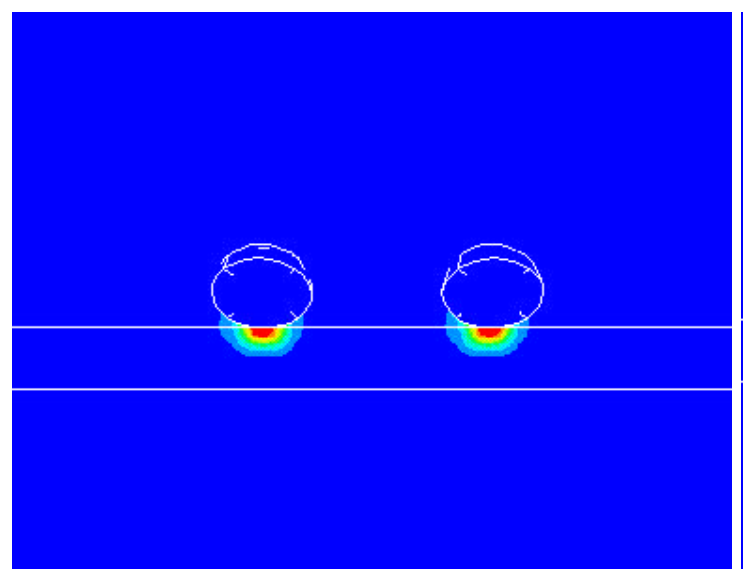

Time $=0.0$ microsec

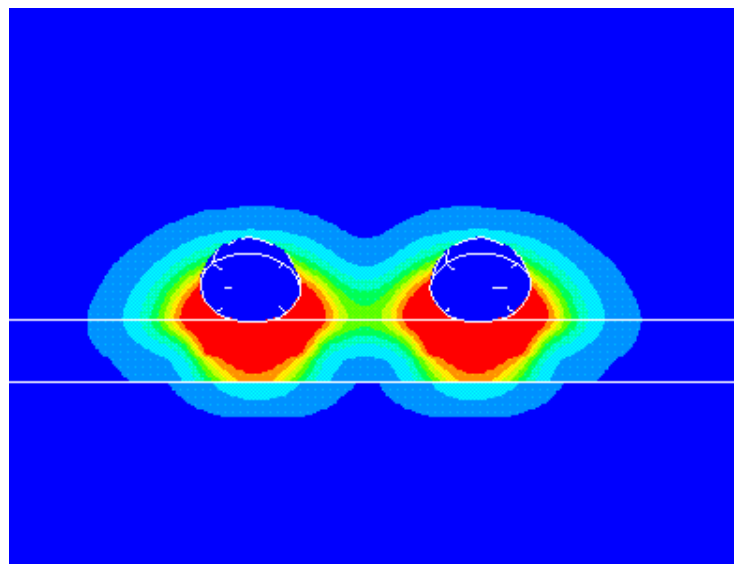

Time $=0.1399$ microsec

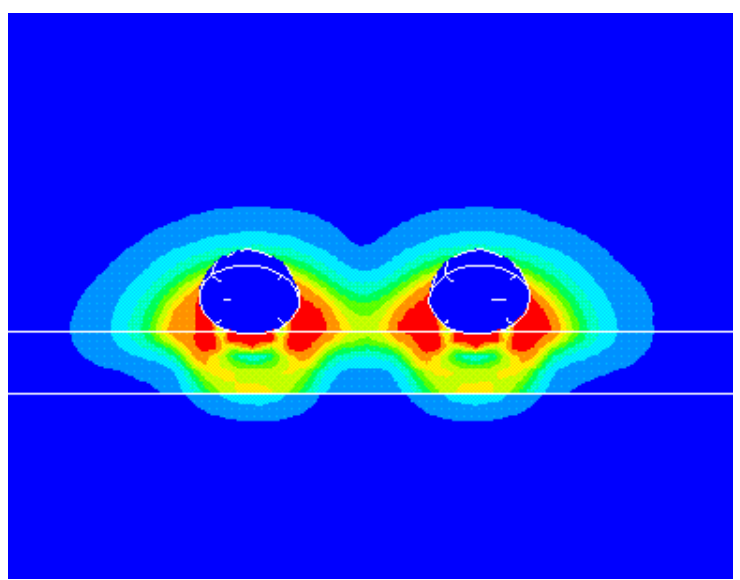

Time $=0.2399$ microsec

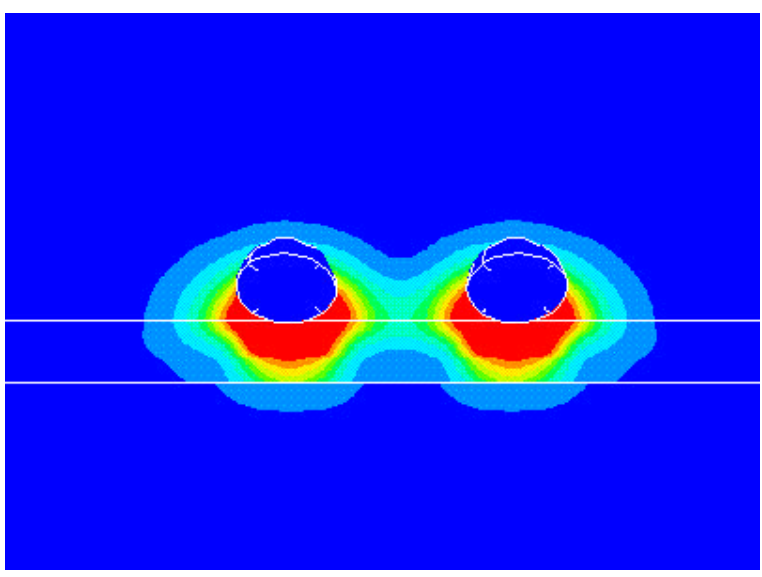

Time $=0.11985$ microsec

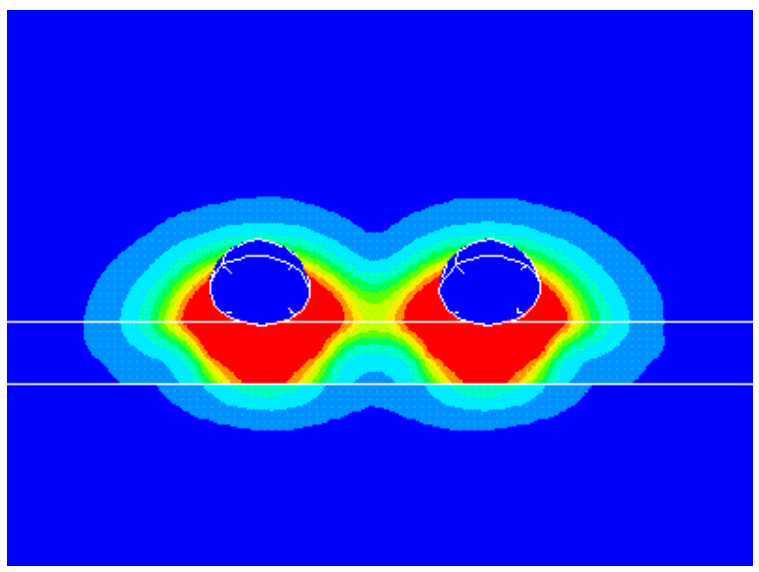

Time $=0.1998$ microsec

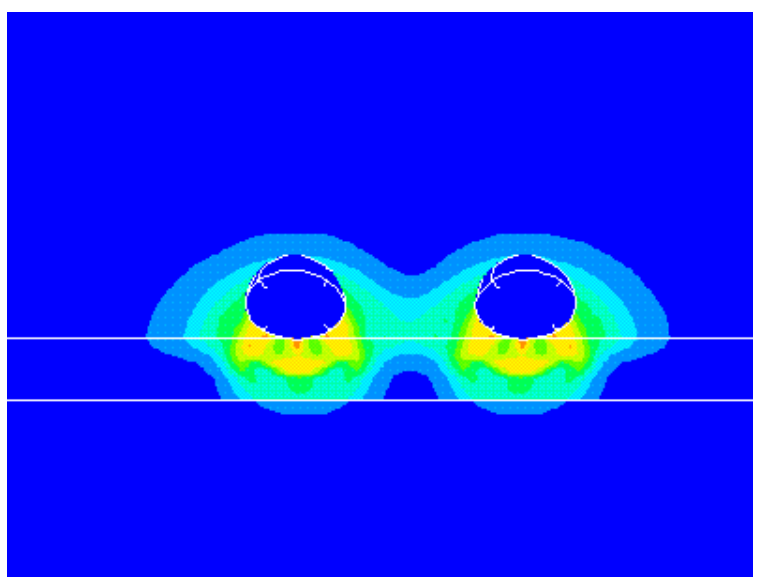

Time $=0.25986$ microsec

Fig. 4.13 Contour of Von-Mises stress for two particle impact at 52 micrometers apart. 


\section{Volume Loss vs Distance Between Erodents}

Erodent Diameter $=40$ micrometer $:$ Velocity $=15 \mathrm{~m} / \mathrm{sec}$

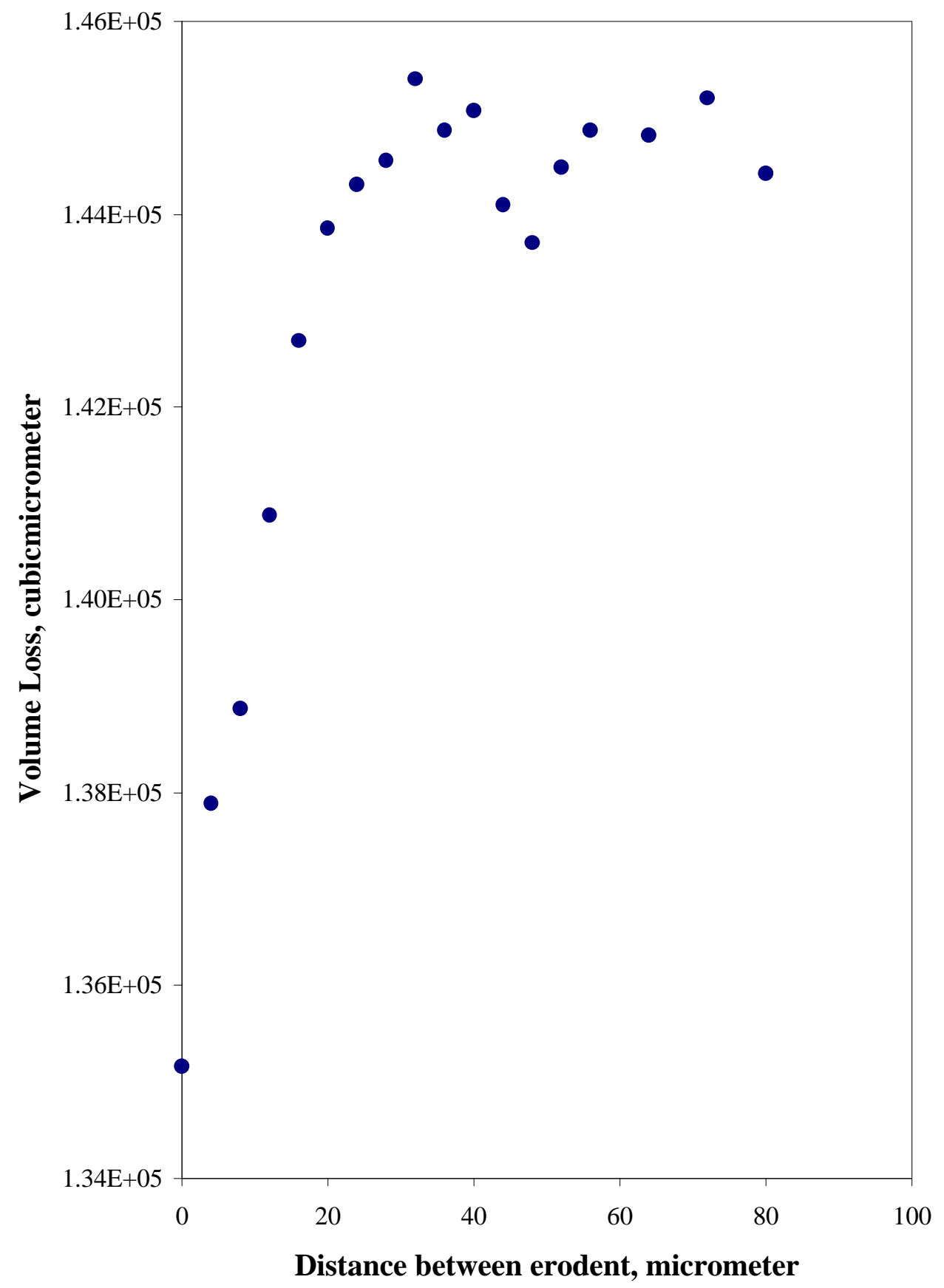

Fig. 4.14 Volume loss due to two particle impact against distance between particles 


\section{CONCLUSIONS AND RECOMMENDATIONS}

\subsection{CONCLUSIONS}

Since there are no experimental data for erosion of iron/iron-oxide system, the results from this study could not be quantified.

The volume loss vs velocity of erodent curve shows three different ranges of oxide loss as was observed by Veluswamy [1994]. They are

- Nonlinear initial range

- Critical linear range

- Reduced-slope linear range

The initial nonlinearity in the volume loss curve is observed for changes in both the velocity and the size of the erodent. In the nonlinear range the failure zone is within the oxide layer. The failure region grows both in the loading direction and also transverse direction. As the failure region approaches the metal interface, it grows only in the transverse direction. The volume loss varies linearly in this range

The angle of attack study shows that volume loss is that of a typical brittle impact as observed by many researchers. Erosion is maximum for normal impact. The volume loss varies nonlinearly with increasing angle of attack and is maximum at 90 deg impact i.e., normal impact. 
The effect of size on erosion is that the volume loss increases nonlinearly with increase in size until the failure region reaches the metal interface, and after which it increases linearly.

For impacts in the neighborhood of previous impact zone, there is a critical distance for volume loss to be equal to an isolated impact.

For two particle impacts, in this work, it is observed that the distance between the erodents does not affect erosion significantly. The variation is within $10 \%$ as that of two isolated impacts.

\subsection{CONTRIBUTIONS}

The main contributions from this work are

- Development of a computational model for multi particle impact and impact in the neighborhood of previous impact site.

- Understanding the effect of impact in the neighborhood of previous impact case

- Failure criteria is based on critical plastic strain than stress, which also simplifies the estimation of material loss by using a built in command of post-processing software LS-TAURUS.

\subsection{RECOMMENDATIONS FOR FUTURE WORK}

- Perfect bonding is assumed for the interface between iron and iron-oxide. For oxide spallation failure properties of the interface have to be defined and studied. 
- In the current work for the case of impact in the neighborhood of previous impact site, the geometry of the mesh defining the failure zone from the first impact did not correspond to the failure zone as that of the next impact. To get a better understanding, the geometry defining the material loss from the first impact should be close to the failure zone due to next impact.

- Some more cases have to be run with various velocities and sizes of erodent to see if the volume loss due to two simultaneous impacts is always nearly equal to two isolated impacts.

- Validation with experimental results. 


\section{REFERENCES}

1. ASM Metals Handbook, 1990, Ninth Edition, Vol. 1, Properties and Selection, pp. 639-663

2. Bahadur, S. and Badruddin, R., "Erodent Particle Characterization and the Effect of Particle Size and Shape and Erosion," Proceedings of International Conference on Wear of materials, ASME, 1989, pp. 143-153.

3. Bellman, R. and Levy, A. V., 1980, LBL Rep. 10289, (Lawrence Berkeley Laboratory, Univ. of California.

4. Bitter, J. G. A., “A Study of Erosion Phenomena,” Part I and Part II, Wear, 1963, Vol. 6, pp. 5-21 and pp. 169-190

5. Brown, R., Jin Jun E., and Edington, J. W., "Mechanisms of Erosive Wear for $90^{\circ}$ Impact on Copper and Iron Targets," Proceedings of International Conference on Wear of Materials, 1981, ASME, pp. 583-591.

6. Bruce, D. and Hancock, P., "Influence of Mechanical Properties of Surface Oxide Films on Oxidation Mechanisms I and II," Journal of the Institute of Metals, 1969, Vol. 97, pp. 140-155.

7. Christon, A. Mark, Donald Dovey, "INGRID, A 3-D Mesh Generator of Modeling Non-Linear Systems," User's Manual, Lawrence Livermore National Laboratory, Sep 1992.

8. Deffenbaugh, D. M., Wei, W. and Page, R. A., "Effect of Operating and Design Parameters on Fluidized-Bed Combustor In-Bed Tube Metal Wastage," Final Report, 1988, Doe/MC/22077-2774, DE90000436, 96 pp. 
9. Duke, G. A., "Erosion Test on a Modified Rover Gas Turbine," Australian Defense Scientific Service," Aeronautical Research Laboratories, Note No. ARL/ME297, 1968.

10. Evans, A. G., and Wilshaw, T. R., Journal of Material Science. 1977, 12, pp. 97-116.

11. Evans, A. G., Gulden, M. E., and Rosenblatt, M. E., Proc. R. Soc. London Ser., 1978, A 361, pp. 343-365.

12. Fellar, W., "An Introduction to probability Theory and its Applications”, 1968, Vol. 1, Willey, New York.

13. Finnie, I., "The Mechanism of Erosion in Ductile Materials," Proc. of the Third US National Congress of Applied Mechanics, Hagthormthwaite, R. M., Ed., ASME, New York, 1958, pp. 70-82.

14. Finnie, I., "Erosion of Surfaces by Solid Particles”, Wear, 1960, Vol. 3, pp. 87-103.

15. Finnie, I., "Erosion of Metals," Proc. of Conf. On Corrosion/Erosion of Coal conventional System Materials, National Association of Corrosion Engineers, 1979, pp. 429-443.

16. Finnie, I., and McFadden, D. H., Wear, 1978, Vol. 48, pp. 181-190.

17. Finnie, I., Wolak, J. and Kabil, Y., "Erosion of Metals by Solid Particles," Journal of Materials, 1967, vol. 2, No. 3, pp. 682-700.

18. Fyall. A. A. and Strain, R. N. C., "Rain Erosion Aspects of Aircraft and Guided Missiles," J. Roy. Aeron. Soc., 66, 1962, pp. 447.

19. Gane N., and Cox, J. M., “The Microhardness of Metals at Very Low Loads," Philos. Mag., 1970, Vol. 22, pp. 881-891. 
20. Goodwin, J. E., Sage, W., Tilly, G. P., "Study of Erosion by Solid Particles," Proc. of Inst. of Mech. Eng., 1969-70, Vol. 184, pp. 279-291.

21. Gulden, M. E. (1978). Proc. ASTM symp. Eros. Prevent. Useful Appl. STP 664.

22. Hallquist, J. O., "LS-DYNA3D, Theoretical Manual," Livermore Software Technology Corporation, July 1993.

23. Hallquist, J. O., “LS-TAURUS User's Manual.” Lawrence Livermore National Labs, 1995.

24. Hallquist, J. O., Stillman, W. Douglas and Lin T., "LS-DYNA3D, Nonlinear Dynamic Analysis of Structures in Three Dimensions - User's Manual," Livermore Software Technology Corporation, May 1, 1995.

25. Hancock, P., and Nicholls, J. R., "Applications of Fracture Mechanica to Failure of Surface Oxide Scales,” Material Science and Technology, 1988, Vol. 4, pp. 398-406

26. Hibbert, W. A., 1965, "Helicopter trials over sand and sea," Journal. Roy. Aeronautical Society, 69 (659).

27. Hockey, B. J., Wiederhorn, S. M. and Johnson, H., "Erosion of Brittle Materials by Solid Particle Impact, Fracture Mechanics of Ceramics," Proc. of Intl. Sym. Of Frac. Mech. of Ceramics, 1978, Vol. 3, pp. 379-402.

28. Hogmark, S., Hammersten, A., and Soderberg, S., "On the Combined Effects of Corrosion and Erosion," Proceedings of the $6^{\text {th }}$ International Conference on Erosion by Liquid and Solid Impact, 1983, University of Cambridge, pp. 37-1 thro' 37-8.

29. Hutchings, I. M., 1977, Int. J. Mech. Sci. 19, pp. 45-52.

30. Hutchings, I. M., 1978, Proc. ASTM Symp. Eros. Prevent. Useful Appl. STP 664. 
31. Hutchings, I. M., "Some Comments on the Theoretical Treatment of Erosive Particle Impacts," Proc. of the $5^{\text {th }}$ Intl. Conf. on Erosion by Solid and Liquid Impact, 1979, Cambridge University, Cambridge, England, pp. 36-1 - 36-9.

32. Hutchings, I. M., "A Model for the Erosion of Metals by Spherical Particles at Normal Incidence,” Wear, 1981, Vol. 70, pp. 269-281.

33. Hutchings, I. M., Winter, R. E., and Field, J. E., "Solid Particle Erosion of Metals; The Removal of Surface Material by Spherical Projectiles," Proc. R. Soc. (London) A, 1976, Vol. 348, pp. 379-392.

34. Kosel, H. Thomas, "Solid Particle Erosion,” ASM Handbook, Vol. 18, pp. 199-213.

35. Liebhard, M., and Levy, A. V., "The Effect of Erodent Particle Characteristics on the Erosion of Metals," Proc. of Intnl. Conf. on Wear of Metals, ASME, 1991, pp. 123127.

36. Tabor, D., “The hardness of Metals," Clarendon, oxford, 1951.

37. Maji, J., and Sheldon, G. L., 1978, Proc. ASTM Symp. Eros. Prevent. Useful Appl. STP 664.

38. Maji, J. and Sheldon, G. L., "Mechanisms of Erosion of a Ductile Material by Solid Particles," Erosion: Prevenention and Useful applications, STP 664, ASTM, 1979, pp. 136-147.

39. Misra, A. and Finnie, I., "On the Size Effect in Abrasive and Erosive Wear," Wear, 1981, Vol. 65, pp. 359-373.

40. Montgomery, J. E., and Clark, J. M., Jun., "Dust Erosion Parameters for a Gas Turbine," Soc. of Automotive Engineers Summer Meeting, 1962, Preprint 538A,. 
41. Neilson, J. H. and Gilchrist, A., "Erosion by a Stream of Solid Particles," Wear, 1968a, Vol 11, pp. 111-122.

42. Neilson, J. H. and Gilchrist, A., "An experimental investigation into aspects of erosion in rocket motor tail nozzles," Wear II, 1968b, pp. 123-143.

43. Preece, C. M., Vidya, S., and Dakshiramoorthy, S., 1978, Proc. ASTM Symp. Eros. Prevent. Useful. Appl. STP 664.

44. Rickerby, D. G. and Macmillan, N. H., Wear, 1980, Vol. 60, pp.369.

45. Ruff, A. W. and Wiederhorn, S. M., "Erosion by Solid Particle Impact," Treatise on Material Science and Technology, 1979, Vol. 16, pp. 69-126.

46. Sheldon, G. L., Trans. ASME J. Basic Eng., 1970, Vol. 92, pp. 619-626.

47. Sheldon, G. L., J. Eng. Mat. Tech. Trans. ASME 99, 1977, pp. 133-137.

48. Sheldon, G. L., and Finnie, I., Trans. ASME J. Eng. Ind., 1966, 88, pp. 393-400.

49. Sheldon, G. L. and Kanhere, A., 1972, Wear 21, pp. 195-208.

50. Sorell, G., "Elevated Temperature Erosion-Corrosion of alloys in Sulfidizing GasSolids Streams : Parametric Studies," Proceedings Corrosion-Erosion-Wear of materials at Elevated Temperatures, Jan. 27-29, 1986, pp. 204-229.

51. Suh, N. P. in Suh, N. P.(ed.), "Fundamentals of Tribology," Massachusetts Institute of Technology Press, Cambridge, MA, 1980, pp. 443.

52. Sundararajan. G, "The Solid Particle Erosion of Metallic Materials at Elevated Temperatures," Paper 11, Proc. of Conf. on Corrosion-Erosion-Wear of Materials at Elevated Temperature, A. V. Levy, Ed., NACE/EPRI/LBL/DOEFE, Berkeley, CA, 31 Jan-2 Feb 1990. 
53. Sundararajan, G. and Shewmon, P. G., "A New Model for the Erosion of Metals at Normal Incidence,” Wear, 1983, Vol. 84, pp. 237-258.

54. Tabakoff, W., Hamed, A. and Eroglu, H., "Study of Particle Rebound Characteristics and Material Erosion at High Temperature," ORNL/Sub/84-89628/02, 78 p.

55. Tilly, G. P., Wear, 1973, Vol. 23, pp. 87-96.

56. Uuemois, H., and Kleis, I., 1975, Wear 31, pp. 359-371.

57. Selvakumaresan Veluswamy, "Computational Model of Erosion of Oxide Layers by Impact," Master's Thesis, Dept. of Mech. Engg., West Virginia University, Morgantown, April 1994.

58. Wellinger, K. and Uetz, H. Gleit-Spul and Strahlverschleiss Prufung, Wear, Vol 1, 1957-58, pp. 225-231.

59. Winter, R. E., and Hutchings, I. M., 1975, Wear 34, pp.141-148.

60. Wright, I. G., Natarajan, V., and Stringer, J., "Observations of the Role of Oxide Scales in High-Temperature Erosion-Corrosion of Alloys," Oxidation of Metals, 1986, Vol. 25, Nos. 3/4, pp. 175-199.

61. Young, J. P., and Ruff, A. W., "Particle Erosion Measurements on Metals," Trans. Of ASME, Journal of Eng. Materials and Technology, 1977, pp. 121125.

62. Zhu, J., "Tube Erosion in Fluidized Beds," Ph.D Dissertation, 1998, University of British Columbia, pp. 330. 


\section{APPENDIX A}

\section{Sample INGRID data file to generate the model for angular impacts.}

c Angular Impact :

Velocity $=50 \mathrm{~m} / \mathrm{sec}:$ Angle of Attack $=10 \mathrm{deg}$

c Units (um,uN,usec)

$\operatorname{dn} 3 d$

c Velocity of the particle

c velocity $=50 \mathrm{~m} / \mathrm{s}$

[theta $=.1745329]$

term 2

si 1 tied;

si 2 sv;

plan $10025010.001 \mathrm{symm}$

$\mathrm{c} * * * * * * * * * * * * * * * * * * * * * * * * * * * * * * * * * * * * * * * * * * * * * * * * * * * * * * * * * * * *$

c DEFINE THE METAL SUBSTRATE

start

c set the index space

14812162023 ;1 810 12;1 4 7;

c Give the corresponding coord for the indices

0130190250310370500

c $0 \quad 130 \quad 180250320370500$

C 0150200250300350500

0120150250

0100150

c for standard part sliding interfaces refer page 183

si $1137431 \mathrm{~m}$

c Define the boundary conditions

b 141743111000

b 111143111000

b 711743111000

b 111741111000

mate 1

end

c DEFINE THE OXIDE LAYER

start

c set the index space

16152433 42 47;1 1820 23; 1 6; 
c Give the corresponding coord for the indices

0130190250310370500

c 0130180250320370500

0120150250

152188

c Define the sliding interface with the metal

si $1117411 \mathrm{~s}$

c Define the sliding interface; slave segment; for the sphere sii $35 ; 12 ; 22 ; 2 \mathrm{~s}$

c Boundary conditions

b 111142111000

b 141742111000

b 711742111000

C element printout blocks

c epb 25010160 ro 311522 ;

mate 2

end

$\mathrm{C} * * * * * * * * * * * * * * * * * * * * * * * * * * * * * * * * * * * * * * * * * * * * * * * * * * * * * * * * * * * * * * * * * * * * * * * * * * * * *$

C DEFINE THE SPHERE

velocity $[-50 * \cos ($ theta $)] 0[-50 * \sin ($ theta $)]$

start

c set the index space

15913 17; 15913 17; 15913 17;

c Give the corresponding coord for the indices $[230+.25 / \tan$ (theta) $][230+.25 / \tan$ (theta) $]$

[250+.25/tan(theta)] [270+.25/tan(theta)] [270+.25/tan(theta)]

$-20-2002020$

208.25208 .25228 .25248 .25248 .25

c Delete the regions at the edges of the cube di $12045 ; 12045$; ;

di $12045 ; ; 12045$;

di ; $12045 ; 12045$;

c project the boundary to a spherical surface.

sfi - $1-5 ;-1-5 ;-1-5 ;$ sp [250+.25/tan(theta)] 0228.2540

$\mathrm{c}$ define the sliding interface; master segments

sii $-1-5 ; 3-5 ;-1-5 ; 2$ m

c Delete the symmetry part of the sphere

d 111535

mate 3

end 
c Define the material properties

mat 11

pr .34

e $1.55 \mathrm{e}+05$

ro $7.81 \mathrm{e}-3$

endmat

mat 23

pr.34

e $1.82 \mathrm{e}+05$

ro $5.190 \mathrm{e}-3$

endmat

mat 320

e $.3479 \mathrm{e}+05$

ro $7.128 \mathrm{e}-3$

pr .34

endmat

end 


\section{APPENDIX B}

*KEYWORD

Sample Input file for LS-DYNA3D

\$\#This is generated by : EASi-CRASH : Version 1.2 on Tue Oct 27 23:52:28 1998

*TITLE

Angular Impact 90 deg : dia $=80$ um : vel $=50 \mathrm{~m} / \mathrm{sec}$

*CONTROL_DYNAMIC_RELAXATION

\$\# NRCYCK DRTOL DRFCTR DRTERM TSSFDR IRELAL EDTTL IDRFLG

$\begin{array}{rrrrrrr}2509.9999 \mathrm{E}-05 & 0.995 & 0 . & 0 . & 0 & 0 . & 0\end{array}$

*CONTROL_ENERGY

$\begin{array}{rrrrr}\text { \$\# } & \text { HGEN } & \text { RWEN } & \text { SLNTEN } & \text { RYLEN } \\ & 2 & 2 & 2 & 1\end{array}$

*CONTROL_SHELL

\$\# WRPANG ITRIST IRNXX ISTUPD THEORY BWC MITER

$\begin{array}{lllllll}0 . & 0 & 0 & 0 & 0 & 0 & 1\end{array}$

*CONTROL_TERMINATION

\$\# ENDTIM ENDCYC DTMIN ENDENG ENDMAS

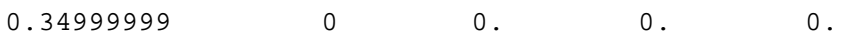

${ }^{*} \mathrm{NODE}$

$\begin{array}{llllll}1 & 0.000000000 \mathrm{E}+00 & 0.000000000 \mathrm{E}+00 & 0.000000000 \mathrm{E}+00 & 7 & 6 \\ 2 & 4.333333206 \mathrm{E}+01 & 0.000000000 \mathrm{E}+00 & 0.000000000 \mathrm{E}+00 & 7 & 6 \\ 3 & 8.666666412 \mathrm{E}+01 & 0.000000000 \mathrm{E}+00 & 5.551115123 \mathrm{E}-15 & 7 & 6 \\ 4 & 1.300000000 \mathrm{E}+02 & 0.000000000 \mathrm{E}+00 & 0.000000000 \mathrm{E}+00 & 7 & 6\end{array}$

$\begin{array}{lllll}9866 & 2.737383118 \mathrm{E}+02 & 2.232050896 \mathrm{E}+01 & 2.505705261 \mathrm{E}+02 & 0\end{array}$

$\begin{array}{llllll}9867 & 2.745118408 \mathrm{E}+02 & 2.309401131 \mathrm{E}+01 & 2.513440247 \mathrm{E}+02 & 0 & 0\end{array}$

*ELEMENT_SOLID

$\begin{array}{llllllllll}1 & 1 & 1 & 2 & 6 & 5 & 33 & 34 & 38 & 37 \\ 2 & 1 & 2 & 3 & 7 & 6 & 34 & 35 & 39 & 38 \\ 3 & 1 & 3 & 4 & 8 & 7 & 35 & 36 & 40 & 39\end{array}$




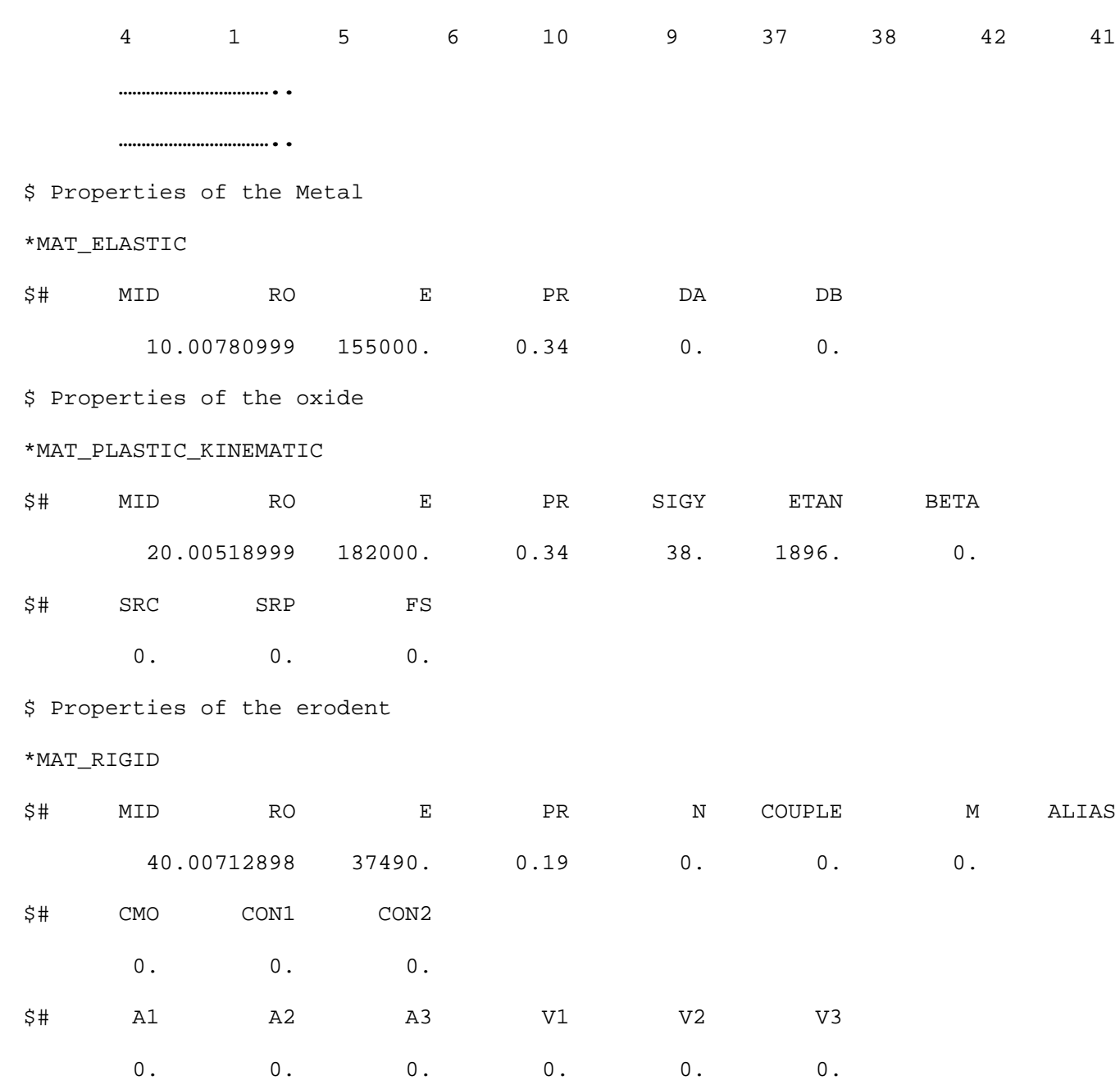

*SECTION_SOLID

\$\# SECID ELFORM

100

*SECTION_SOLID

\$\# SECID ELFORM AET

$2 \quad 2 \quad 0$

*SECTION_SOLID

\$\# SECID ELFORM AET

$\begin{array}{lll}3 & 0 & 0\end{array}$

*PART

\$\#

material type \# 1 (elastic)

\$\# PID SECID MID EOSID HGID GRAV ADPOPT

$\begin{array}{llllllll}1 & 1 & 1 & 0 & 0 & 0 & 0 & 0\end{array}$

*PART 
$\$ \#$

material type \# 1 (elastic) $\begin{array}{cr}\text { MID } & \text { EOSID } \\ 2 & 0\end{array}$

*PART

$\$ \#$

material type \# 1 (elastic)

$\$$

\begin{abstract}
MID EOSID
\end{abstract}
4

*SET_NODE_LIST

$\$$

\$

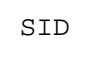

5

NID1

NID2

1

161

675

1347

1779

2473

*SET_NODE_LIST

\$ \#

\$

\$\# NID

6

2

193

676

1348

1803

7733

SID

DA 1

0.

NID2

$5 \quad 6$

$13 \quad 14$

21

29

30
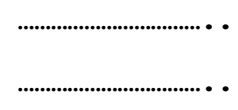

$8398 \quad 8399$

8414

8415

8400

8401

8417

*SET_NODE_LIST

$\$ \# \quad$ SID

DA 1

0.

\$\# NID1

NID2

34

\begin{abstract}
35
\end{abstract}
8416

NID 3

NID 4

NID 5

NID

HEAD ING

HGID

GRAV

ADPOPT

TMID

.

\section{Appendix}




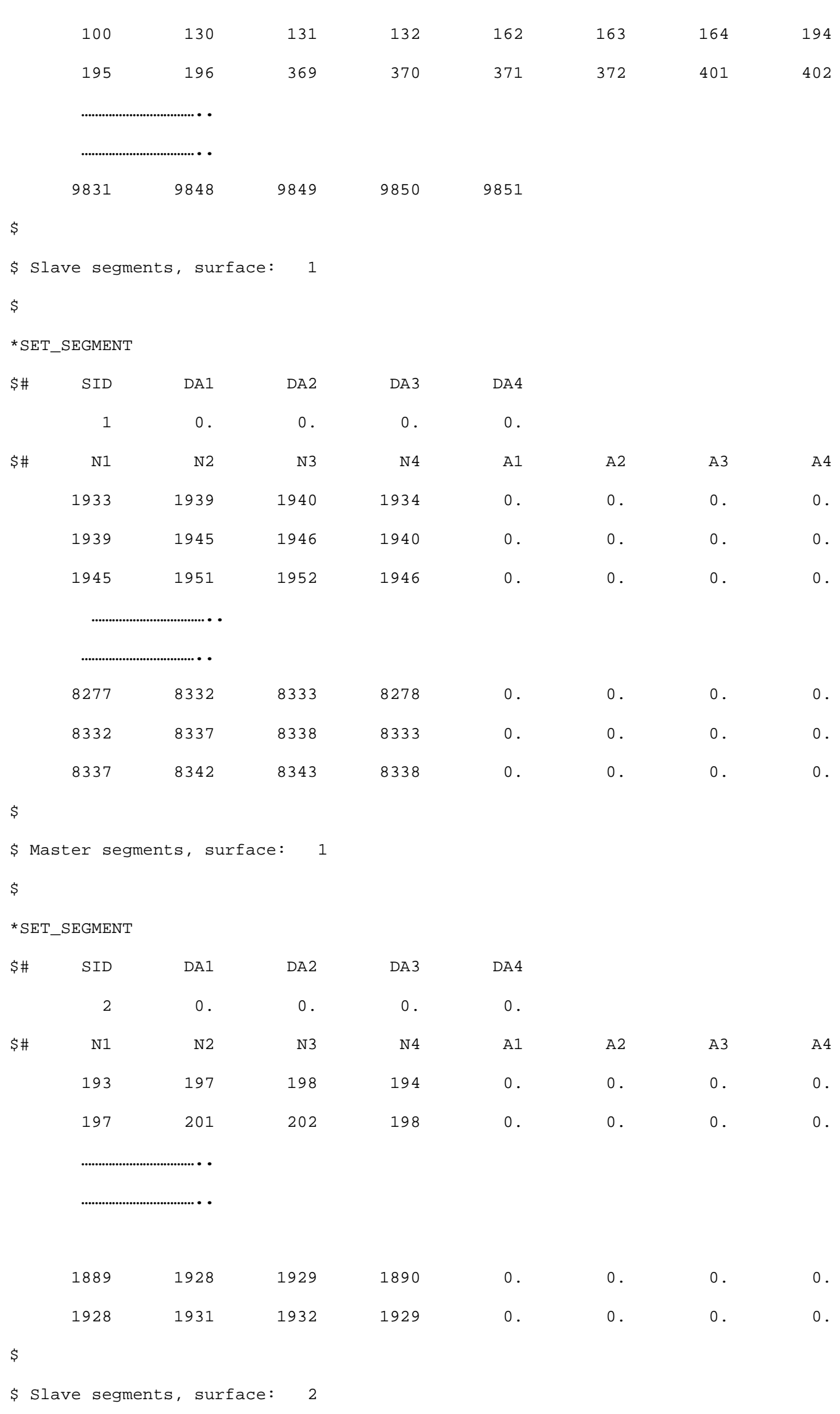


$\$$

*SET_SEGMENT

\begin{tabular}{|c|c|c|c|c|c|c|c|c|}
\hline \$\# & SID & DA1 & $\mathrm{DA} 2$ & DA3 & DA4 & & & \\
\hline & 3 & 0. & 0. & 0. & 0 . & & & \\
\hline \$\# & N1 & N2 & N3 & N4 & $\mathrm{A} 1$ & $\mathrm{~A} 2$ & A3 & A4 \\
\hline & 3579 & 3588 & 4822 & 4813 & 0 . & 0. & 0. & 0 . \\
\hline & 3588 & 3597 & 4831 & 4822 & 0 . & 0. & 0. & 0 . \\
\hline & 3597 & 3606 & 4840 & 4831 & 0. & 0. & 0. & 0 . \\
\hline & 6197 & 6206 & 6207 & 6198 & 0. & 0 . & 0 . & 0 . \\
\hline & 6206 & 6215 & 6216 & 6207 & 0 . & 0. & 0 . & \\
\hline
\end{tabular}

$\$$

\$Master segments, surface: 2

$\$$

*SET_SEGMENT

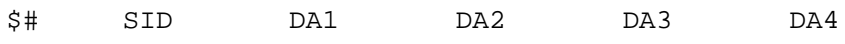

40.0 .00$.

$\begin{array}{llllll}\text { \$\# } & \text { N1 } & \text { N2 } & \text { N3 } & \text { N4 } & \text { A1 }\end{array}$

$\begin{array}{lllll}8419 & 8444 & 8449 & 8424\end{array}$

0

0 .

9827

0 .

0

0 .

0 .

9843

9863

9867

9847

0.

0 .

0 .

0 .

*SET_NODE_LIST

$\begin{array}{rrrrr}\text { \$\# } & \text { DA1 } & \text { DA2 } & \text { DA3 } & \text { DA4 } \\ 8 & 0 . & 0 . & 0 . & 0 .\end{array}$

\begin{tabular}{|c|c|c|c|c|c|c|c|}
\hline NID 1 & NID2 & NID 3 & NID 4 & NID 5 & NID 6 & NID 7 & NID 8 \\
\hline 8419 & 8420 & 8421 & 8422 & 8423 & 8424 & 8425 & 8426 \\
\hline 8427 & 8428 & 8429 & 8430 & 8431 & 8432 & 8433 & 8434 \\
\hline 9851 & 9852 & 9853 & 9854 & 9855 & 9856 & 9857 & 9858 \\
\hline 9859 & 9860 & 9861 & 9862 & 9863 & 9864 & 9865 & 9866 \\
\hline
\end{tabular}




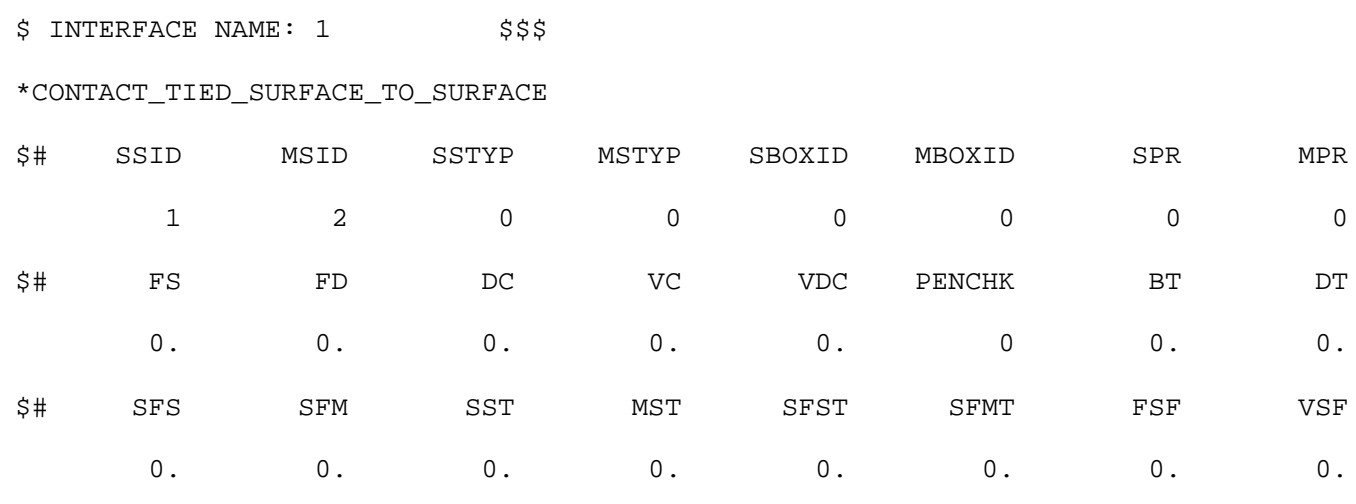

\$\# SOFT SOFSCL LCIDAB MAXPAR PENTOL DEPTH BSORT FRCFRQ

\begin{tabular}{|c|c|c|c|c|c|c|c|c|}
\hline & 0 . & 0.1 & 0 . & 0 . & 0 . & 2 . & 0. & 1. \\
\hline \multirow[t]{2}{*}{ \$\# } & PENMAX & THKOPT & & SNLOG & ISYM & & & \\
\hline & 0 . & 0 & & 0 & 0 & & & \\
\hline \multirow[t]{2}{*}{$\$$} & INTERFACE & NAME : 2 & $\$ \$$ & & & & & \\
\hline & \multicolumn{8}{|c|}{ CONTACT_SURFACE_TO_SURFACE } \\
\hline \multirow[t]{2}{*}{ \$\# } & SSID & MSID & SSTYP & MSTYP & SBOXID & MBOXID & SPR & MPR \\
\hline & 3 & 4 & 0 & 0 & 0 & 0 & 0 & 0 \\
\hline \multirow[t]{2}{*}{ \$\# } & FS & $\mathrm{FD}$ & DC & VC & VDC & PENCHK & BT & DT \\
\hline & 0 . & 0 . & 0 . & 0 . & 0 . & 0 & 0 . & 0 . \\
\hline \multirow[t]{2}{*}{ \$\# } & SFS & SFM & SST & MST & SFST & SFMT & FSF & VSF \\
\hline & 0 . & 0 . & 0 . & 0 . & 0 . & 0 . & 0 . & 0 . \\
\hline
\end{tabular}

\$\# SOFT SOFSCL LCIDAB MAXPAR PENTOL DEPTH BSORT FRCFRQ

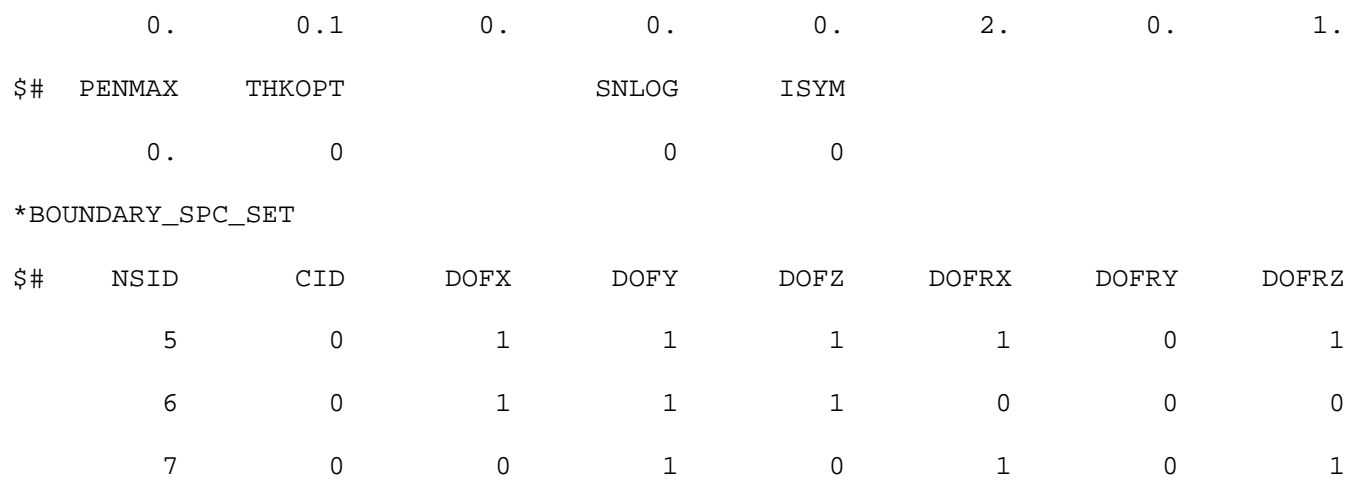

*INITIAL_VELOCITY

$\begin{array}{rrrrrrr}\$ \# & \text { NSID } & \text { NSIDEX } & \text { BOXID } & & & \\ & 8 & 0 & 0 & & & \\ & \text { \$\# } & \text { VY } & \text { VZ } & \text { VXR } & \text { VYR } & \text { VZR } \\ -49.240387 & 0.0000000-8.6824074 & 0 . & 0 . & 0 .\end{array}$

*DATABASE_GLSTAT

$\$ \# \quad$ DT $\quad$ FLAG1 $\quad$ FLAG2 
0.00200000

0

0

*DATABASE_MATSUM

\$\# $\quad$ DT $\quad$ FLAG1 FLAG2

0.00200000

0

0

*DATABASE_RCFORC

\$\# $\quad$ DT $\quad$ FLAG1 $\quad$ FLAG2

$0.00200000 \quad 0 \quad 0$

*DATABASE_RBDOUT

$\begin{array}{llll}\$ \# & \text { DT } & \text { FLAG1 } & \text { FLAG2 }\end{array}$

0.00200000

0

0

*DATABASE_BINARY_D3PLOT

\$\# DT LCDT NOBEAM NPLTC

$\begin{array}{llll}0.02 & 0 & 0 & 0\end{array}$

*DATABASE_BINARY_D3THDT

$\$ \# \quad$ DT $\quad$ LCDT

$0.00999999 \quad 0$

*END 


\section{APPENDIX C}

C Program to identify the elements that have failed, from the output file of LSTaurus.

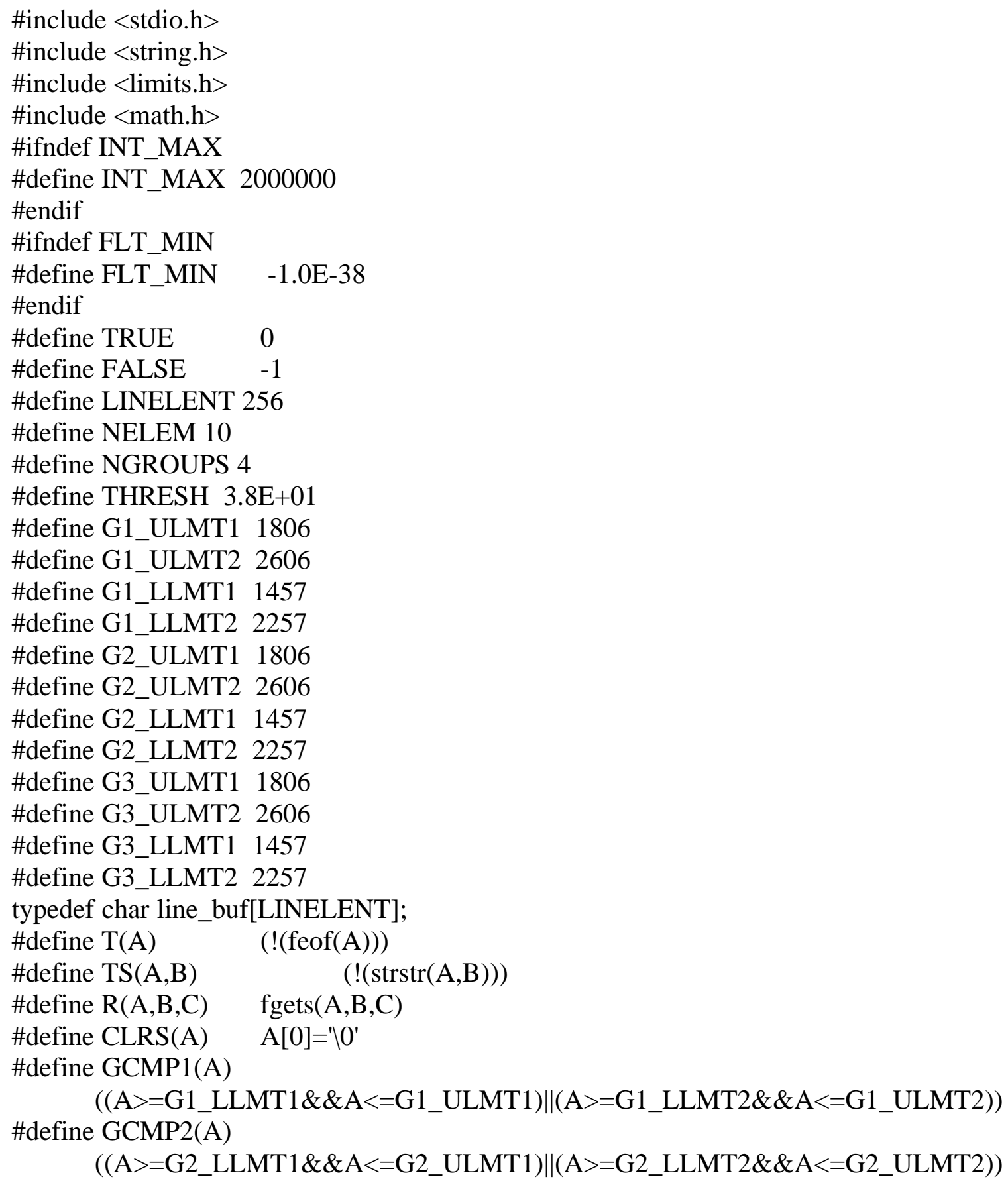




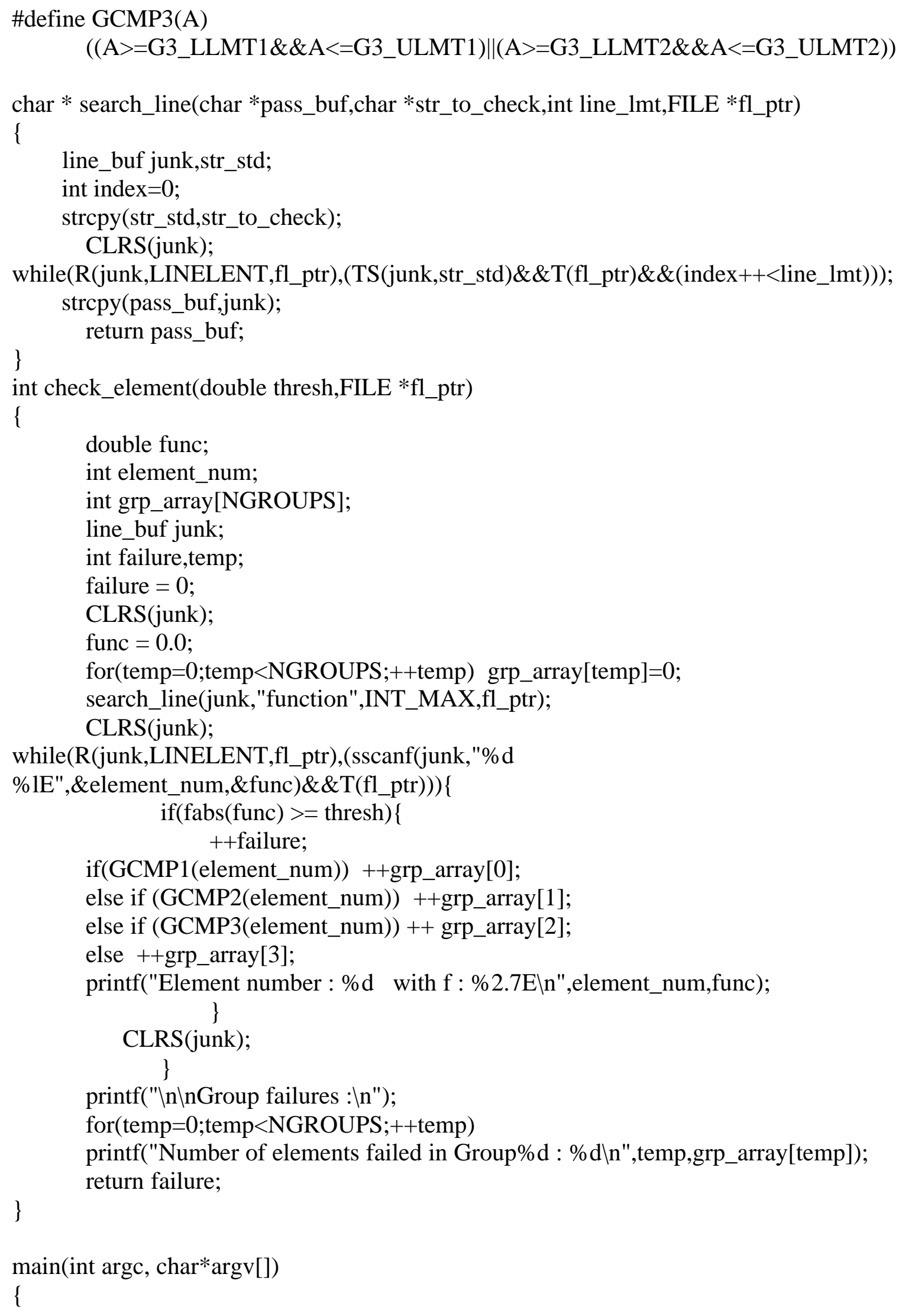




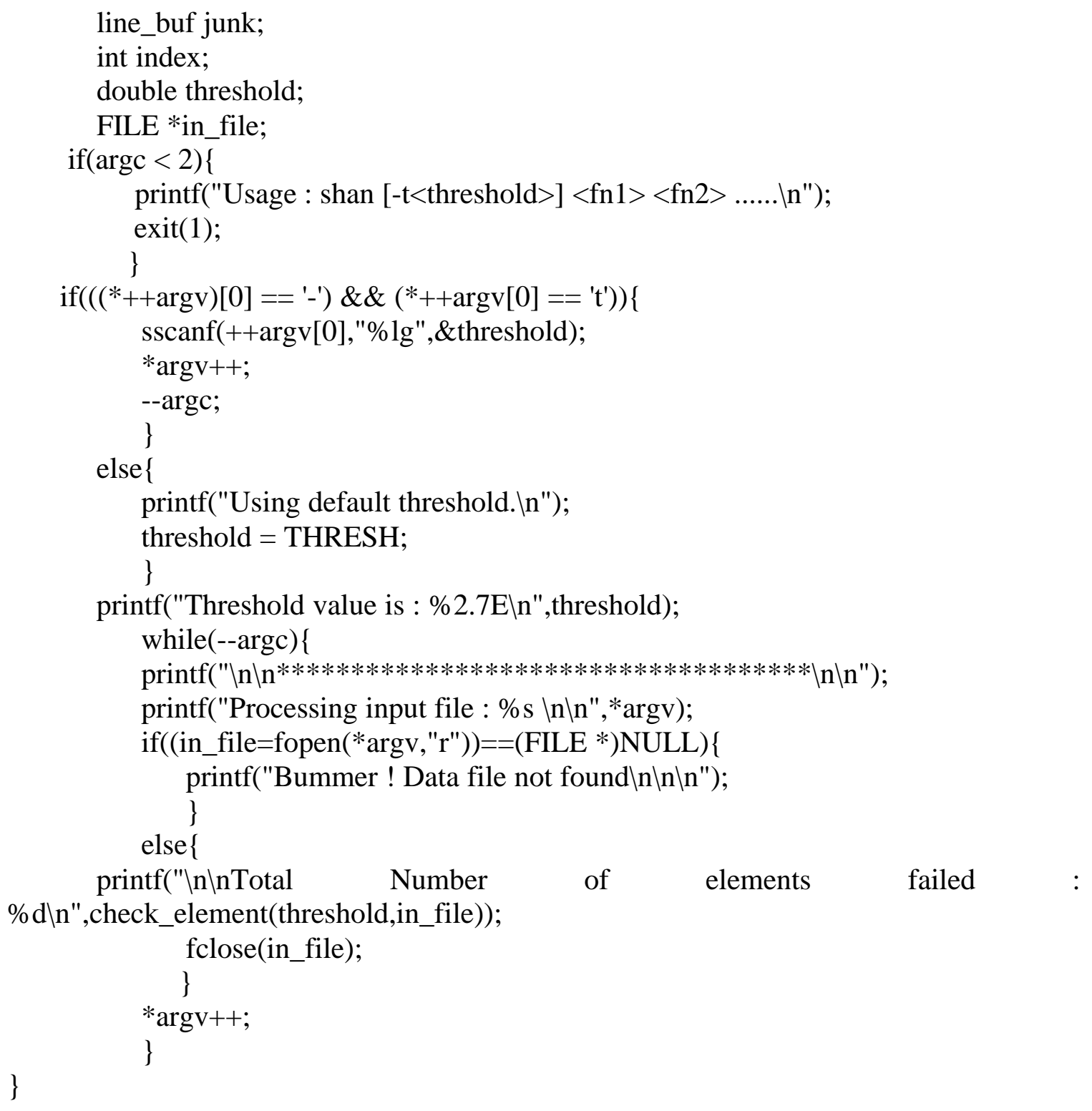




\section{APPROVAL OF EXAMINING COMMITTEE}

Nithi T. Sivaneri, Ph.D.

Victor Mucino, Ph.D.

Kenneth H. Means, Ph.D.

(Chairman)

Date: 